JOSÉ EDUARDO RODRIGUES

INTERFERÊNCIA DE HARMÔNICAS EM EQUIPAMENTOS DE MEDIÇÃO DE ENERGIA ELÉTRICA

São Paulo

2009 
JOSÉ EDUARDO RODRIGUES

\section{INTERFERÊNCIA DE HARMÔNICAS EM EQUIPAMENTOS DE MEDIÇÃO DE ENERGIA ELÉTRICA}

Dissertação apresentada à Escola Politécnica da Universidade de São Paulo para obtenção do Título de Mestre em Engenharia Área de Concentração: Engenharia Elétrica Orientador: Prof. Doutor Cícero Couto de Moraes

São Paulo 
TERMO DE JULGAMENTO 
JOSÉ EDUARDO RODRIGUES

INTERFERÊNCIA DE HARMÔNICOS EM EQUIPAMENTOS DE MEDIÇÃO DE ENERGIA ELÉTRICA

Dissertação apresentada à Escola Politécnica da Universidade de São Paulo para obtenção do Título de Mestre em Engenharia Área de Concentração: Engenharia Elétrica Orientador: Prof. Doutor Cícero Couto de Moraes

São Paulo

2009 
Este exemplar foi revisado e alterado em relação à versão original, sob responsabilidade única do autor e com anuência de seu orientador.

São Paulo, 24 de junho de 2009.

Assinatura do autor:

Assinatura do orientador:

FICHA CATALOGRÁFICA

Rodrigues, José Eduardo

Interferência de harmônicos em equipamentos de medição

de energia elétrica / J.E. Rodrigues. - ed.rev.- São Paulo, 2009.

$138 \mathrm{p}$.

Dissertação (Mestrado) - Escola Politécnica da Universidade de São Paulo. Departamento de Engenharia de Energia e Automação Elétricas.

1. Equipamentos de medidas elétricas 2. Energia elétrica (Qualidade) I. Universidade de São Paulo. Escola Politécnica. Departamento de Engenharia de Energia e Automação Elétricas II. t. 


\section{DEDICATÓRIA}

Dedico este trabalho a minha esposa Áurea Prates Rodrigues, pela paciência e compreensão e aos meus pais Frederico Rodrigues Oliver e Antonia Gomes Rodrigues pela vida e orientação que me deram. 


\section{AGRADECIMENTOS}

Ao Departamento de Engenharia de Energia e Automações Elétricas, por possibilitar, com seus grupos de pesquisa, o desenvolvimento deste trabalho.

A ANEEL, pela aprovação do projeto e desenvolvimento da pesquisa de um Projeto de um Dispositivo para Caracterização de Harmônicas nas Medições de Faturamento, que serviu de base para este trabalho.

A Unesp de Bauru que, por meio do Professor Doutor André Nunes de Souza, viabilizou a participação do autor como pesquisador bolsista deste tema.

Ao Professor Doutor Cícero Couto de Moraes, pela orientação e pelo constante estímulo transmitido durante todo o trabalho.

Ao amigo, Professor Nelson Matsuo, pela grande atenção, contribuição e apoio durante a elaboração desta pesquisa.

A Eletropaulo, Enerq e IEE-USP, que contribuíram com equipamentos e técnicos para as pesquisas laboratoriais. 


\section{RESUMO}

Este trabalho aborda a conformidade dos medidores de energia em sistemas não senoidais, na busca do aumento de qualidade no faturamento de energia elétrica. Para tanto, enfoca a medição mais justa e um melhor relacionamento entre concessionária e consumidor. As análises foram realizadas nos laboratórios da Eletropaulo, do Instituto de Eletrotécnica e Energia da Universidade de São Paulo, e no Laboratório do Centro de Estudos em Regulação e Qualidade de Energia (Enerq), USP. Trata-se de um estudo que faz parte de um projeto maior de Pesquisa e Desenvolvimento da Agência Nacional de Energia Elétrica (ANEEL). Seu objetivo foi investigar se a distorção de tensão e corrente nos medidores de faturamento de energia elétrica provoca desvios na energia medida. Pretendeu-se ainda avaliar se as harmônicas inseridas nos medidores eletromecânicos possuem maior ou menor desvio na energia medida, em comparação aos medidores eletrônicos. A metodologia utilizada incluiu levantamento de estudos de pesquisa e desenvolvimento, além de ensaios de laboratório com amostras de equipamentos de dois fabricantes nacionais. Como parâmetros para os ensaios, levantaram-se curvas, por meio de medições de cargas reais. Os resultados das medições obtidas em situações reais foram comparados com aquelas levantadas nos laboratórios. Os resultados dos ensaios laboratoriais foram analisados e comparados com os limites estabelecidos nas normas vigentes, dentre as quais, destacam-se: o Regulamento Técnico Metrológico do INMETRO e os Procedimentos de Distribuição de Energia Elétrica no Sistema Elétrico Nacional - PRODIST. O presente estudo concluiu que os instrumentos ensaiados em conforme normas, quando parametrizados para não considerar a potência de distorção no cálculo de reativo, atendem os parâmetros de exatidão. Esses dados são válidos tanto para as funções de VArh quanto para Wh.

Palavras chave: Equipamento de medição. Qualidade de energia. Harmônicas 


\begin{abstract}
This work addresses the reliability of energy meters in nonsinusoidal systems, looking for the increase of quality in the electric energy billing. To that purpose, it focuses on a fairer metering and a better relationship between the concessionaire and consumer. The tests were carried through in the laboratories of Eletropaulo, of the Electro-Technology and Energy Institute in the University of São Paulo, and in the Laboratory of the Center of Studies in Power Quality Regulation (Enerq), USP. This study is part of a bigger project in Research and Development of the Electric Energy National Agency (Aneel). Its objective was to investigate whether the distortion of voltage and current in the electric energy billing meters had deviations in the metered energy. It was also intended to evaluate whether the inserted harmonics in the electromechanical meters have greater or minor deviation in the metered energy, in comparison to the electronic meters. The methodology used included a survey of studies, research and development of the electric sector, besides laboratory tests with two national equipment samples. As parameters for the tests, wave were formulated by means of real load metering. The results of the metering obtained in real situations were compared with those collected in the laboratories. The results of the laboratory tests were analyzed and compared with the limits established in the norms in force, amongst which one highlights: the Technical Metrological Regulation from "Inmetro" and the Electric Power Distribution Procedures in the National Electric System - Prodist. The present study concluded the instruments analyzed under normalized conditions, when parameterized to not consider the distortion power in the calculation of reactive, meet the $60 \mathrm{~Hz}$ frequency, within the accuracy parameters. These data are valid both for the VArh functions and the Wh.
\end{abstract}

Keywords: Metering equipment. Power quality. Harmonics 


\section{LISTA DE TABELAS}

Tabela 1 - Erros encontrados na aferição em condição senoidal de alimentação 33

Tabela 2 - Condições das ondas de tensão e corrente dos ensaios e erros apresentados pelo

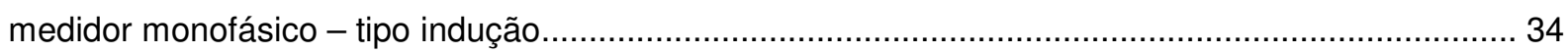

Tabela 3 - Ensaio de medidor com corrente senoidal pura.(Situação 1) …………………................ 36

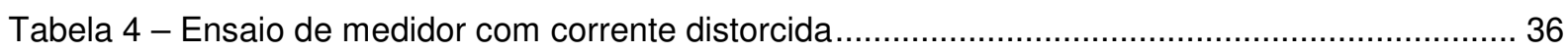

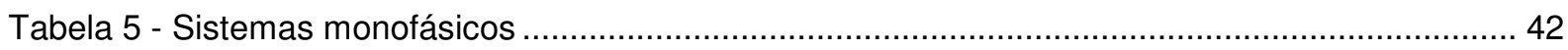

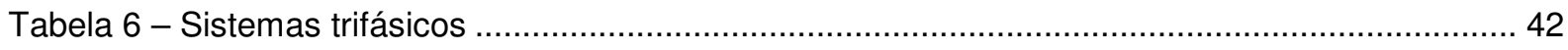

Tabela 7 - Terminologia Harmônica - Fonte: ANEEL - PRODIST - 2008 ........................................ 52

Tabela 8 - Níveis de referência para distorção harmônica total - Fonte: ANEEL - PRODIST - 200853

Tabela 9 - Níveis de referência para distorções harmônicas individuais - Fonte: ANEEL - PRODIST -

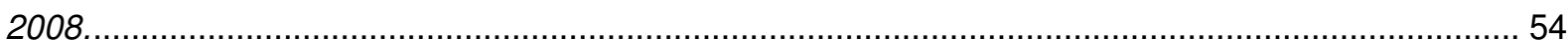

Tabela 10 - Definições de pertubação conforme norma EN 50160 - Fonte: EN 50160 - 1999. …...... 57

Tabela 11 - Condições de referência para medidores de energia elétrica - Fonte: ASSOCIAÇÃO

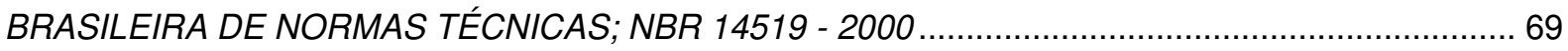

Tabela 12 - Elementos para o ensaio laboratorial 1, Programa 10, Medição A. ................................... 77

Tabela 13 - Elementos para o ensaio 1, Programa 10, Pacific 390 AMX, Seqüências A, B e C. ........ 77

Tabela 14 - Elementos para o ensaio laboratorial 2, Programa 11, Medição B ……............................ 78

Tabela 15 - Elementos para o ensaio 2, Programa 11, Pacific 390 AMX, Seqüências A, B e C......... 78

Tabela 16 - Elementos para o ensaio laboratorial 3, Programa 12, Medição C …................................ 79

Tabela 17 - Elementos para o ensaio 3, Programa 12, Pacific 390 AMX, Seqüências A, B e C. ........ 79

Tabela 18 - Elementos para o ensaio 4, Programa 13, Medição em Instalação Residencial .............. 80

Tabela 19 - Elementos para o ensaio 4, Programa 13, Pacific 390 AMX, Seqüências A, B e C......... 80

Tabela 20 - Cargas Elétricas da Instalação Residencial ......................... Erro! Indicador não definido.

Tabela 21 - Elementos para o ensaio 5, Programa 14, Medição com Onda Teórica A ….................... 82

Tabela 22 - Elementos para o ensaio 5, Programa 14,Onda Teórica A-Âng 0, Seq A, B e C ........... 82

Tabela 23 - Elementos para o ensaio 6, Programa 15, Medição com Onda Teórica B ...................... 83

Tabela 24 - Elementos para o ensaio 6, Programa 15,Onda Teórica B-Âng 180, Seq A, B e C....... 83

Tabela 25 - Elementos para o ensaio 8, Programa 15-Pacific 390 AMX - Medição com Onda Teórica C

Tabela 26 - Elementos para o ensaio 8, Programa 15,Onda Teórica C-Âng 180, Seq A, B e C....... 84 Tabela 27 - Elementos para o ensaio 10, Programa 16-Pacific 390 AMX - Medição com Onda Teórica $\mathrm{E}$

Tabela 28 - Elementos para o ensaio 10, Programa 16,Onda Teórica E-Âng 180ํ, Seq A, B e C..... 85 Tabela 29 - Elementos para o ensaio 12, Programa 17-Pacific 390 AMX - Medição com Onda Teórica $\mathrm{F}$.

Tabela 30 - Elementos para o ensaio 12, Programa 17, Onda Teórica F-Âng $180^{\circ}$ ou $0^{\circ}$ 86 
Tabela 31 - Onda teórica fundamental - Com espectros de harmônicos iguais a zero para tensão e corrente

Tabela 32 - Elementos para o ensaio (12. Programa 17)-Onda teórica $F$ - Âng.-180ํo ou 0-seq. A, B e C. 87

Tabela 33 - Ensaios comparativos de metodologia contagem de pulso $X$ tensão e corrente . 89

Tabela 34 - Resultado do ensaio (A) com corrente nominal - 15 Ampéres 91

Tabela 35 - Resultado do ensaio (B) com corrente a 25\% da corrente máxima - 25 Ampéres...... 92

Tabela 36 - Resultado do ensaio (C) com corrente a 10\% da corrente nominal - 1,5 Ampéres ...... 93

Tabela 37 - Erros apresentados nos medidores submetidos a ondas de tensão e corrente não senoidais 94

Tabela 38 - Comparativo dos erros apresentados para faixa de corrente de 1,5 ampéres. 98

Tabela 39 - Comparativo dos erros apresentados para faixa de corrente de 15 ampéres. 99

Tabela 40 - Comparativo dos erros apresentados para faixa de corrente de 25 ampéres...... 100

Tabela 41 - Distribuição da corrente harmônica no transformador - Fonte: MORAES, C.C. (1978). 109

Tabela 42 - Banco de dados do capacitor - Fonte: IEEE-18-1980(1980). 114

Tabela 43 - Distribuição harmônica da tensão - Fonte: IEEE-18-1980(1980) 115

Tabela 44 - Limites do banco de capacitores - Fonte: IEEE-18-1980(1980). 116

Tabela 45 - Categorias e características típicas de fenômenos de distorção da forma de onda Fonte:IEEE Std 1159-1995 


\section{LISTA DE GRÁFICOS}

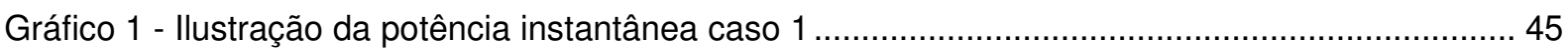

Gráfico 2 - Ilustração da potência instantânea caso 2 ................................................................. 45

Gráfico 3 - Comportamento do medidor (A) comparado ao WT-2030 …......................................... 95

Gráfico 4 - Comportamento do medidor (B) comparado ao WT-2030 …............................................ 95

Gráfico 5 - Relação entre distorção de harmônicas e torque do motor elétrico- Fonte: SAIDEL, M.A.

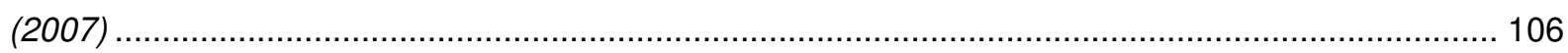

Gráfico 6 - Medição com medidor FLUKE 43B de distorções harmônicas em motores - Fonte:

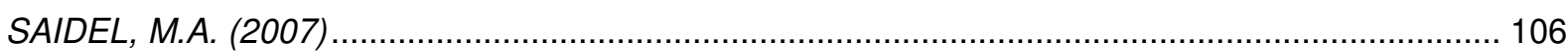




\section{LISTA DE FOTOS}

Foto 1 - Medidores Eletrônicos de Energia Fonte: AES - Eletropaulo - 2009................................... 71

Foto 2 - Sistema de calibração Zera e padrões e Callport 400 WT2030 - Fonte: AES - Eletropaulo -

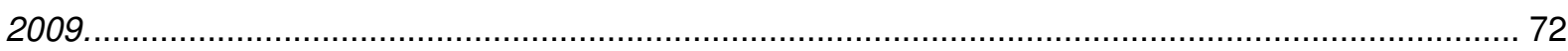

Foto 3 - Medidores eletrônicos (A) e (B) - Fonte: AES - Eletropaulo - 2009................................... 73

Foto 4 - Fonte de energia Pacific 390 AMX - Fonte: ENERQ - 2009............................................ 73

Foto 5 - Osciloscópio Tektronix TDS 1002 - Fonte: ENERQ - 2009................................................ 74

Foto 6- Circuito de ensaios - Fonte: ENERQ - 2009............................................................... 75 


\section{LISTA DE FIGURAS}

Figura 1 - Medidor eletromecânico...

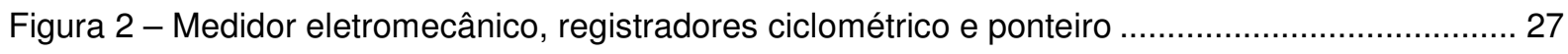

Figura 3 - Medidor eletromecânico bobinas ............................................................................ 27

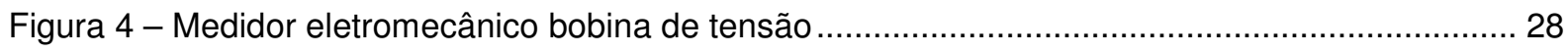

Figura 5 - Medidor eletromecânico bobinas de corrente............................................................... 28

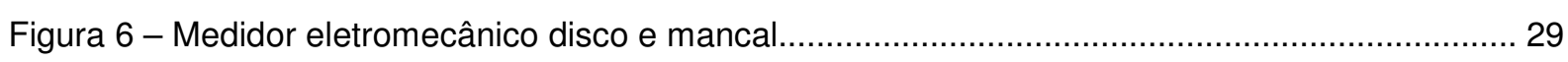

Figura 7 - Medidor eletromecânico elementos móveis ............................................................... 30

Figura 8 - Principais partes constituintes de um medidor de energia eletromecânico.......................... 30

Figura 9 - Medidor eletromecânico vista explodida.................................................................... 31

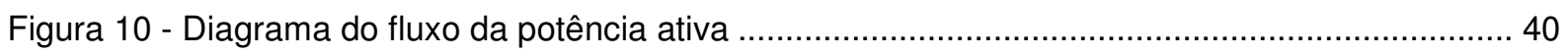

Figura 11 - Wattimetro eletrônico - Fonte: Driesen - 1998.......................................................... 59

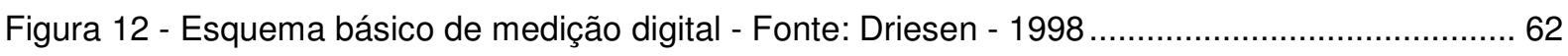

Figura 13 - Circuito para testes laboratoriais dos medidores - Fonte: Elaborado pelo autor (2009).... 75

Figura 14 Fluxo magnético em um transformador - Fonte: MORAES, C.C. (1978) .......................... 108

Figura 15 - Distorção harmônica em forno de indução - Fonte: JÚNIOR, H.F(2004) ..................... 118

Figura 16 - Retificador a diodos de 12 pulsos - Fonte: V.E. Wagner, et al.(1993) ............................. 122

Figura 17 - Retificador a tiristorizado de 12 pulsos - Fonte: V.E. Wagner, et al.(1993) ..................... 122

Figura 18 - Torque eletromagnético do motor na freqüência fundamental e na presença da $2^{\underline{a}}$ harmônica para TDHV=20\% - Fonte: V.E. Wagner, et al.(1993) ............................................... 123

Figura 19 - Formas de ondas de tensão e corrente lâmpadas incandescentes- Fonte: Henriques, $A$.

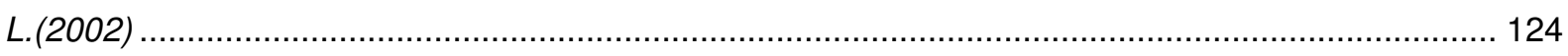

Figura 20 - Características lineares de lâmpadas incandescentes - Fonte: Henriques, A. L.(2002) 125

Figura 21 - Formas de ondas de tensão e corrente lâmpadas FLCs - Fonte: Henriques, A. L.(2002)

Figura 22 - Características não linear lâmpadas FLCs - Fonte: Henriques, A. L.(2002) ................. 126

Figura 23 - Espectro harmônico do sinal de corrente em relação à fundamental das FLCs testadas -

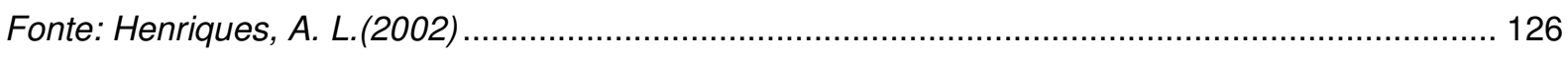

Figura 24 - Forma de onda da corrente harmônica por reator eletrônico - Fonte: Henriques, A.

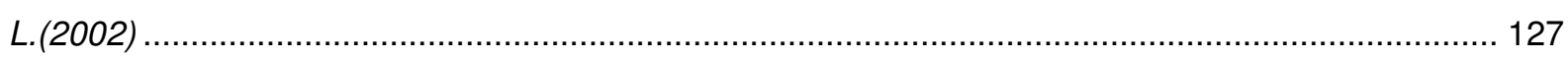




\section{LISTA DE ABREVIATURAS E SIGLAS}

DHI Distorção harmônica individual: grandeza que expressa o nível individual de uma das componentes que totalizam o espectro de freqüências de um sinal distorcido, normalmente referenciada ao valor da componente fundamental.

DHT Distorção harmônica total: composição das distorções harmônicas individuais que expressa o grau de desvio da onda em relação ao padrão ideal, normalmente referenciada ao valor da componente fundamental.

FD Fator de demanda: razão entre a demanda máxima num intervalo de tempo especificado e a carga instalada na unidade consumidora.

FP Fator de potência: razão entre a energia elétrica ativa e a raiz quadrada da soma dos quadrados das energias elétricas ativas e reativas, consumidas num mesmo período especificado.

KVArh Energia elétrica reativa: energia que circula entre os diversos campos magnéticos e elétricos do sistema ou por efeito de chaveamento sem produzir trabalho. Esta energia é expressa em quilovolt-ampèrereativo-hora.

KWh Energia elétrica ativa: energia elétrica que pode ser convertida em outra forma de energia, expressa em quilowatts-hora.

PQ Power Quality: Qualidade de Energia.

UFER Fator de carga: razão entre a demanda média e a demanda máxima da unidade consumidora, ocorridas no mesmo intervalo de tempo especificado.

ANEEL Agência Nacional de Energia Elétrica.

ENERQ Centro de Estudos em Regulamentação e Qualidade de Energia da Universidade de São Paulo.

IEE Instituto de Eletrotécnica e Energia da Universidade de São Paulo.

CPFL Companhia Paulista de Força e Luz.

PRODIST Procedimentos de Distribuição de Energia Elétrica no Sistema Elétrico Nacional.

INMETRO Instituto Nacional de Metrologia, Normalização e Qualidade Industrial. 


\section{GRANDEZAS:}

A Potência de assimetria ou de desequilíbrio (não ativa)

D Potência de distorção (não ativa)

DFT Transformada discreta de Fourier

DIT $_{h}$ Distorção harmônica individual de tensão de ordem $h$

DR Proporção da energia total distorcida em relação à potência ativa

DSP Processador de sinal digital

DTT Distorção harmônica de tensão

EH Tensão elétrica eficaz total das componentes harmônicas

En Tensão elétrica eficaz da componente harmônica de ordem " $n$ "

f Freqüência elétrica

FFT Transformada rápida de Fourier

FR Fator de potência de referência

FRA Fator de potência de referência assimétrico

FRD Fator de potência de referência de deslocamento

FRH Fator de potência de referência harmônico

h Ordem Harmônica

hmáx Ordem Harmônica máxima

hmin Ordem Harmônica mínima

I Corrente elétrica (total)

I1 Corrente elétrica fundamental

IH Corrente elétrica total das componentes harmônicas

Ih Corrente harmônica de ordem $\mathrm{h}$

In Corrente elétrica da componente harmônica de ordem " $n$ "

ITHD Distorção harmônica total de corrente

P Potência ativa (total)

P1 Potência ativa fundamental

PH Potência ativa total das componentes harmônicas

Pn Potência ativa da componente harmônica de ordem " $n$ "

Q Potência reativa de deslocamento

S Potência aparente

T Período de um sinal elétrico 
T1 Preço unitário do fundamental (tarifa)

TDD Distorção total da demanda

TH Preço unitário do harmônico (tarifa)

UPS / SEI Fontes de Alimentação e em Sistemas de Energia Ininterruptos

V Tensão elétrica ( total)

V1 Tensão elétrica fundamental

VH Tensão elétrica total das componentes harmônicas

$\mathbf{V}_{\mathbf{h}} \quad$ Tensão harmônica de ordem $\mathrm{h}$

VTHD Distorção harmônica total de tensão

X1i Excedente fundamental do cliente

X1V Excedente fundamental da concessionária

Xc Reatância capacitiva

XHi Excedente harmônico do cliente

XHV Excedente harmônico da concessionária

XTr Reatância do transformador

YTHD Admitância harmônica

Zc Impedância capacitiva

Zcc Impedância de curto - circuito

ZTr Impedância do transformador

\section{UNIDADES DE MEDIDAS:}

$\begin{array}{ll}\text { A } & \text { Ampére } \\ \mathbf{h} & \text { hora } \\ \text { VA } & \text { Volt-Ampére } \\ \text { VAh } & \text { Volt-Ampére-hora } \\ \text { VAr } & \text { Volt-Ampére-reativo } \\ \text { VArh } & \text { Volt-Ampére-reativo-hora } \\ \text { W } & \text { Watt } \\ \text { Wh } & \text { Watt-hora }\end{array}$


CONVENÇÕES:

CL's Cargas lineares

CNL's Cargas não lineares

BC's Bancos de capacitores 


\section{SUMÁRIO}

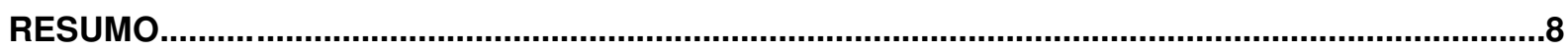

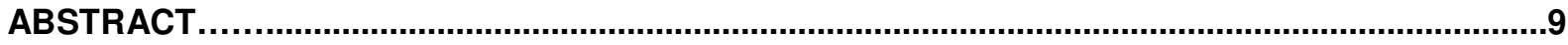

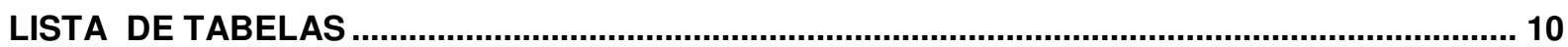

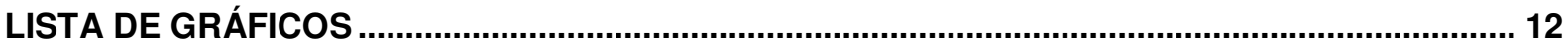

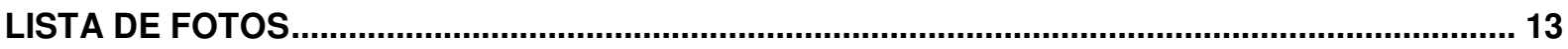

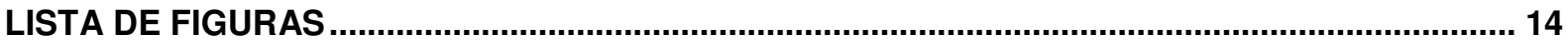

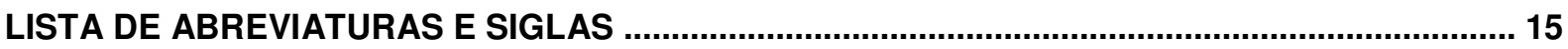

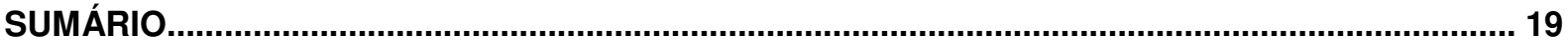

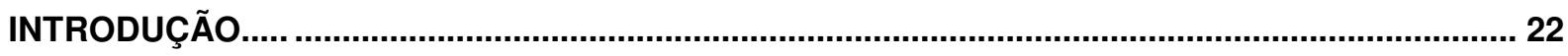

CAPÍTULO 1 - ANÁLISE E ASPECTOS CONSTRUTIVOS DOS MEDIDORES

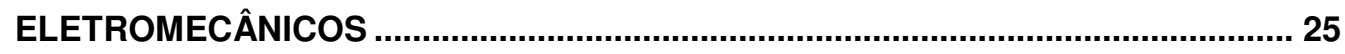

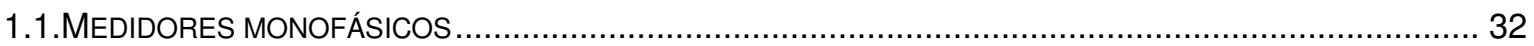

1.2. AfERIÇÃO E CALIBRAÇÃO DO MEDIDOR DE INDUÇÃO EM CONDIÇÕES SENOIDAIS DO FABRICANTE (A). 33

1.3. Conclusões SOBRE OS TESTES MEDIDOR MONOFÁSICO - TIPO INDUÇÃO do FABRICANTE (A) ....... 34

1.4. AfERIÇÃO E CALIBRAGEM DO MEDIDOR DE INDUÇÃO EM CONDIÇÕES SENOIDAIS DO FABRICANTE (B). 35

CAPÍTULO 2 - HARMÔNICAS EM SISTEMAS DE DISTRIBUIÇÃO DE ENERGIA ........................ 38

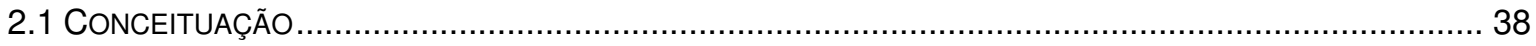

2.1.1 Fluxo de potência ativa harmônica ....................................................................... 38

2.1.2 Conceito de potências (S,P,Q,D e outras), em sistemas com grandezas distorcidas. ..... 41

2.1.3 Análise da potência ativa para tensão senoidal e corrente não senoidal.......................... 43

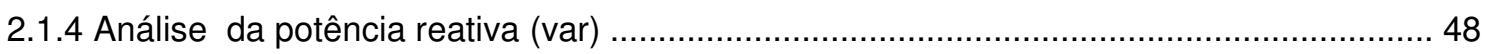

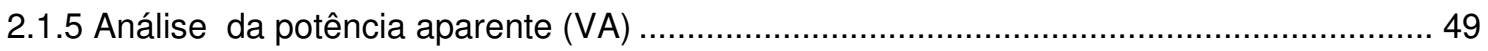

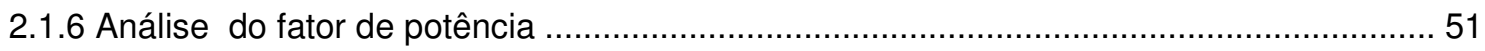

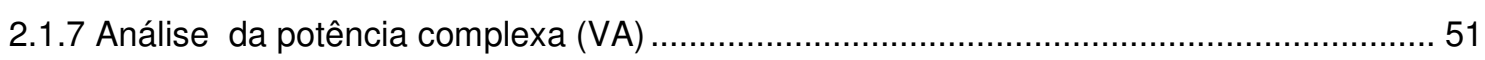

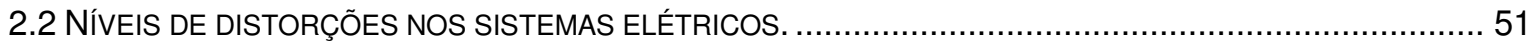

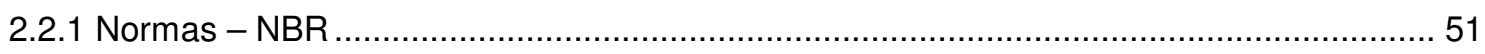

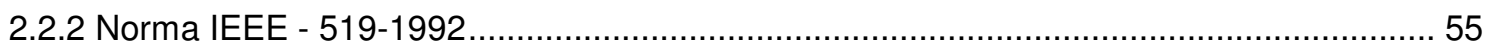

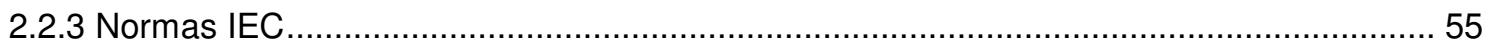

2.3 EFEITO DE DISTORÇÕES EM MEDIÇÃO DE ENERGIA COM MEDIDOR ELETRÔNICO. ............................. 58

2.3.1 Análise dos equipamentos eletrônicos de medição. (Funcionamento de medidor eletrônico digital) 


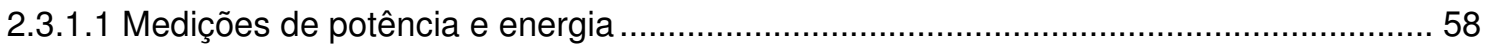

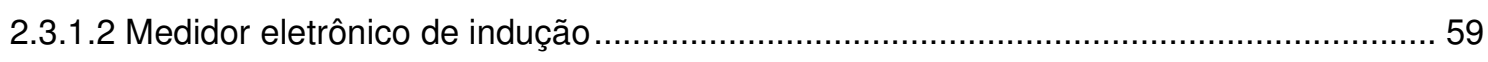

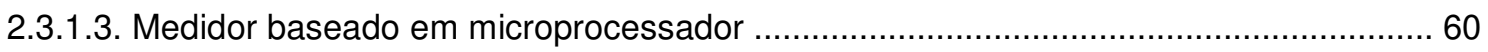

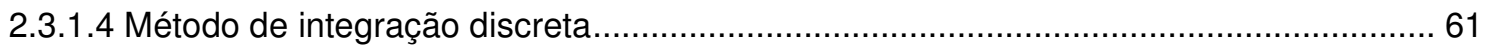

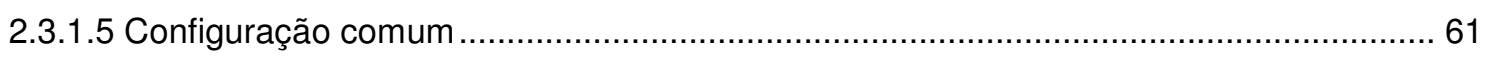

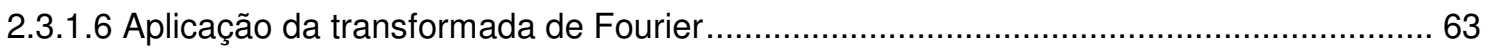

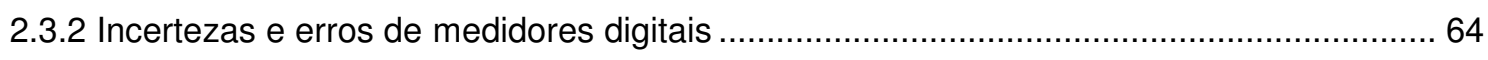

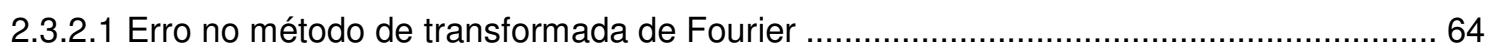

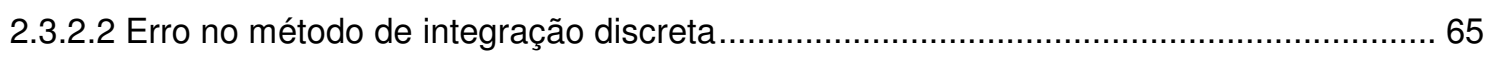

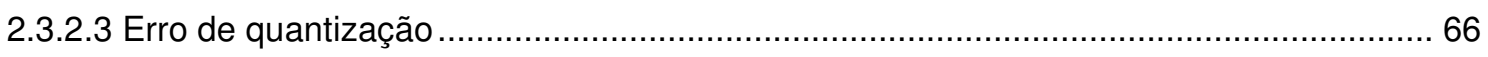

2.3.2.4 Erro de flutuação do instante de amostragem ("time-jitter") ........................................... 66

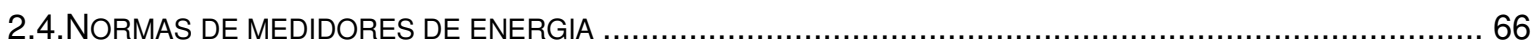

\section{CAPÍTULO 3 - COMPORTAMENTO DOS MEDIDORES ELETRÔNICOS SUBMETIDOS A ONDAS DE TENSÃO E CORRENTE NÃO SENOIDAIS. .................................................. 71}

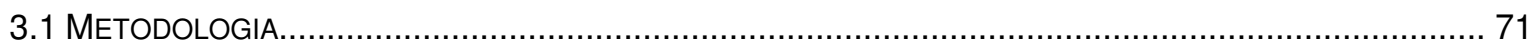

3.2 COMPARATIVO E CARACTERÍSTICA DOS MEDIDORES SUBMETIDOS A SINAIS DE ONDAS DE TENSÃO E

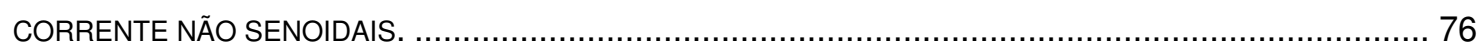

3.2.1 Valores das componentes harmônicas aplicados nos ensaios realizados.......................... 76

3.2.1.1 Dados de medições feitas em um prédio comercial, no secundário do transformador

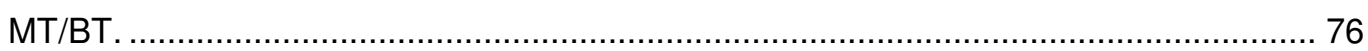

3.2.1.2. Dados de medições feitas em uma instalação residencial .......................................... 79

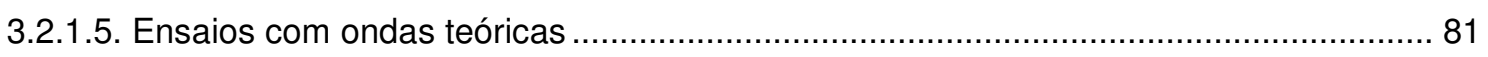

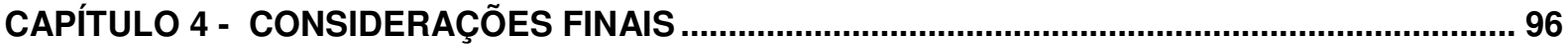

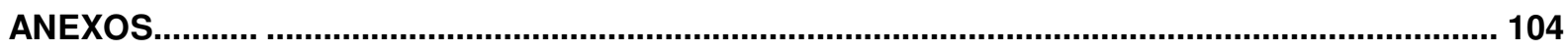

A NEXO 1 - ANÁLISE GERAL DA PRESENÇA DE HARMÔNICAS NO SISTEMA ELÉTRICO …........................ 104

1.1. Harmônicas de tensão e corrente no sistema elétrico .................................................... 104

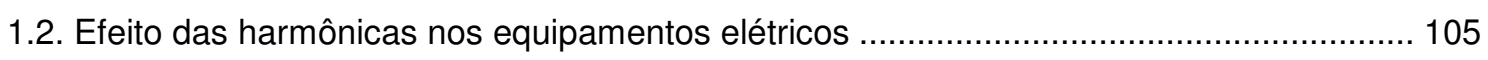

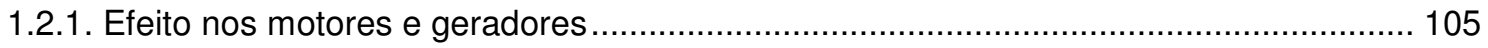

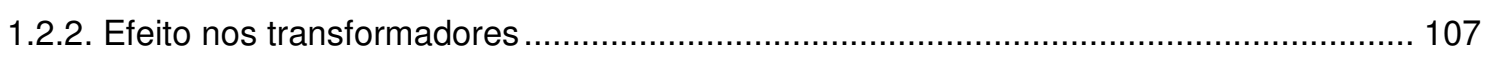

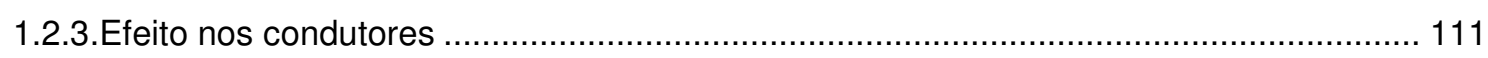

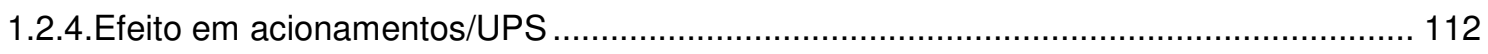

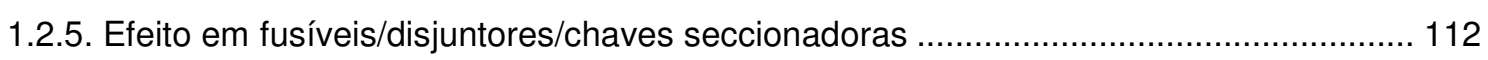

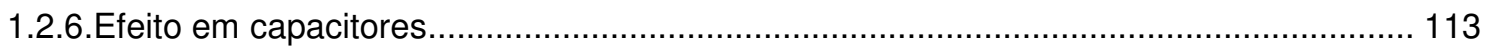

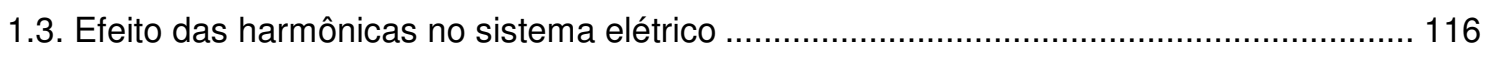

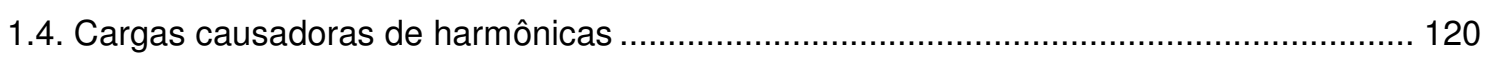

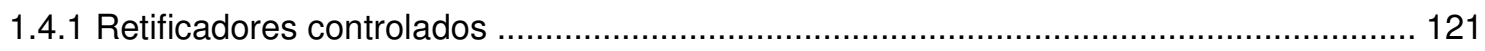

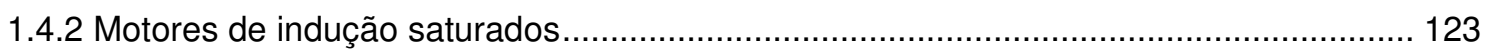




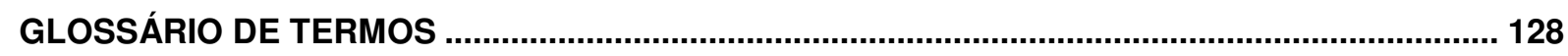

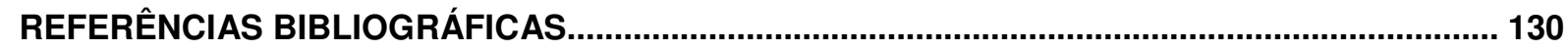




\section{INTRODUÇÃO}

Em 1878, Thomas Edison ${ }^{1}$ inventou a lâmpada incandescente e percebeu a necessidade de um sistema de distribuição elétrica para fornecer energia, viabilizando a iluminação pública. Em 1882, ele criou o primeiro sistema de distribuição do mundo, fornecendo 110 volts em corrente continua para uma pequena vila da cidade de Manhattan, nos Estados Unidos.

Na mesma época, George Westinghouse ${ }^{2}$ já atuava no setor de distribuição de gás e telefonia e, pesquisando os estudos de Edison, interessou-se também pela distribuição de energia elétrica. Vários foram os europeus que trabalharam em corrente alternada. Porém, foi Westinghouse - juntamente com William Stanley ${ }^{3}$ que, em 1886, instalou a primeira rede de distribuição em corrente alternada.

Desde então, os sistemas de distribuição de energia começaram a modificar a vida das pessoas, elevando a necessidade de estudos tecnológicos para geração, transmissão e distribuição de energia elétrica. Em 1908, iniciou-se a Era Eletrônica, com a invenção do tríodo, por Lee De Forest ${ }^{4}$. Esse período trouxe também a necessidade de uma "energia limpa", que não interferisse no bom funcionamento dos equipamentos eletrônicos.

O conceito de distorções harmônicas trata de componentes senoidais de uma função periódica, com freqüência múltipla inteira de uma freqüência fundamental f.

\footnotetext{
${ }^{1}$ Thomas Alva Edison - Nasceu em Milan em 11 de Fevereiro de 1847 - West Orange, faleceu em 18 de Outubro de 1931, foi um inventor e empresário dos Estados Unidos que desenvolveu muitos dispositivos importantes de grande interesse industrial.

${ }^{2}$ George Westinghouse, Jr. - Nasceu em 6 de Outubro de 1846 - faleceu em 12 de Março de 1914, foi um empresário e engenheiro norte americano. Entre muitas outras invenções, foi um dos pioneiros da indústria da eletricidade. O seu nome é especialmente conhecido devido à marca de acessórios e equipamentos eléctricos que ostenta o seu nome.

${ }^{3}$ William Stanley, Jr. - Nasceu no Brooklyn, Nova York em 28 de novembro de 1858, faleceu em 14 de maio de 1916, foi um físico que em sua carreira, obteve 129 patentes abrangendo uma variedade de dispositivos elétricos.
}

\footnotetext{
${ }^{4}$ Lee De Forest - Nasceu em Council Bluffs, lowa em 26 de agosto de 1873, foi um físico e inventor americano, faleceu em 30 de junho de 1961.
} 
Tensões e correntes periódicas podem ser representadas por uma série de Fourier ${ }^{5}$, com funções senoidais puras, na freqüência fundamental e em suas múltiplas inteiras, chamadas "harmônicas".

É conveniente destacar que as harmônicas produzem a operação anormal ou indevida dos medidores de energia elétrica do tipo indução. Esses equipamentos são amplamente utilizados para medir o faturamento de energia elétrica, sendo citados em alguns estudos de pesquisa e desenvolvimento do setor elétrico. Os medidores eletromecânicos têm sua operação fundamentada no fenômeno da interação eletromagnética, ou seja, o conjugado motor do medidor, associado ao registro de energia, é obtido em função da interação entre uma corrente e um fluxo magnético, este último, oriundo da tensão aplicada ao medidor. A presente pesquisa dará ênfase à abordagem dos medidores eletrônicos.

Entende-se, que um medidor eletromecânico, submetido a tensões e a correntes distorcidas, recebe conjugados gerados pela corrente. Esses conjugados fazem com que o disco acelere ou desacelere, ocasionando erros de medição. Estes poderão, futuramente, representar perda de receita da concessionária e/ou alto custo na tarifa utilizada com os consumidores.

Embora os projetistas de medidores eletrônicos planejam filtros que reduzam as distorções harmônicas, a intensificação de cargas poluidoras no sistema elétrico produz distorções harmônicas de ordem superior às estabelecidas para a garantia da sua exatidão. Trata-se, desse modo, de uma situação que pode ocasionar incorreções de dados.

Os medidores eletrônicos têm como características construtivas transformadores de corrente que, por influência de correntes distorcidas, podem produzir falhas. Estas são corrigidas por meio de softwares, atendendo às normas da ABNT vigentes.

${ }^{5}$ Em matemática, uma série de Fourier, nomeada em honra de Jean-Baptiste Joseph Fourier (17681830), é a representação de uma função periódica (muitas vezes, nos casos mais simples, tidas como tendo período 2t) como uma soma de funções periódicas da forma $x \mapsto e^{\text {inx }}$, que são harmônicas de $e^{i}$ $x$. 
Este estudo oriunda da necessidade da AES Eletropaulo através de um projeto de P\&D e busca analisar os estudos ciêntificos das perturbações de tensão e corrente sobre os medidores de energia eletromecânicos, devido ao fato de os referidos princípios serem os principais geradores de harmônicas e de erros de medição. Adicionalmente, procura observar se os medidores eletrônicos colocados em condições harmônicas reais "superiores às estabelecidas por normas" sofrem alteração na energia medida, comparando os efeitos entre medidores eletromecânicos e eletrônicos. 


\section{CAPÍTULO 1 - ANÁLISE E ASPECTOS CONSTRUTIVOS DOS MEDIDORES ELETROMECÂNICOS}

De acordo com [70], o medidor de energia elétrica é um instrumento composto por duas partes: uma eletromecânica e outra por um sistema de relojoaria. Este sistema destina-se a quantificar ou medir o consumo de energia elétrica ativa (kWh) de uma unidade consumidora.

Em 1881, [75], Thomas Edison projetou o primeiro medidor de energia elétrica, no qual ocorria deposição de metal em um eletrodo. Para encontrar o valor da energia, bastava multiplicar a corrente elétrica por um fator envolvendo a tensão da linha. Em 1903, esse fator adquiriu uma forma de cálculo que, praticamente, é mantida até os dias atuais.

Com o passar dos anos, os medidores foram aperfeiçoados, melhorando suas características elétricas de sobrecarga, sobretensão, resistência elétrica e classe de exatidão. Porém, seu pressuposto de funcionamento continuou o mesmo: trata-se de um equipamento cujo princípio físico é denominado "indução".

Por se tratar de uma tecnologia utilizada há, aproximadamente, um século, as concessionárias afirmam que é um equipamento de alta confiabilidade, chegando a atingir 30 anos de funcionamento, sem que sejam alteradas suas características técnicas. Pode ainda ser recuperado e funcionar por mais alguns anos, de maneira confiável.

O uso e a aplicação dos medidores de energia elétrica são regulamentados, acompanhados e vistoriados pela ANEEL, por intermédio de diversos órgãos normativos e reguladores. Isto se deve à importância do medidor nos contextos econômico e social. É por meio dele que as concessionárias, responsáveis pelo fornecimento de energia elétrica, efetuam o faturamento do consumo de seus clientes.

As regulamentações elaboradas pelo Inmetro e pela ABNT visam garantir que todos os medidores fabricados e em uso estejam dentro dos parâmetros da metrologia legal. Desse modo, assegura que os valores registrados estejam dentro dos limites preestabelecidos por lei.

Em [76], os medidores monofásicos possuíam características construtivas compostas por uma bobina de tensão e outra de corrente, normalmente, conhecidos 
como "medidores de um elemento", dois fios. Estes medidores (Figura 1) são utilizados nas unidades consumidoras cuja alimentação é feita por circuitos compostos de dois elementos, como em residências etc.

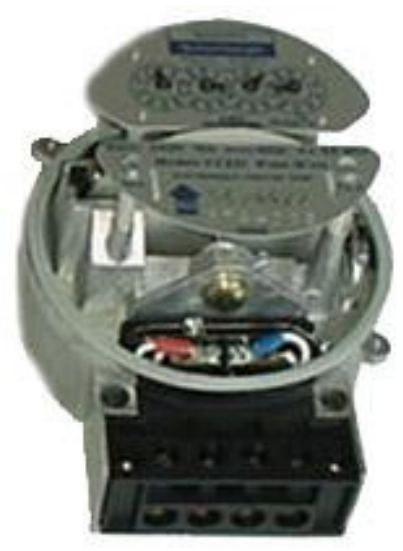

Figura 1 - Medidor eletromecânico

Fonte: Eletropaulo, E. S.P.S/A - 1993

Os medidores de energia elétrica eletromecânicos dividem-se, basicamente, em dois tipos, com diversas variações relacionadas à tensão e à capacidade de corrente: monofásicos, de um elemento; polifásicos, de dois e três elementos. Ainda podem ser equipados com registradores tipo ponteiro ou ciclométrico, demonstrados na Figura 2 [76].

A função dos registradores é idêntica: ambos registram a energia elétrica consumida igualmente. Os primeiros registradores construídos foram os do tipo ponteiro e são utilizados até hoje com perfeito funcionamento. Ao longo dos anos e com o avanço da tecnologia, especialmente no setor do plástico, foi possível construir registradores do tipo tambor ciclométrico. Esses equipamentos apresentam a leitura por um hodômetro similar ao utilizado pelos veículos automotores. 

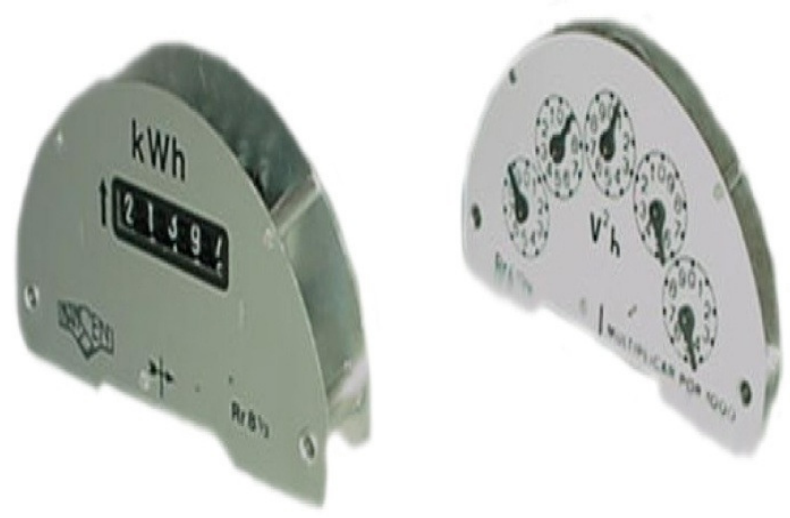

Figura 2 - Medidor eletromecânico, registradores ciclométrico e ponteiro

Fonte: Eletropaulo, E. S.P.S/A - 1993

Os medidores polifásicos possuem duas bobinas de tensão e duas de corrente, normalmente, conhecidos como "medidores de dois elementos", conforme indica a Figura 3 [76]. São utilizados nas unidades consumidoras cuja alimentação é feita por circuitos de três condutores, podendo ainda ser adotados em medições direta ou indireta.

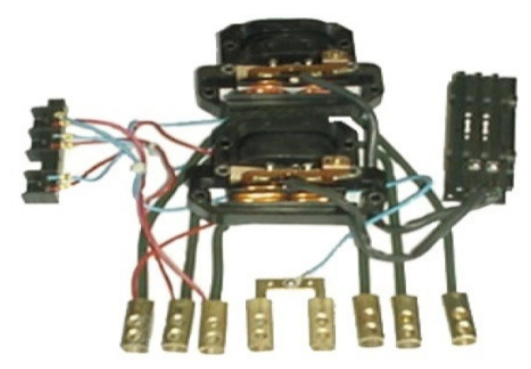

Figura 3 - Medidor eletromecânico bobinas

Fonte: Eletropaulo, E. S.P.S/A - 1993

Na medição direta, toda a carga utilizada passa pelo medidor; já na medição indireta, toda a carga passa pelos transformadores de corrente. Assim, é enviada para o medidor somente uma relação exata entre a potência real fornecida e aquela que é vista pelo medidor.

As bobinas dos medidores de energia possuem as seguintes características construtivas: 
Bobina de tensão: é constituída de muitas espiras com condutor fino; é ligada em paralelo com a carga que está sendo medida. Essa carga deve ficar permanentemente energizada, independente da utilização da energia elétrica pelo consumidor, como ilustra a Figura 4 [76].

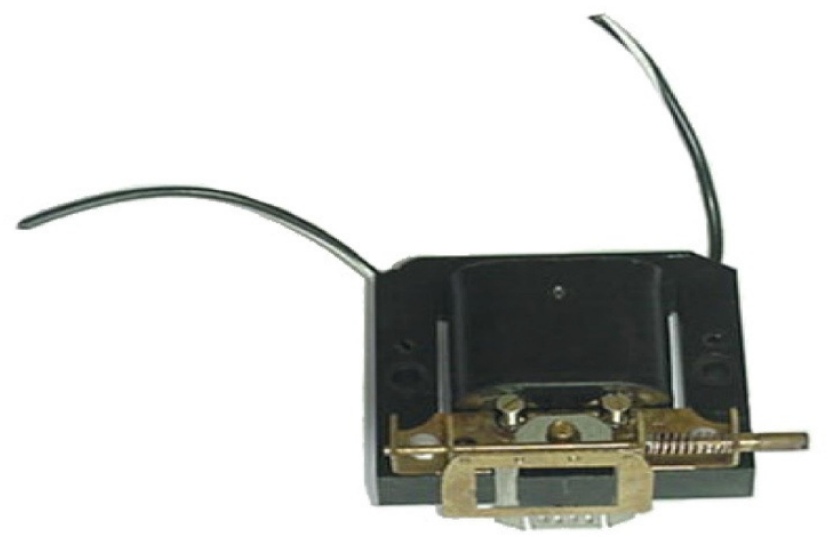

Figura 4 - Medidor eletromecânico bobina de tensão

Fonte: Eletropaulo, E. S.P.S/A - 1993

Bobina de corrente: é constituída com poucas espiras, com a finalidade de permitir a passagem da corrente elétrica referente a toda quantidade de energia que está sendo medida. Deverá ser ligada em série com a carga que está sendo consumida, conforme expõe a Figura 5 [76].
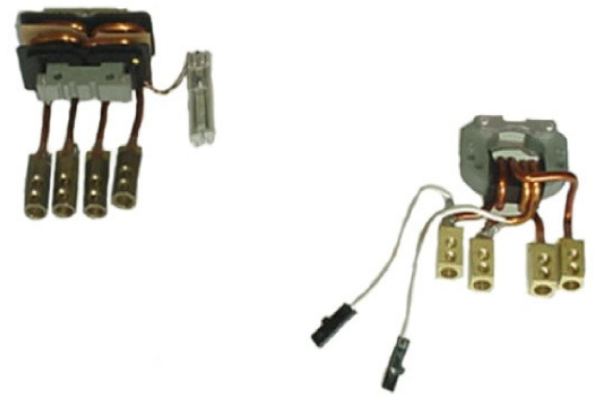

Figura 5 - Medidor eletromecânico bobinas de corrente

Fonte: Eletropaulo, E. S.P.S/A - 1993 
Medidores eletromecânicos possuem também um elemento móvel ou rotor. Esse elemento é formado por disco, eixo e mancais que giram com velocidade proporcional à potência elétrica do circuito, cuja energia pretende-se medir, como se vê na Figura 6 [76].

Os mancais formam um conjunto de peças destinadas a manter o elemento móvel em posição ideal entre as bobinas de corrente e de tensão, permitindo sua rotação. Atualmente, os mancais são do tipo magnético, teoricamente, pode-se afirmar que o coeficiente de atrito é igual a zero.

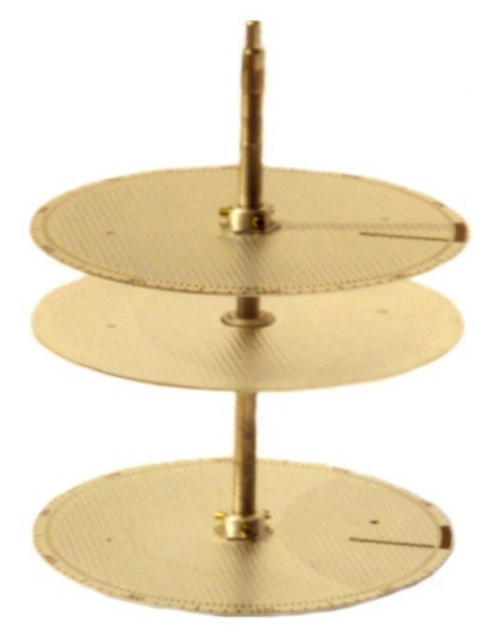

\section{Figura 6 - Medidor eletromecânico disco e mancal}

Fonte: Eletropaulo, E. S.P.S/A - 1993

Em 1889 [29], surgiu o medidor comutador, o primeiro medidor de energia elétrica, desenvolvido por Elihu Thompson ${ }^{6}$. Este medidor é essencialmente um pequeno motor, com a armadura alimentada pela tensão da linha e um enrolamento de campo, composto de poucas espiras de fio grosso, percorrido pela corrente da carga. O elemento motor de um medidor eletromecânico apresenta um conjunto formado pela bobina de potencial e por uma ou mais bobinas de corrente com seus

\footnotetext{
${ }^{6}$ Elihu Thomson - Nasceu em 29 de março de 1853, faleceu em 13 de março de 1937 foi um engenheiro e inventor que foi fundamental na fundação de grandes eletrodomésticos empresas nos Estados Unidos, Reino Unido e França.
} 
respectivos núcleos. Destina-se a produzir um conjugado motor sobre o elemento móvel, indicado na Figura 7 [76].

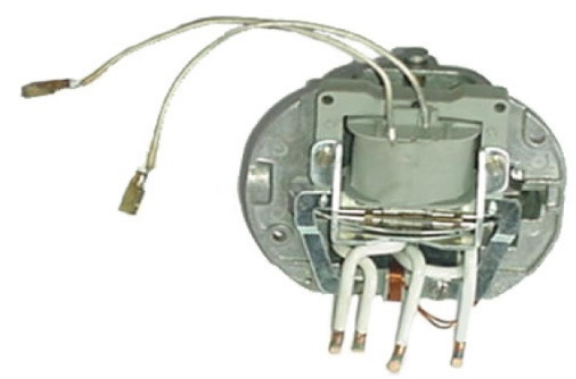

\section{Figura 7 - Medidor eletromecânico elementos móveis}

Fonte: Eletropaulo, E. S.P.S/A - 1993

Seu princípio de funcionamento baseia-se na interação entre os fluxos magnéticos produzidos pelas bobinas de tensão e de corrente.

A interação dos dois fluxos magnéticos resulta na rotação do elemento móvel, ou seja, quando houver tensão e corrente (V.I. $\cos \varphi$ ). Caso falte qualquer um desses elementos (tensão e corrente), o disco não gira, conseqüentemente, o medidor não registra. Isso significa que não haverá consumo de energia elétrica.

Os estudos realizados sobre interferência de harmônicas [77] em medidores de energia elétrica têm como principal foco os medidores de indução eletromecânicos, por sua característica construtiva, conforme ilustra a Figura 8.

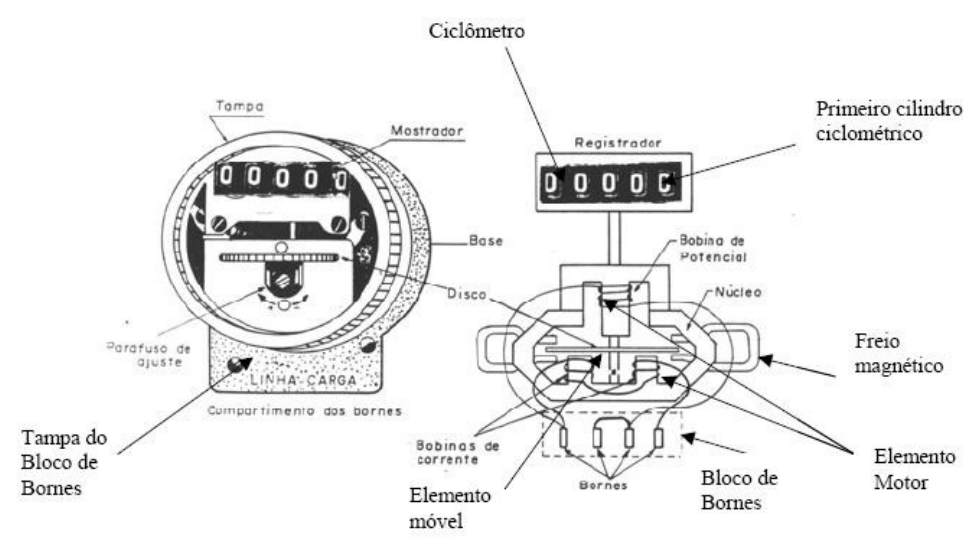

Figura 8 - Principais partes constituintes de um medidor de energia eletromecânico

Fonte: Krung, S. $R-2000$ 
Aparelhos de medição e instrumentação em geral são afetados por harmônicas, especialmente se ocorrerem fluxos magnéticos que afetam [77] a grandeza medida.

Dispositivos com discos de indução, como os medidores de energia Figura 9 , são sensíveis a componentes harmônicas, podendo apresentar erros positivos ou negativos, dependendo do tipo de medidor e da harmônica presente. Em geral, a distorção deve ser elevada (>20\%) para produzir erro significativo

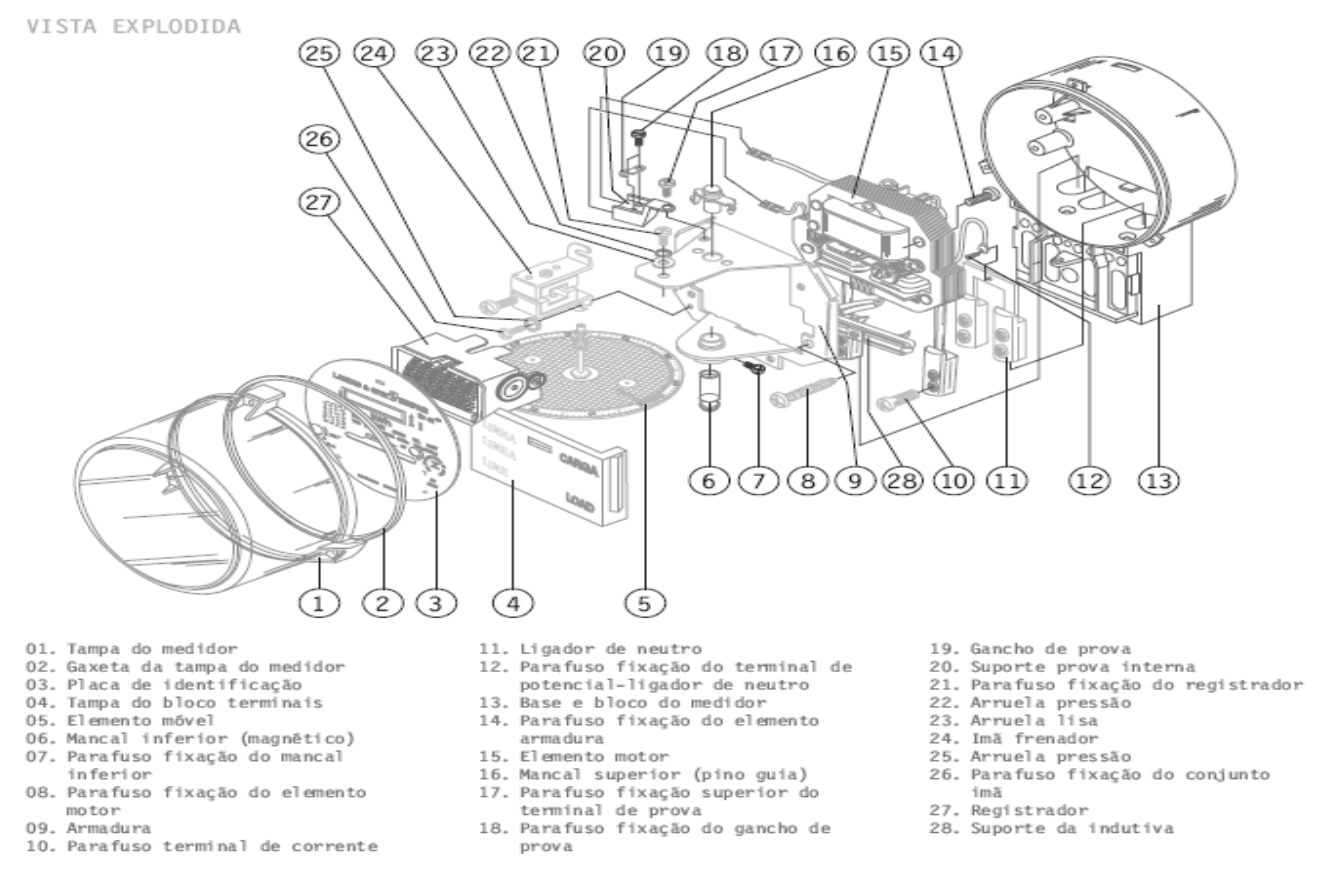

Figura 9 - Medidor eletromecânico vista explodida

Fonte: www.landisgyr.com.br - 2009

Segundo [70], o medidor mais importante e utilizado de energia foi o medidor eletromecânico do tipo indução.

Trata-se de um motor de indução em que a saída é absorvida por um sistema de frenagem e dissipada na forma de calor. Seus princípios básicos, utilizando dois campos magnéticos deslocados no tempo e no espaço, foram formulados por Shallemberger ${ }^{7}$, em 1888 [29]. Nessa experiência, utilizou-se um medidor de ampére-

7 Oliver Blackburn Shallenberger - Nasceu em 07 de Maio de 1860, faleceu em 23 de Janeiro de 1898 , foi um engenheiro e inventor. 
hora, bastante independente das pesquisas de $\mathrm{Tesla}^{8}$, na invenção do motor de indução, em 1888.

Atualmente, estudos [73] vêm demonstrando os interesses sobre a influência dos sinais harmônicos de tensão e corrente sobre o desempenho dos medidores de energia elétrica. Vários pesquisadores chegaram a considerar a possibilidade de repensar a aplicação e o uso do medidor clássico de indução.

Para entender melhor os efeitos das harmônicas em um medidor de energia, um grupo de pesquisadores do CED - Centro de Exelência em Distribuição, realizaram testes laboratoriais, sendo os resultados apresentados a seguir.

\subsection{Medidores monofásicos}

Em vários artigos técnicos levantados pelo referido grupo, segundo [73], os estudiosos, por um lado, têm mostrado a possibilidade de ocorrer erros de até $40 \%$, os quais inviabilizariam por completo a utilização de medidores eletromecânicos de indução. Por outro, mostram que erros bastante aceitáveis podem ocorrer desde que os níveis harmônicos dos sinais de corrente e de tensão não ultrapassem as balizas definidas na norma internacional IEC 1000 ou na americana IEEE 519. Alguns desses pesquisadores [73] destacam a dificuldade em se repetirem as mesmas condições de erro para instrumentos diferentes. Assim, só se poderá repetir um fenômeno em certo medidor, se os testes forem realizados nas mesmas condições laboratoriais.

Questionam-se, neste contexto, as condições reais brasileiras. Estas demonstram, em vários casos, que o nível de distorção harmônica é superior às normas acima citadas. O valor chega a apresentar entre 30\% e $40 \%$ de distorção na corrente medida em instalações elétricas de consumidores.

Os procedimentos adotados para a verificação do desempenho do medidor monofásico tipo indução, segundo [73], dividem-se em duas partes: aferição e calibragem do medidor em condições senoidais; aferição em condições harmônicas.

\footnotetext{
${ }^{8}$ Uma bobina Tesla é um tipo de transformador de circuito ressonante inventado pelo cientista sérvioamericano Nikola Tesla em torno de 1891. É geralmente utilizado para gerar tensão muito alta, baixa corrente, alta freqüência de corrente alternada eletricidade.
} 
1.2. Aferição e calibração do medidor de indução em condições senoidais do fabricante $(A)$.

Em [73], por se tratar de um rigoroso teste de exatidão, no qual um determinado medidor será submetido a condições adversas de operação, foram realizados testes laboratoriais com um crivo mais rígido do que o estabelecido pela ABNT. Definiu-se a necessidade de praticamente anular os erros do medidor sob aferição, nas condições de plena carga, pequena carga e carga indutiva.

No teste, utilizou-se um medidor eletromecânico com as seguintes características:

Marca: Fabricante A

Tipo: Monofásico 1 fase 2 fios

Classe 2

Faixa de tensão nominal de rede 110 a $127 \mathrm{~V}$

Freqüência: $60 \mathrm{~Hz}$

Faixa de corrente: 0,75 a $60 \mathrm{~A}$

Corrente nominal: $7,5 \mathrm{~A}$

Corrente de partida: 0,3 A

Constante do registrador: $1,0 \mathrm{Ah} / \mathrm{unidade}$

Constante de aferição: 0,01 Ah/pulso

Número de elementos: 1

Classe de exatidão: $0,5 \%$

$N^{\circ}$ Série: 1215843

O método de aferição empregado pelo grupo foi o do Wattímetro-Padrão, utilizando-se como referência o wattímetro de classe $0,15 \%$, devidamente rastreado.

$1^{\text {a }}$ situação:

Os resultados encontrados, segundo [73], foram os apresentados na Tabela 1.

\begin{tabular}{lcc}
\hline AFERIÇÃO & ERRO & ERRO DEIXADO\% \\
& ENCONTRADO & \\
\hline Carga Plena & $+2,70$ & $-0,11$ \\
Carga Pequena & $-3,43$ & $-0,28$ \\
Carga Indutiva & $+2,11$ & $-0,03$ \\
\hline
\end{tabular}

Tabela 1 - Erros encontrados na aferição em condição senoidal de alimentação 
Os erros deixados tiveram como objetivo, praticamente, anular aqueles em condições de tensão e corrente senoidais. Assim, caso realmente houvesse erros decorrentes de efeitos harmônicos, aqueles seriam evidenciados, sem a possibilidade de mascará-los.

\section{$2^{\mathrm{a}}$ situação:}

$\mathrm{Na}$ segunda parte do experimento, segundo [73], realizaram-se sete ensaios diferentes, com a finalidade de verificar o desempenho do medidor. As condições das ondas de tensão e da corrente estabelecida, bem como o erro do medidor para cada ensaio, são mostrados na Tabela 2.

\begin{tabular}{lllllll}
\hline Grandeza & Ensaio1 & Ensaio2 & Ensaio3 & Ensaio4 & Ensaio5 & Ensaio6 \\
\hline Tensão(Vrms) & 119,80 & 120,60 & 111,22 & 120,30 & 120,21 & 98,15 \\
THDV & $1,09 \%$ & $1,12 \%$ & $10,92 \%$ & $11,34 \%$ & $1,12 \%$ & $25,62 \%$ \\
Corrente(Arms) & 15,003 & 1,5535 & 15,354 & 1,5692 & 1,4884 & 5,1492 \\
THDI & $54,86 \%$ & $60,76 \%$ & $54,37 \%$ & $62,37 \%$ & $61,69 \%$ & $56,33 \%$ \\
$\begin{array}{l}\text { Defasagem } \\
\text { fundamental }\end{array}$ & $-2,4^{0}$ & $+1,8^{0}$ & $-17,7^{0}$ & $-14,6^{0}$ & $-57,0^{0}$ & $-69,4^{0}$ \\
$\begin{array}{l}\text { Potência } \\
\text { padrão (W) }\end{array}$ & 1559,8 & 158,75 & 1473,3 & 160,98 & 84,60 & 160,98 \\
Erro do & & & & & & \\
Medidor & $-0,56 \%$ & $+1,67 \%$ & $-3,48 \%$ & $-2,58 \%$ & $-8,52 \%$ & $-18,3 \%$ \\
\hline
\end{tabular}

Tabela 2 - Condições das ondas de tensão e corrente dos ensaios e erros apresentados pelo medidor monofásico - tipo indução

Fonte: CED 322 / QUEN 004 (III) / RL 001/OR - 2000

1.3. Conclusões sobre os testes Medidor Monofásico - Tipo Indução do fabricante (A).

Segundo [73], os resultados obtidos nos ensaios realizados mostram que um medidor de energia tipo indução pode apresentar elevado erro instrumental quando submetido a condições harmônicas.

Quando somente a corrente era distorcida, associada a pequenos ângulos de defasagem em relação à tensão, os erros encontrados foram toleráveis e compatíveis com a classe de exatidão do medidor aferido. Porém, a deformação do sinal de tensão e/ou ângulos de defasagem mais elevados podem conduzir a erros intoleráveis. 
Um fato interessante a ser notado, segundo [73], é a predominância de erros negativos, sobretudo, aqueles associados às condições mais adversas, significando elevadas perdas de receita para a concessionária.

1.4. Aferição e calibragem do medidor de indução em condições senoidais do fabricante (B).

Em [73], os testes no medidor de ampére-hora indicam as seguintes características:

Marca: Fabricante B

Modelo: $\mathrm{MAH}-100$

Faixa de tensão nominal de rede 110 a $127 \mathrm{~V}$

Freqüência: $60 \mathrm{~Hz}$

Faixa de corrente: 0,75 a $60 \mathrm{~A}$

Corrente nominal: 7,5 A

Corrente de partida: $0,3 \mathrm{~A}$

Constante do registrador: 1,0 Ah/unidade

Constante de aferição: 0,01 Ah/pulso

Número de elementos: 1

Classe de exatidão: $0,5 \%$

A saída de aferição foi realizada por captação de pulso, com o sensor eletrodinâmico externo, ou por captação visual do movimento do primeiro tambor do registrador.

Primeiramente, o ensaio avaliou o erro cometido na presença de uma onda de tensão e corrente senoidais e, em seguida, na presença de uma onda distorcida. Desta forma, dividiu-se o ensaio em duas situações:

\section{$1^{\mathrm{a}}$ situação:}

Aplicou-se uma corrente senoidal pura, de valor eficaz conhecido (medido com erro não superior a 0,05\%, de acordo com o padrão) e contabilizou-se o ampére-hora. O intervalo de tempo adotado foi de 5 pulsos, observados no primeiro tambor registrador, bem como pelo som característico emitido pelo medidor aferido. Foram obtidos os dados expostos na Tabela -3. 
Ensaio de medidor com corrente senoidal pura com erro não superior a $0,05 \%$

Tipo de onda de corrente

Corrente senoidal pura

Corrente eficaz

$2,566 \mathrm{~A}$

Pulsos contabilizados

5

Constante de aferição

0,01 A.h/pulso

A.hmedidor teste

$0,01 \times 5$ A.h $=50$ A.h

A.hmedidor padrão

$47,69 \mathrm{~mA} . \mathrm{h}$

Tempo decorrido

$0,01858 \mathrm{~h}=66,89 \mathrm{~s}$

Erro para a corrente senoidal

Erro

(A.hmedidor - A.hpadrão) $\times 100 /$

A. hpadrão $=+4,84 \%$

( $O$ erro se encontra dentro da tolerância da classe)

Tabela 3 - Ensaio de medidor com corrente senoidal pura.(Situação 1)

Fonte: CED 322 / QUEN 004 (III) / RL 001/OR - 2000

\section{2a situação:}

Aplicou-se uma corrente distorcida, semelhante a uma carga eletrônica com fonte retificadora e capacitor de filtragem do lado $\mathrm{CC}$, de valor eficaz conhecido (medido com erro não superior a $0,05 \%$, de acordo com o padrão). Igualmente, contabilizou-se o ampére-hora no padrão e cronometrou-se o tempo para 5 pulsos. A Tabela - 4 aponta os resultados obtidos.

Ensaio de medidor com corrente distorcida com erro não superior a $0,05 \%$

\begin{tabular}{ll}
\hline Tipo de onda de corrente & Corrente distorcida \\
Onda de corrente & Senoidal distorcida, DHTi E 99\%. \\
Corrente eficaz & $2,518 \mathrm{~A}$ \\
Pulsos contabilizados & 5 \\
Constante de aferição & $0,01 \mathrm{~A} . \mathrm{h} /$ pulso \\
$\begin{array}{l}\text { A.hmedidor teste } \\
\text { A.hmedidor padrão }\end{array}$ & $0,01 \times 5 \mathrm{~A} . \mathrm{h}=50 \mathrm{~A} . \mathrm{h}$ \\
$\begin{array}{l}\text { Tempo decorrido } \\
\text { Erro para a corrente senoidal }\end{array}$ & $0,93 \mathrm{~mA} . \mathrm{h}$ \\
Erro & (A.hmedidor - A.hpadrão) x 100/ \\
& $\begin{array}{l}\text { A.hpadrão }=-38,2 \% \\
\text { ( O erro se encontra dentro da tolerância } \\
\text { da classe) }\end{array}$ \\
\hline
\end{tabular}

Tabela 4 - Ensaio de medidor com corrente distorcida 
Segundo [73], a conclusão sobre o medidor ampére-hora teve como premissa aplicar aproximadamente o mesmo valor eficaz de corrente para ambos os casos, contabilizando-se 5 pulsos. Na situação com corrente senoidal, o medidor ficou dentro de sua classe de exatidão, porém, no limite. Aplicando-se a corrente distorcida, o medidor errou de maneira exagerada. Portanto, seu uso é desaconselhável na presença de cargas não lineares, ou seja, erro negativo $(-38,2 \%)$. 


\section{CAPÍTULO 2 - HARMÔNICAS EM SISTEMAS DE DISTRIBUIÇÃO DE ENERGIA}

\subsection{Conceituação}

\subsubsection{Fluxo de potência ativa harmônica}

A medição de potência elétrica e consumo de energia é de importância fundamental na engenharia de potência.

A potência instantânea é definida como o produto dos valores instantâneos de corrente e tensão:

$$
p(t)=u(t) \cdot i(t) \quad \text { Equação } 1
$$

Para a ilustração do fluxo de potência ativa harmônica de um circuito que alimenta uma carga não linear, consideramos o circuito da Figura 10, em que se tem uma CNL constiuída de um diodo e uma resistência.

A fonte é constituída por um gerador com uma resistência em série. A tensão do gerador é dada por:

$$
e=120 \sqrt{2} \operatorname{sen}_{1} t \cdot V
$$

\section{Equação 2}

Valores rms complexos das correntes harmônicas dados por:

$$
I_{n}=\frac{\sqrt{2}}{T} \int_{0}^{T} i(t) e^{-j \omega} 1^{t} d t
$$

Equação 3

A potência ativa no ponto de conexão da carga pode ser calculada com a equação 4:

$$
P_{n}=\operatorname{Re}\left(U_{n} I_{n}{ }^{4}\right) \quad \text { Equação } 4
$$

O asterísco indica o número complexo conjugado. 
Tem-se a soma das potências ativas da fundamental e das harmônicas:

$$
\sum P_{n}=P_{1}-\left(P_{0}+P_{2}+P_{3}+\cdots \cdot\right)
$$

Equação 5

Exceto a fundamental, todas as potências ativas harmônicas são negativas, isso significa que as energias harmônicas são transmitidas das cargas para a fonte.

Tal fato ocorre porque a tensão senoidal da fonte é uma carga onde geralmente a corrente harmônica é dissipada pela potência ativa suprimida por uma resistência, $R_{g}$. A potência ativa transmitida da carga para a fonte:

$$
\Delta P_{h}=-\left(P_{0}+P_{2}+P_{3}+\cdots\right) \quad \text { Equação } 6
$$

Essa potência é entregue à carga pela harmônica fundamental. Portanto, a potência ativa na frequência fundamental $P_{1}$ é mais alta do que a potência ativa $P$ da carga sendo a diferença dada por:

$$
\Delta P_{h}=P_{1}-P=R_{z}\left\|i_{h}\right\|^{2} \quad \text { Equação } 7
$$

Tem-se $\left\|i_{h}\right\|$ como sendo o valor rms da corrente harmônica. A transmissão da potência ativa $P_{1}$ causa um incremento da perda de potência no sistema de suprimento igual a:

$$
\Delta P_{1}=R_{g} I_{1}^{2} \quad \text { Equação } 8
$$

A perda de potência ativa na fonte $\Delta \mathrm{P}_{\varepsilon}$ pode ser expressa como a soma seguinte. 


$$
\Delta P_{s}=\Delta P_{1}+\Delta P_{h}=R_{s} l_{1}^{2}+\left(P_{1}-P\right) \quad \text { Equação } 9
$$

As equações (7), (8) e (9) são ilustradas na Figura 10, que mostra um diagrama do fluxo da potência ativa em um circuito não linear.

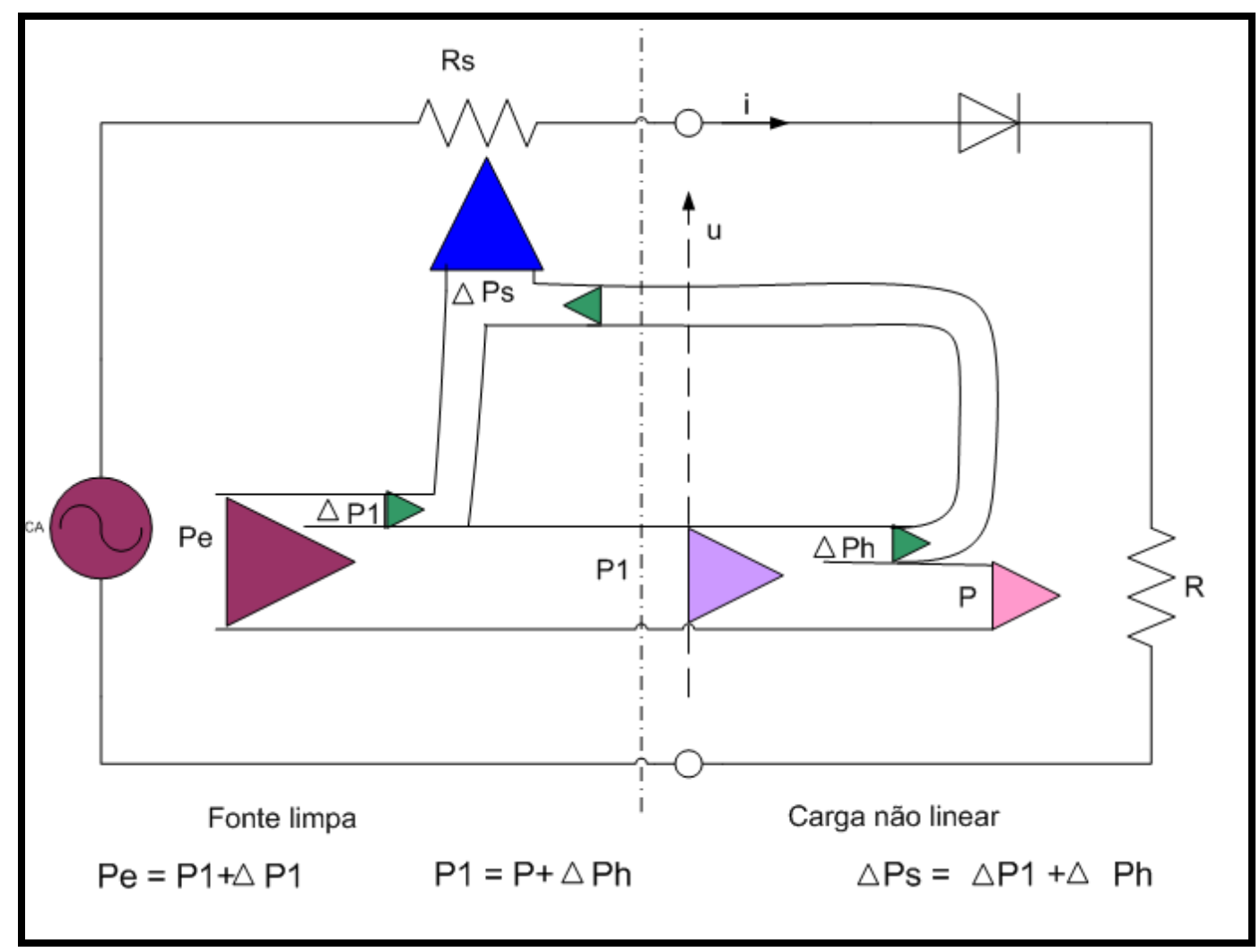

Figura 10 - Diagrama do fluxo da potência ativa

Fonte: CZARNECKI, L. S - 1996

Se o valor $R_{\varepsilon}$ resistência de fonte da freqüência fundamental é conhecido, então, com a Equação 9, é possível calcular a perda de potência ativa. Essa perda é causada por cargas não lineares em uma fonte de alimentação com tensão senoidal, com base nos valores medidos $I_{1}, P_{1}$ e $P$. Esta fórmula permanece válida mesmo quando a fonte com resistência $\mathrm{R}_{\varepsilon}$ apresentar harmônicas de corrente. 
A fórmula da Equação 9 permite calcular a perda da potência ativa na resistência da fonte, devido às correntes harmônicas geradas pela carga, sem a necessidade da análise completa Fourier.

Para o cálculo da potência ativa fundamental harmônica $P_{1}$, necessita-se calcular apenas os valores complexos das componentes fundamentais da tensão $U_{1} \mathrm{e}$ da corrente $I_{1}$.

A medição dos valores $I_{1}, P_{1}, P$ e da corrente de carga com valor rms $\|i\|$ possibilita calcular a resistência equivalente $R_{g \theta}$ da fonte. Assim, o fornecimento de resistência é equivalente no que diz respeito à potência ativa harmônica de perda $\Delta P_{h}$ e corrente $i_{k}$. Para tal resistência, tem-se as relações:

$$
R_{s g}\left\|i_{h}\right\|^{2}=\Delta P_{h^{\prime}} \quad \text { Equação } 10
$$

Também:

$$
\left\|i_{k}\right\|^{2}=\left\|i_{h}\right\|^{2}-I_{1}^{2} \quad \text { Equação } 11
$$

Portanto, na equação abaixo, obtem-se:

$$
R_{s e}=\frac{P_{1}-P}{\|t\|^{2}-I_{1}^{2}}
$$

Equação 12

2.1.2 Conceito de potências (S,P,Q,D e outras), em sistemas com grandezas distorcidas.

A norma [4] IEEE 1459 foi publicada em 2000, com a finalidade de fornecer um conjunto de definições para a medida de potências elétricas sob condições senoidais, não-senoidais, equilibradas e desequilibradas.

O conceito-chave para a resolução da potência aparente é a separação das componentes de tensões e correntes harmônicas de todas as outras componentes. Isto permite realizar uma medida correta das quantidades convencionais de faturamento (potências: ativa, reativa e aparente, e fator de potência). As demais 
componentes da potência aparente podem ser usadas para avaliar o nível de poluição harmônica no medidor de energia.

A norma [4] IEEE 1459 foi publicada em 2000, com a finalidade de fornecer um conjunto de definições para a medida de potências elétricas sob condições senoidais, não-senoidais, equilibradas e desequilibradas.

Para sistemas trifásicos, a tensão e as correntes $V_{e}$ e $l_{e}$ são definidas e relacionadas a um sistema equivalente virtual equilibrado que possui as mesmas perdas do sistema desequilibrado real. Assim, a potência aparente efetiva $S_{e}$ é definida, e sua resolução é realizada [4] e [5].

As principais definições da norma IEEE são reportadas na Tabela 5, referentes aos sistemas monofásico e trifásico.

As grandezas para as formas de ondas não-senoidais estabelecidas na norma ABNT- NBR1459-2000 para os sistemas monofásicos e trifásicos demonstrados nas Tabelas 5 e 6.

\begin{tabular}{|c|c|c|c|}
\hline Grandezas & Combinada & Fundamental & Harmônica \\
\hline Aparente [VA] & $\mathrm{S}$ & $S_{1}$ & $S_{N}, \quad S_{H}$ \\
\hline Ativa [W] & $\mathrm{P}$ & $P_{1}$ & $\mathrm{P}_{\mathrm{H}}$ \\
\hline Não ativa [var] & $\mathrm{N}$ & $\mathrm{Q}_{1}$ & $\begin{array}{lll}D_{1} & D_{V} & D_{H}\end{array}$ \\
\hline Utilização - linha & $P F=P / S$ & $P F_{1}=P_{1} / S_{1}$ & - \\
\hline Poluição harmônica & - & & $\mathrm{S}_{\mathrm{N}} / \mathrm{S}_{1}$ \\
\hline
\end{tabular}

Tabela 5 - Sistemas monofásicos

Fonte: IEEE Std 1459-2000-2003

\begin{tabular}{|c|c|c|c|}
\hline Grandezas & Combinada & Fundamental & Harmônica \\
\hline Aparente [VA] & $\mathrm{S}_{\mathrm{e}}$ & $S_{e,} S_{1}^{+}, S_{U 1}$ & $\mathrm{~S}_{\mathrm{eN}}$ \\
\hline Ativa [W] & $\mathrm{P}$ & $\mathrm{P}_{1}^{+}$ & $\mathrm{P}_{\mathrm{H}}$ \\
\hline Não ativa [var] & $\mathrm{N}$ & $\mathrm{Q}_{1}^{+}$ & $D_{\mathrm{e} 1} \quad D_{\mathrm{eV}} \quad \mathrm{D}_{\mathrm{eH}}$ \\
\hline Utilização - linha & $P F=P / S_{e}$ & $\mathrm{PF}_{1}{ }^{+}=\mathrm{P}_{1}{ }^{+} / \mathrm{S}_{1}{ }^{+}$ & - \\
\hline Poluição harmônica & - & & $\mathrm{S}_{\mathrm{eN}} / \mathrm{S}_{\mathrm{e} 1}$ \\
\hline
\end{tabular}

Tabela 6 - Sistemas trifásicos

Fonte: IEEE Std 1459-2000 - 2003 
A norma IEEE 1459 [4] serve somente para fornecer diretrizes no projeto de instrumentação de medidas de energia e potência. Ela sugere quantidades que poderiam ser medidas para faturamento, decisões econômicas de engenharia e principais agentes poluidores de harmônicas. Entretanto, cabe observar que os componentes não-fundamentais da composição da potência aparente não podem fornecer qualquer informação sobre a fonte de harmônicas. Na realidade, é impossível avaliar a partir de seus valores, se o fluxo de harmônicas vai da carga para a rede ou da rede para a carga.

A única grandeza capaz de detectar a fonte de harmônica é a potência ativa harmônica $\mathrm{P}_{\mathrm{H}}$, cujo valor é positivo ou negativo, quando o conteúdo harmônico decorre da rede ou da carga, respectivamente [5]-[6]. Em relação aos métodos de detecção de distorção harmônica, a norma [4] não sugere nenhum método de medida.

Em [6] e [7], os autores apresentam uma estratégia no domínio do tempo para a extração das componentes harmônicas e fundamental. Esta estratégia enquadra-se às novas definições de potência, pois são essencialmente baseadas na separação dos componentes fundamentais das correntes e tensões.

\subsubsection{Análise da potência ativa para tensão senoidal e corrente não senoidal.}

Potência e energia ativas possuem um significado físico claro: refletem o fluxo líquido da potência ou energia transferida num período de integração.

A potência média medida num intervalo $T$ é chamada de "potência ativa", sendo dada por:

$$
P=\frac{1}{T} \int_{0}^{T} u(t) \cdot i(t) d t \quad \text { Equação } 13
$$

A energia, num certo intervalo de tempo de medição Tm, é obtida da integração:

$$
\Delta W=\int_{0}^{T m} p(t) d t=\int_{0}^{T m} u(t) \cdot i(t) d t \quad \text { Equação } 14
$$


Analisando a potência ativa temos:

$$
V_{i}(x)=\operatorname{sen}(x)
$$

\section{Equação 15}

$$
i_{h}(x)=\operatorname{sen}\left(h_{x}+\varphi_{h}\right)
$$

Equação 16

$$
P_{a t}=\frac{1}{2 \pi} \int_{0}^{2 \pi} \operatorname{sen}(x) \cdot \operatorname{sen}\left(h x+\varphi_{k}\right) \cdot d x
$$

Equação 17

Intervalo de integração $\rightarrow x_{1}=0 \rightarrow \mu_{1}=-\varphi_{k}$

$$
x_{2}=2 \pi \rightarrow \mu_{2}=2 \pi(1-h)-\varphi_{h} \quad \text { Equação } 18
$$

$$
\int_{0}^{2 \pi} X_{1 d x}=\int_{\mu 1}^{\mu 2} \cos \mu \frac{d_{R}}{1-h}=\left.\frac{1}{1-h} \operatorname{sen} \mu\right|_{\mu 1} ^{\mu 2}=
$$

$$
\left\{\operatorname{sen}\left[2 \pi(1-h)-\varphi_{h}\right] \text { Equação } 19\right.
$$

Analogamente:

$$
\int_{0}^{2 \pi} y_{1} d x=0
$$

Equação 20

Portanto, $P_{a t}=0$, isto é, tensão fundamental e corrente harmônica não produzem potência ativa. 
Exemplificando essa demonstração são apresentados dois casos de tensão senoidal e corrente de $3^{\text {a }}$ harmônica.

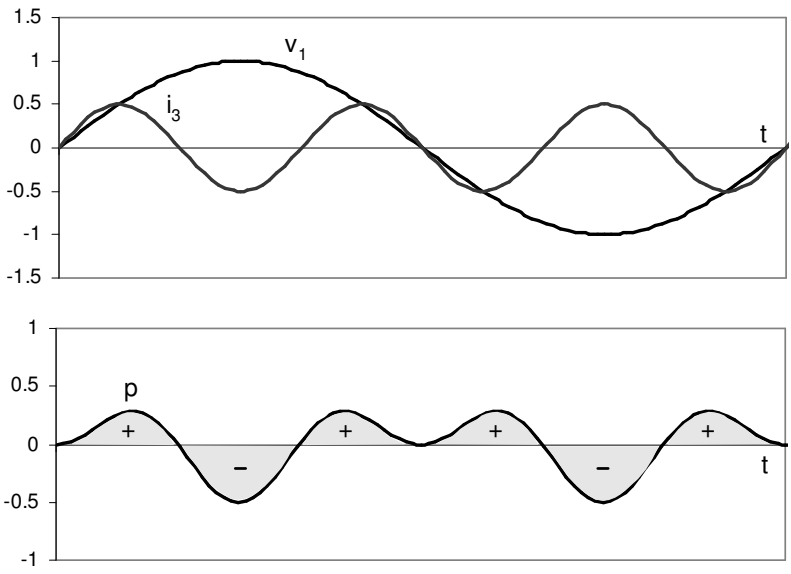

Gráfico 1 - Ilustração da potência instantânea caso 1 Fonte: IEEE Std 1459-2000 - 2003

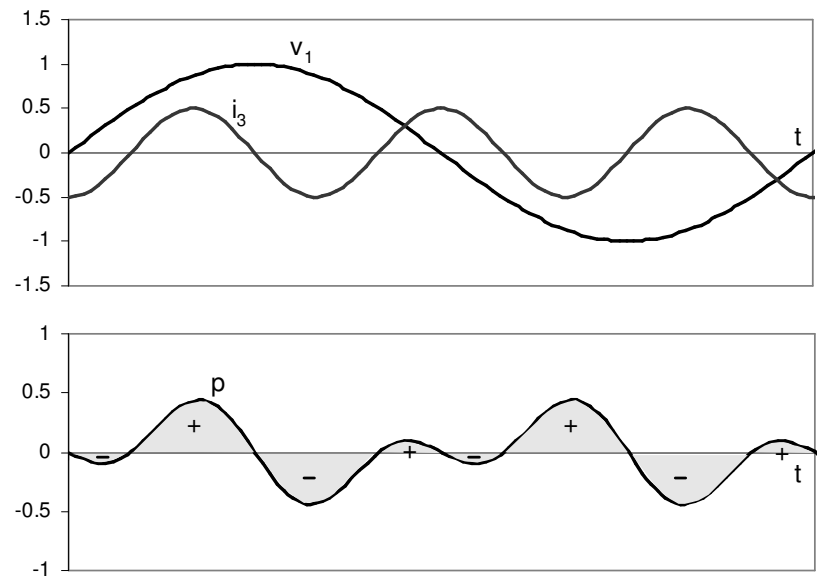

Gráfico 2 - Ilustração da potência instantânea caso 2

Fonte: IEEE Std 1459-2000 - 2003 
Adicionando-se uma carga linear, obtem-se uma forma de onda senoidal, como:

$$
i=\sqrt{2} I \operatorname{sen}(\omega t-\theta) \quad \text { Equação } 22
$$

Onde:

$$
\begin{array}{ll}
V & \rightarrow \text { é o valor rms da tensão }(\mathrm{V}) \\
I & \rightarrow \text { é o valor rms da corrente }(\mathrm{A}) \\
\omega & \rightarrow \text { é a freqüência angular } 2 \pi f(\mathrm{rad} / \mathrm{s}) \\
f & \rightarrow \text { é a frequência }(\mathrm{Hz}) \\
t & \rightarrow \text { é o tempo }(\mathrm{s}) . \\
\theta \quad & \rightarrow \text { é o ângulo de fase (rad) }
\end{array}
$$

A potência instantânea $p$ [4] é dada por:

$$
\begin{aligned}
& \| p=v i \\
& \quad \text { Equação 23 } \\
& p=p_{a}+p_{q} \text { Equação } 24
\end{aligned}
$$

Onde:

$p_{a}=V I \cos \theta[1-\cos (2 \omega t)]=P[1-\cos (2 \omega t)] ; \quad P=V I \cos \theta \quad$ Equação 25

$p_{q}=-V I \operatorname{sen} \theta \operatorname{sen}(2 \omega t)=-Q \operatorname{sen}(2 \omega t) ; \quad Q=V I \operatorname{sen} \theta \quad$ Equação 26 
Tem-se que:

A potência instantânea é produzida pela componente do ativo atual, ou seja, o componente que está em fase com a tensão. Trata-se da quantidade do fluxo de energia.

$$
w_{a}=\int p_{a} d t=P \tau-\frac{P}{2 \omega} \operatorname{sen}(2 \omega t) ; \text { Equação } 27
$$

O fluxo de energia gerado é unidirecional, partindo da fonte para a carga. A quantidade de fluxo gerada não é negativa, $p_{a} \geq 0$.

A potência instantânea $p_{q}$ é produzida pela componente reativa atual, ou seja,

o mesmo componente que está em quadratura com a tensão. Desse modo, a quantidade de fluxo de energia é obtida por:

$$
w_{q}=\int p_{q^{a t}}=\frac{Q}{2 \omega} \cos (2 \omega t) \quad \text { Equação } 28
$$

Este tipo de energia oscila entre a fonte geradora e as indutâncias, capacitâncias, relativas às atividades de massas em movimento de sistemas eletromecânicos, como motor e rotores geradores. $O$ valor médio presente na quantidade de fluxo é zero; e o valor da transferência para a carga é nulo.

A potência ativa $P(W)[4]$ tem o valor médio da potência instantânea observado durante o intervalo de tempo $t$ para $t+k T$

$$
\| P=\frac{1}{k T} \int_{t}^{t+k T} p d t \quad \text { Equação } 29
$$


Onde:

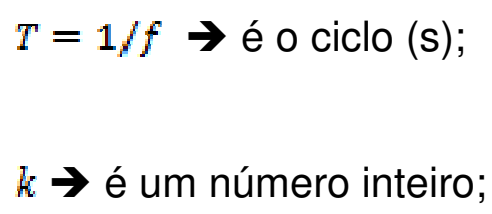

$t \rightarrow$ é o momento em que começa a medição.

$$
\| P=V I \cos \theta \quad \text { Equação } 30
$$

2.1.4 Análise da potência reativa (var)

De acordo com [4], além da potência ativa, há, no sistema tradicional, a potência reativa, cujo conceito está bem estabelecido para o sistema senoidal, definições de grandezas de sistemas de corrente alternada aplicadas em medidores convencionais funcionam bem em sistema senoidal. Todavia, hoje, novas definições são necessárias. Num sistema senoidal, tem-se a potência reativa expressa pela seguinte equação:

$$
Q=U I \operatorname{sen} \varphi \text { Equação } 31
$$

A potência $Q$ é a amplitude da potência instantânea oscilante $P_{q}$ da equação 25

$$
\begin{gathered}
Q=\frac{1}{2 \pi} \oint v d i=\frac{-1}{2 \pi} \oint i d v=\frac{1}{k T} \int_{t}^{t+k T} v \frac{d i}{d t} d t=\frac{-1}{k T} \int_{t}^{t+k T} i \frac{d i}{d t} d t=\frac{-\omega}{k T} \int_{t}^{t+k t} v \int[i d t] d t \quad \text { Equação } 32 \\
\| Q=\frac{\omega}{k T} \int_{t}^{t+k T} i\left[\int v d t\right] d t \quad \text { Equação } 33
\end{gathered}
$$




$$
Q=V I \operatorname{sen} \theta \quad \text { Equação } 34
$$

Nota: Se a carga for indutiva: $Q>0$. Se a carga for capacitiva: $Q<0$.

2.1.5 Análise da potência aparente (VA)

Segundo [4], a potência aparente $S$ é o produto da raiz média do quadrado (rms) da tensão e a raiz média do quadrado (rms) atual.

$$
\begin{gathered}
\| S=V I \quad \text { Equação } 35 \\
S=\sqrt{P^{2}+Q^{2}} \quad \text { Equação } 36
\end{gathered}
$$

Nota: A energia instantânea $p$ segue uma oscilação senoidal com uma frequência $2 f=2 \omega / 2 \pi$, os quais são distorcidos pela potência ativa P. A Amplitude da oscilação senoidal é a potência aparente $S$.

$\mathrm{Ou}$

$$
S=U_{e f} I_{e f}=\sqrt{P^{2}+Q^{2}} \quad \text { Equação } 37
$$

Para condições não senoidais a definição da potência aparente como o produto de tensão eficaz e corrente eficaz:

$$
S=U_{e f} I_{e f} \quad \text { Equação } 38
$$


Se a tensão e a corrente forem funções periódicas com período $\mathrm{T}$, elas podem ser expressas como série de Fourier, e as potências aparentes e ativas podem ser definidas como:

$$
\begin{array}{ll}
S=\sqrt{\sum_{n} U_{n}^{2} \sum_{n} I_{n}^{2}} & \text { Equação } 39 \\
P=\sum_{n} U_{n} I_{n} \cos \varphi_{n} & \text { Equação } 40
\end{array}
$$

Separando as partes relativas à fundamental e às harmônicas, tem-se:

$$
P=P_{1}+\sum_{h=2}^{\infty} P_{h}=U_{1} I_{1} \cos \left(\varphi_{1}\right)+\sum_{h=2}^{\infty} U_{h} I_{h} \cos \left(\varphi_{h}\right) \quad \text { Equação } 41
$$

Esta expressão considera desprezível a componente contínua, o que é uma aproximação geralmente válida para redes de distribuição e transmissão.

É bastante difundida a seguinte definição da potência reativa, em sistema não senoidal:

$$
Q=\sum_{n} U_{n} I_{n} \operatorname{sen} \varphi_{n} \quad \text { Equação } 42
$$

Separando as partes relativas à fundamental e às harmônicas, tem-se:

$$
Q=Q_{1}+\sum_{h=2}^{\infty} Q_{h}=U_{1} I_{1} \operatorname{sen}\left(\varphi_{1}\right)+\sum_{h=2}^{\infty} U_{h} I_{h} \operatorname{sen}\left(\varphi_{h}\right) \quad \text { Equação } 43
$$

Uma outra expressão, muitas vezes utilizada em medidores para a definição da potência reativa, é:

$$
Q=\frac{1}{T} \int_{0}^{T} u\left(t-\frac{T}{4}\right) i(t) d t \quad \text { Equação } 44
$$

Essa expressão é similar àquela da potência ativa, mas introduz uma defasagem de $90^{\circ}$ na forma de onda da tensão. Evidentemente, essa expressão tem origem nos conceitos de corrente alternada, na freqüência fundamental.

Conforme [4], atualmente, a utilidade prática dessa definição é questionada, e novos conceitos de potência têm sido propostos para condições não senoidais por 
especialistas de vários países, registrados no documento IEEE 1459-2000 [69]. Esse documento propõe grandezas que permitem separar as componentes fundamentais e harmônicas, bem como as partes ativas e não ativas. Por exemplo, a potência aparente não ativa $S_{N}$ permite determinar o nível da poluição de uma carga, o que pode se tornar importante se a estrutura tarifária possibilitar alguma forma de taxar a poluição harmônica.

2.1.6 Análise do fator de potência

Conforme [4] o fator de potência é obtido pela fórmula;

$$
\| P_{F}=\frac{P}{s} \quad \text { Equação } 45
$$

2.1.7 Análise da potência complexa (VA)

$$
S=V I=P+j Q \quad \text { Equação } 46
$$

Tem-se:

$V=V \angle 0^{\circ} \rightarrow$ é a tensão do fasor.

$I=I \angle \theta \rightarrow$ é o fasor conjugado da corrente.

Nota: Esta expressão origina-se do triângulo das potências, $S, P, e Q$, a qual é utilizada para os estudos dos fluxos das potências.

2.2 Níveis de distorções nos sistemas elétricos.

\subsubsection{Normas - NBR}

As distorções harmônicas presentes nas redes elétricas, segundo [61], são fenômenos associados a deformações na onda das tensões e nas correntes. 
Estas perturbações tendem a se intensificar, na medida em que dispositivos residenciais, comerciais e industriais, utilizando componentes físicos não lineares, têm sido cada vez mais empregados.

Este é o caso da tecnologia eletrônica e de outras, a exemplo do emprego de equipamentos baseados na saturação magnética e arcos elétricos. Em vista dos impactos negativos relacionados com a operação sob tais condições, esta subseção tem por propósito apresentar as premissas necessárias a assegurar o controle desses distúrbios.

A Tabela 7 [61] apresenta uma síntese da terminologia aplicável para a formulação do cálculo de valores de referência às distorções harmônicas.

\begin{tabular}{ll}
\hline Identificação da Grandeza & Símbolo \\
\hline Distorção harmônica individual de tensão ordem h & $D I T_{h} \%$ \\
Distorção harmônica total de tensão & $D T T \%$ \\
Tensão harmônica de ordem h & $V_{h}$ \\
Ordem harmônica & $H$ \\
Ordem harmônica máxima & $H m a ́ x$ \\
Ordem harmônica mínima & $H m i n$ \\
Tensão fundamental medida & $V_{1}$ \\
\hline
\end{tabular}

Tabela 7 - Terminologia Harmônica - Fonte: ANEEL - PRODIST - 2008

As expressões para o cálculo das grandezas DITh\% e DTT\% são:

$$
D I T_{R} \%=\frac{V_{h}}{V_{1}} \times 100 \quad \text { Equação } 47
$$




$$
D T T=\frac{\sqrt{\sum_{R=1}^{R m a ̊ x} v_{h}^{2}}}{V_{1}} \times 100 \quad \text { Equação } 48
$$

O espectro harmônico a ser considerado para o cálculo da distorção total deve compreender uma faixa de freqüências que considere desde a componente fundamental até, no mínimo, a 25ª ordem harmônica (hmin-25).

Os valores de referência para as distorções harmônicas de referência são demonstrados na Tabela 8.

\begin{tabular}{|c|c|}
\hline Tensão nominal do & Distorção Harmônica Total de \\
\hline Barramento & Tensão $\quad D T T[\%]$ \\
\hline$V_{N} \leq 1 \mathrm{kV}$ & 10 \\
\hline $1 \mathrm{kV}<V_{n} \leq 13,8 \mathrm{kV}$ & 8 \\
\hline $13,8 k V<V_{n} \leq 69 k V$ & 6 \\
\hline $69 k V<V_{n} \leq 138 k V$ & 3 \\
\hline
\end{tabular}

Tabela 8 - Níveis de referência para distorção harmônica total - Fonte: ANEEL - PRODIST - 2008 
Para as distorções harmônicas individuais, devem ser considerados os limites indicados na Tabela 9.

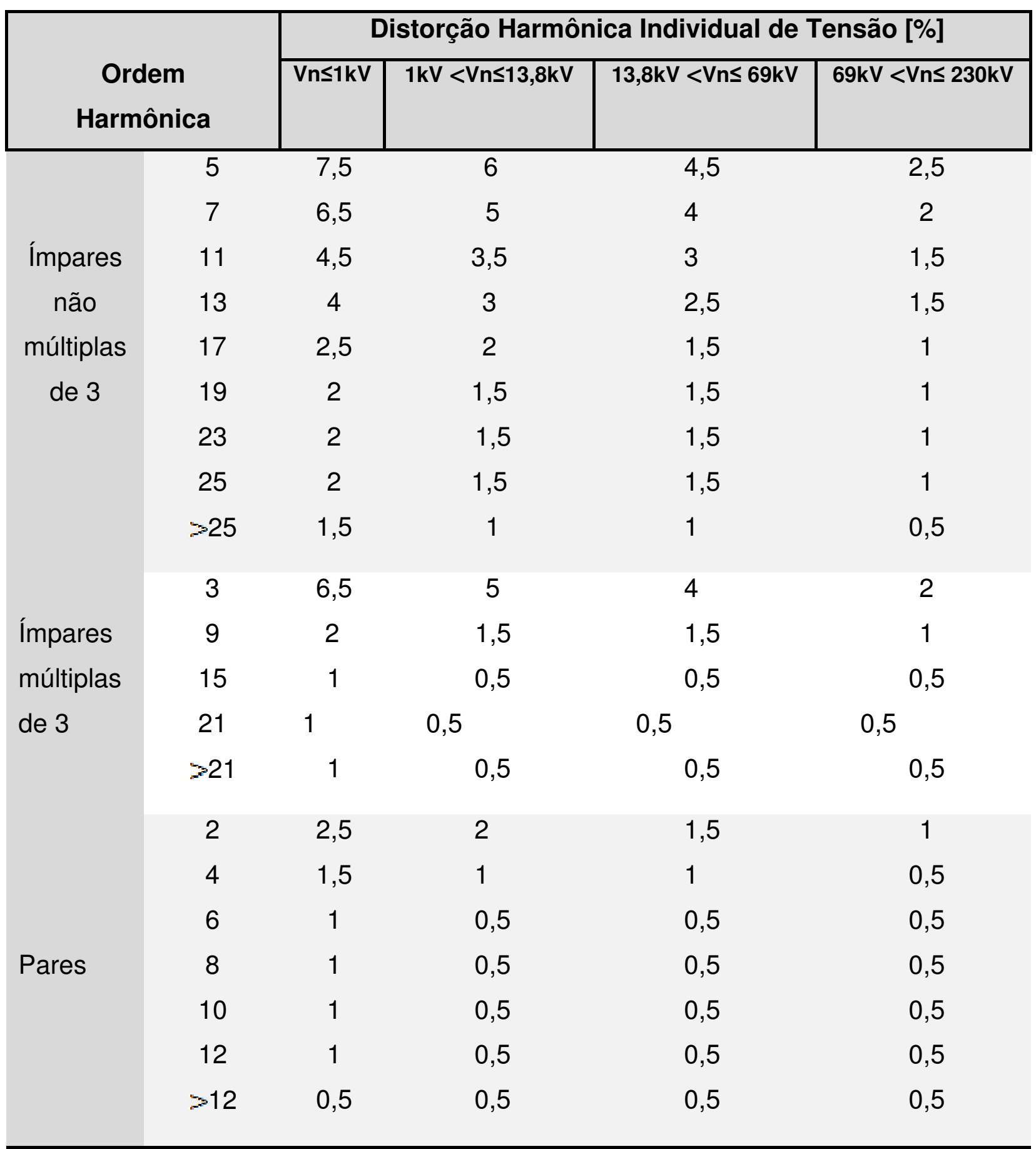

Tabela 9 - Níveis de referência para distorções harmônicas individuais - Fonte: ANEEL PRODIST - 2008. 


\subsubsection{Norma IEEE - 519-1992}

A norma IEEE [69], recomenda valores-limite relacionados às tensões e às correntes harmônicas máximas em sistemas de potência. Esses limites são operações normais com duração maior (uma hora). Os limites da distorção da tensão dependem somente da tensão do barramento.

Os limites atuais da distorção estão especificados, enquanto a distorção total da demanda, TDD, depende da relação da corrente do curto-circuito, no ponto do acoplamento comum, à corrente fundamental máxima da carga calculada com a corrente média da demanda máxima (15 ou 30 intervalos minuciosos) para os 12 ciclos precedentes. Os limites TDD da distorção da corrente são expressos nos porcentuais da corrente máxima da carga da demanda.

\subsubsection{Normas IEC}

De acordo com [45], as normas IEC inserem-se em seis categorias:

Geral: fornece definições, terminologia etc. (IEC 61000-1-x);

Ambiente: define as características do ambiente, onde serão instalados os equipamentos (IEC-61000-2-x);

Limites de emissão: dão os limites permissíveis de perturbações que podem ser ocasionadas pelos equipamentos conectados ao sistema de potência (IEC 61000$3-\mathrm{x})$;

Técnicas de medição e provas: fornecem diretrizes detalhadas para os equipamentos de medição e procedimentos de prova para assegurar o cumprimento com as partes restantes da norma. (IEC 61000-4-x);

Diretrizes de mitigação e instalação: fornecem um guia detalhado dos equipamentos, como filtros, condicionadores de energia, mitigadores, supressores de sobretensões etc. (IEC 61000-5-x);

Normas genéricas e de produtos: definem os níveis de imunidade requeridos para os equipamentos específicos ou gerais (IEC 61000-6-x)";

Estas normas, que ainda não foram escritas na sua totalidade, são adotadas pela Comunidade Européia (Cenelec), sendo requisito para a venda de produtos na Europa e alguns outros países sob influência européia. Poucas delas estão em vias de aplicação nos USA. 
Outra norma importantes é a EN $50160^{9}$. A (Tabela 10) resume os níveis de perturbações, segundo esta norma.

A (Tabela 10) resume os níveis de perturbações segundo esta norma.

\footnotetext{
${ }^{9}$ As características da tensão fornecida pelas redes de distribuição pública de energia eléctrica estão definidas na Norma Internacional EN 50160:1999
} 


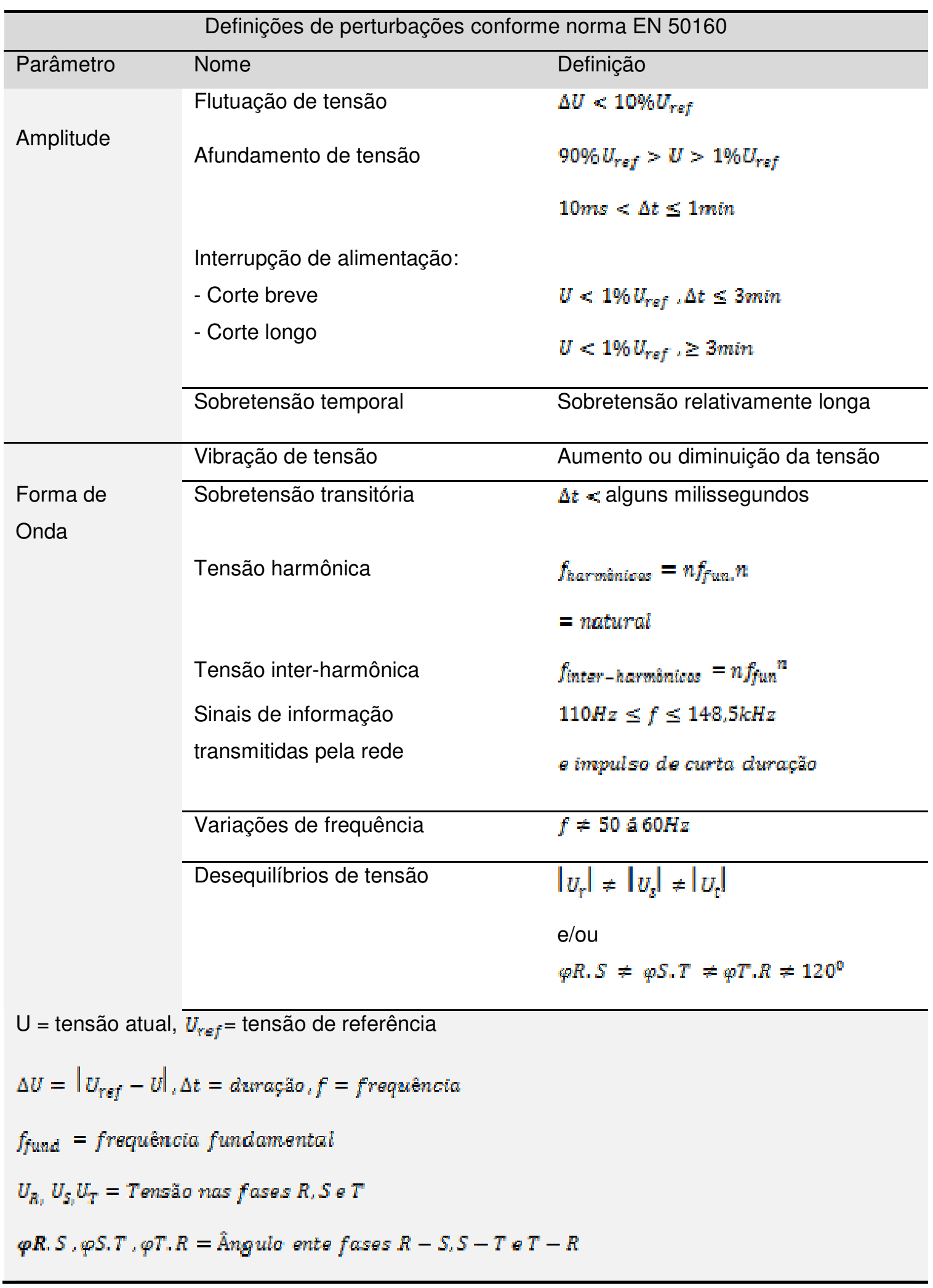

Tabela 10 - Definições de pertubação conforme norma EN 50160 - Fonte: EN 50160 1999. 
2.3 Efeito de distorções em medição de energia com medidor eletrônico.

2.3.1 Análise dos equipamentos eletrônicos de medição. (Funcionamento de medidor eletrônico digital)

\subsubsection{Medições de potência e energia}

Há, na literatura, algumas referências que abordam possíveis erros em medições de potência ou de energia ativa e reativa de medidores analógicos e digitais em condições não senoidais. De acordo com [63], testes realizados com medidores monofásicos e trifásicos eletromecânicos e digitais usando formas de onda reais registradas indicaram erros de até $10 \%$, inclusive em medição de potência ativa com medidor digital.

Existem outros autores [64] que se concentram na potência reativa, concluindo que a definição do parâmetro usado como referência foi a maior fonte de erros. Ainda segundo esse autor [64], erros na faixa de $-41 \%$ a $+68 \%$ foram encontrados com formas de onda de redes reais.

Outras pesquisas [65] demonstram a possibilidade de erros consideráveis na medição de potência ativa com um medidor eletromecânico, mas não com medidor digital. Além disso, constataram-se diferenças nas potências reativas, mas associadas a diferentes definições de potência reativa.

Para uma avaliação da precisão de medições de potências e energias no sistema elétrico, é necessário o entendimento não apenas dos princípios de funcionamento dos medidores, mas também das grandezas medidas. Também é preciso compreender sua relação com a finalidade da medição, bem como todas as implicações relacionadas à utilização de energia elétrica, em sistemas elétricos cada vez mais distorcidos.

Algumas questões fundamentais das medições em condições não senoidais surgem do fato de que os métodos de medição para faturamento de consumo de energia existentes foram concebidos para condições senoidais ou condições em que as distorções ainda não tinham muitas implicações nos processos de medição.

Neste contexto, ressaltam-se questões como resposta do medidor às freqüências harmônicas, além do fato de as frequências das grandezas medidas não estarem devidamente definidas ou adaptadas para medições em condições distorcidas. 
Existem, atualmente, os seguintes tipos básicos de medidores eletrônicos:

- indução

- eletrônico com tecnologia digital

- eletrônico com componentes analógicos ou híbridos

2.3.1.2 Medidor eletrônico de indução

O medidor que usa o convencional disco de indução Ferraris, baseado em princípios eletromecânicos, tem sido adotado, em grande escala, há mais de um século. Recentemente, as necessidades de precisão, desenvolvimento de sistemas de aquisição de dados e gerenciamento de energia à comunicação para medições elétricas modernas têm estimulado a idéia de desenvolver medições inteligentes, baseadas em técnicas eletrônicas e microprocessadas. A tecnologia tem tido grandes evoluções, além do barateamento nos custos de medidores microprocessados.

A Figura 11 ilustra o esquema básico de um wattímetro eletrônico, que pode usar princípio de multiplicador analógico ou usar método de amostragem digital. No último caso, geralmente, são medidas também as potências reativa e aparente.

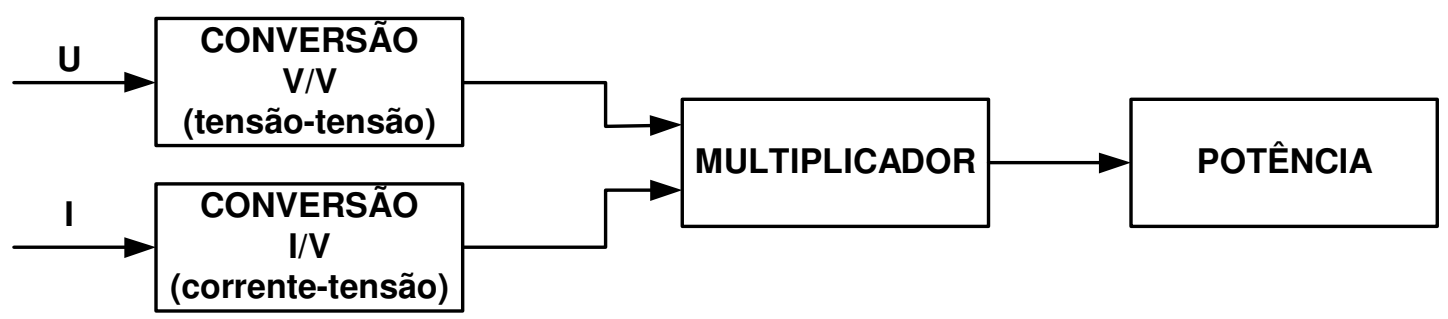

Figura 11 - Wattimetro eletrônico - Fonte: Driesen - 1998.

A energia é medida por meio de medidor de watt-hora, que é simplesmente um wattímetro com integração. Assim, circuitos que usam wattímetro para medição de potência podem também ser usados para medição de consumo de energia, substituindo o wattímetro com o medidor de watt-hora.

Este documento focará os medidores de tecnologia digital, que utiliza os princípios de amostragem de sinais de tensão e corrente. 


\subsubsection{Medidor baseado em microprocessador}

Uma das vantagens de um sistema baseado em amostragem digital é o fato de ele ser mais simples de calibrar, além disso, sua multiplicação digital é precisa e não causa problemas de linearidade, os quais poderiam ocorrer em medidores baseados na multiplicação analógica. Esse tipo de sistema também permite medições com novos conceitos de potência para condições não senoidais, incluindo separação adequada de grandezas fundamentais e não fundamentais, ou de componentes ativas e não ativas.

Há pouco tempo, a aplicação da técnica de amostragem digital ainda apresentava problemas de velocidade e de precisão necessária para a conversão analógico/digital $(A / D)$ e problemas de velocidade de cálculo. Entretanto, os avanços nas técnicas de amostragem e de conversão $A / D$ têm sido significativos e rápidos, aumentando a precisão e a taxa de amostragem desse processo.

Para obter todas as informações desejadas num ponto do sistema elétrico como o fluxo de potência, a distribuição das harmônicas num sistema, a possível variação da amplitude fundamental e a freqüência do sistema de suprimento ou deslocamento de fase -, é necessário apenas medir as tensões e correntes (nas três fases, se o sistema for trifásico).

A medição de todas as harmônicas até uma determinada ordem exige que os princípios de amostragem de sinais periódicos sejam seguidos. Contudo, quando se trata de medição de potência ou energia ativa total, existem outros princípios que podem possibilitar o processo a partir de condições menos exigentes.

Em medição digital, a forma de onda contínua é representada por uma sucessão de valores discretos. Para converter forma de onda contínua de tensão em uma sucessão de amostras de tensão, é usado um sistema de amostragem e um conversor A/D.

Usualmente, a potência é medida multiplicando amostras digitalizadas de corrente e tensão.

Uma das vantagens de um sistema baseado em amostragem digital é o fato de ele ser mais simples de calibrar, além disso, sua multiplicação digital é precisa e não causa problemas de linearidade, os quais poderiam ocorrer em medidores baseados na multiplicação analógica. 


\subsubsection{Método de integração discreta}

A integral para o cálculo da potência ativa pode ser aproximadamente obtida pela soma dos valores amostrados:

$$
P=\frac{1}{N} \sum_{0}^{N-1} u(n) \cdot i(n) \quad \text { Equação } 49
$$

Onde $u(n)$ e i(n) são amostras simultâneas de tensão e corrente igualmente espaçadas no tempo, e $\mathrm{N}$ é o número de amostras tomadas num período de tempo. As amostras não precisam ser tomadas sobre um período simples da forma de onda, mas podem ser estendidas sobre $\mathrm{m}$ períodos (sendo $\mathrm{m}$ um inteiro), possibilitando que o intervalo de amostragem seja aumentada.

As condições requeridas são:

A amostragem deve ocorrer sobre um número inteiro da forma de onda;

A forma de onda deve ser estacionária no período medido.

Completa-se a capacidade de medição de watt-hora usando um clock, que é iniciado quando a função watt-hora é selecionada. Cada vez que dados são processados, o clock é lido, e o intervalo de tempo, desde a última atualização da medição, é computado. Essa diferença é multiplicada pela última atualização de potência, e o resultado, somado à medição watt-hora, é acumulado. Esse procedimento admite que a potência se mantenha essencialmente constante entre as atualizações.

\subsubsection{Configuração comum}

A configuração básica de um wattímetro digital é mostrada na Figura 12, em que o instrumento é controlado por processador. A interface de condicionamento de sinal compreende um amplificador de ganho de tensão selecionável e conversor corrente-tensão (sensores).

A digitalização é realizada pelos conversores $A / D$, que são simultaneamente disparados a cada intervalo de amostragem e previamente determinados pelo processador.

Normalmente, a informação do instante de tempo a partir do período de amostragem é determinada pelo cruzamento do sinal de tensão no número zero. 
Recentemente, um dos avanços mais significativos em eletrônica se deu no processador digital de sinal (Digital Signal Processor - DSP). Esse dispositivo de chip simples é um microprocessador de alto desempenho, com hardware interno especialmente projetado para executar rapidamente multiplicações e operações de acumulação sucessivas. O DSP é adequado para implementar filtros digitais, FFT (Fast Fourier Transform), processamento de voz ou imagem ou algoritmos mais complexos de processamento de dados.

O uso de DSP possibilita grandes vantagens e benefícios para medições e sistemas de controle.

Medições de corrente podem ser realizadas medindo a queda de tensão sobre um shunt resistivo, ou por meio de transdutor de corrente, ou por sensor de efeito Hall.

Pode ser que os valores dos sinais precisem ser condicionados em um formato adequado para o conversor A/D.

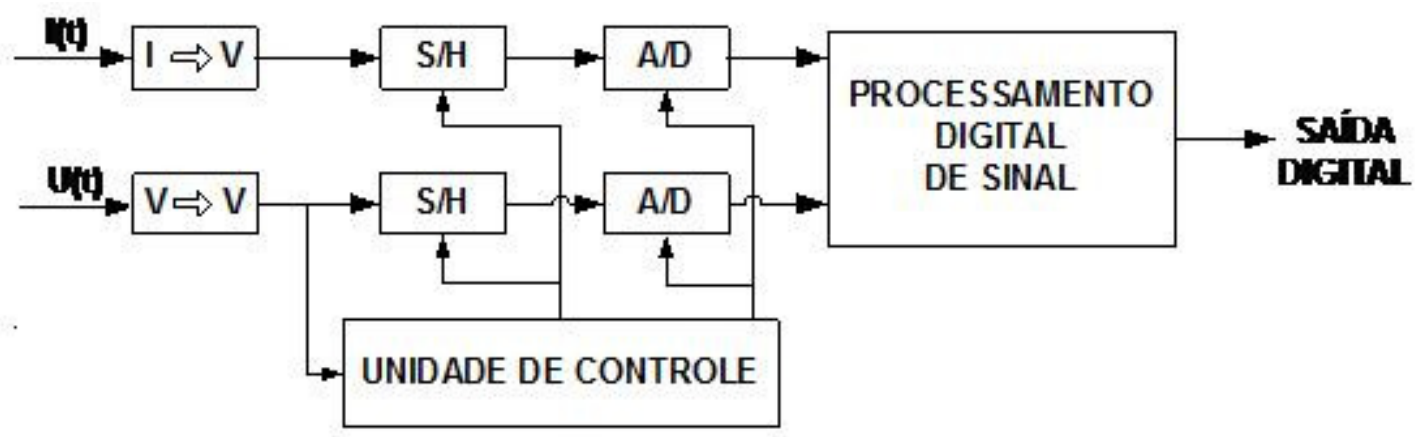

Figura 12 - Esquema básico de medição digital - Fonte: Driesen - 1998

Nota: $\mathrm{I} \Rightarrow \mathrm{V}$ e $\mathrm{V} \Rightarrow \mathrm{V}$ : condicionamento de sinais;

$\mathrm{S} / \mathrm{H}$ : sample and hold;

A/D: conversor analógico/digital 


\subsubsection{Aplicação da transformada de Fourier}

No caso de sinais periódicos, a expansão de série de Fourier pode ser usada para realizar análise espectral de formas de onda de tensão e corrente. No processamento de sinal digital, a Transformada Discreta de Fourier (Discrete Fourier Transform - DFT) é usualmente aplicada às amostras dos sinais medidos, sendo útil quando se quer separar componentes fundamentais e harmônicos dos sinais de tensão ou corrente.

Como um computador digital pode somente armazenar e manipular um conjunto finito de números, é necessário representar um sinal analógico por um conjunto finito de valores. Sem perda de generalidade, podemos admitir que essas amostras são definidas com a aplicação da Transformada Discreta de Fourier à seqüência usando a Equação 51:

$$
U(\Omega)=\sum_{n=1}^{N-1} u(n) e^{-j \Omega n} \quad \text { Equação } 50
$$

Esta ainda não é uma forma conveniente para computação, pois $\Omega$ é uma variável contínua com valores no intervalo $[0,2 \pi]$. O passo final, portanto, é avaliar $\mathrm{U}(\Omega)$ apenas em um número finito de valores, $\Omega_{\mathrm{k}}$, processando as amostras uniformemente na faixa $[0,2 \pi]$, da seguinte forma:

$$
U\left(\Omega_{k}\right)=\sum_{n=1}^{N-1} u(n) e^{-j \Omega_{k} n}, k=0,1, \ldots, M-1 \quad \text { Equação } 51
$$

Onde:

$$
\Omega_{\mathrm{k}}=\frac{2 \pi}{\mathrm{M}} \mathrm{k} \quad \text { Equação } 52
$$

O número de amostras de freqüência, m, pode ser qualquer valor. Entretanto, escolhemos de maneira que fosse o mesmo que o número de amostras no tempo (N). Com essa modificação e escrevendo $\mathrm{U}\left(\Omega_{\mathrm{k}}\right)$ como $\mathrm{U}(\mathrm{k})$, tem-se: 


$$
U(k)=\sum_{n=1}^{N-1} u(n) e^{-j \frac{2 \pi}{N} n k} \quad \text { Equação } 53
$$

Uma das razões do amplo uso de DFT e outras transformadas discretas é a existência de algoritmos para computação rápida e eficiente no computador. Para a DFT, esses algoritmos são chamados de Transformada Rápida de Fourier (Fast Fourier Transform - FFT). A idéia básica é dividir uma dada seqüência em subseqüências de comprimento menor. Combinam-se, então, esses DFTs menores adequadamente, para obter a DFT da seqüência original.

Se a freqüência de amostragem for $\mathrm{f}_{\mathrm{a}}$, o espectro medido é mostrado para freqüências de $0 \mathrm{a} \mathrm{f}_{\mathrm{a}} / 2$.

O processamento digital permite que o instrumento faça medições de uma variedade de parâmetros para avaliação do impacto de harmônicas em sistemas de potência como:

Tensões harmônicas Uh e Ih

Tensões e correntes eficazes (rms):

Potência ativa

Potência aparente

Fator de potência

Distorção harmônica total,Etc.

\subsubsection{Incertezas e erros de medidores digitais}

As questões aqui apresentadas se restringem aos possíveis erros do medidor, não sendo objetivo tratar dos erros de transformação de tensão ou corrente existente entre a rede elétrica e o medidor.

Seguem algumas fontes de possíveis erros na medição digital.

\subsubsection{Erro no método de transformada de Fourier}

$\mathrm{Na}$ aplicação de decomposição de Fourier, para que seja possível reconstruir um sinal periódico a partir de amostras de uma janela de amostragem, devem ser 
satisfeitas as seguintes condições (Teorema de Nyquist ${ }^{10}$ ): a duração da janela deve ser exatamente igual a um número inteiro do período do sinal, a freqüência de amostragem $\mathrm{f}_{\mathrm{a}}$ deve ser maior do que 2 vezes a máxima freqüência contida no sinal. Isto significa que, se as condições acima forem satisfeitas, não haverá nenhum erro na aplicação da DFT.

Quando a janela não for exatamente um múltiplo inteiro do período do sinal, ocorrem o erro de vazamento (leakage) e o erro de efeito cerca (picket fence effect) [67]. É possível que o medidor apresente - nos intervalos de tempo de amostragem fixos, independente da freqüência fundamental do sistema de potência - uma eventual diferença entre o período considerado pelo medidor e o período da forma de onda do sinal de tensão do sistema elétrico. Caso aconteça essa diferença, o processo pode conter erros.

Quando o sinal revela uma freqüência acima da máxima admissível pelas condições de Nyquist, ocorre o recobrimento (ou rebatimento) do espectro. Um componente de freqüência $f$ maior do que $f_{a} / 2$ será interpretado como tendo a freqüência $f_{a}-f$, causando erro de medição de harmônica.

\subsubsection{Erro no método de integração discreta}

Clark e Stockton [66] mostraram que, se a tensão e a corrente não contiverem harmônicas superiores a um número inteiro $\mathrm{n}$, é suficiente uma taxa de amostragem de cerca de 3 amostras por período. Esse raciocínio vale se o número de amostras em cada seqüência $\mathrm{N}$ for superior a $2 \mathrm{n}$ [42]. $\mathrm{O}$ importante é tomar essas amostras (igualmente espaçadas) durante exatamente $\mathrm{M}$ períodos e certificar-se de que $\mathrm{M}$ e $\mathrm{N}$ não possuem fatores comuns. Mostrou-se que isso é equivalente a tomar $\mathrm{N}$ amostras em um período se o sinal for estável. Aqui também vale a observação relativa à possibilidade de erros nas medições, caso o medidor tenha intervalos de tempo de amostragem fixos e se o período da forma de onda do sinal de tensão do sistema elétrico não for igual ao período considerado pelo medidor.

${ }^{10}$ Segundo o Teorema de Nyquist, a freqüência de amostragem de um sinal analógico, para que possa posteriormente ser reconstituído com o mínimo de perda de informação, deve ser igual ou maior a duas vezes a maior freqüência do espectro desse sinal. 
Caso o medidor tenha os intervalos de tempo de amostragem fixos, independentemente da freqüência fundamental do sistema de potência, eventuais mudanças na freqüência do sistema podem gerar erros nas medições.

\subsubsection{Erro de quantização}

Na conversão $A / D$, o número finito de passos de amplitude causa um erro de quantização que depende do tamanho do passo de quantização $\Delta$. Para um conversor $A / D$ de $n$-bit com faixa dinâmica $D$, o máximo erro poderia ser calculado como a amplitude de um passo:

$$
\text { emax }=\Delta=D / 2^{n} \quad \text { Equação (54) }
$$

Esse erro introduz um ruído na medição. O conversor $A / D$ é de 12 bits. e esse ruído é de cerca de $0,02 \%$. Trata-se de um nível pequeno, comparado às classes de exatidão dos medidores para faturamento utilizadas normalmente.

\subsubsection{Erro de flutuação do instante de amostragem ("time-jitter")}

Se houver erro de tempo $\Delta$ t no instante em que o sinal de corrente ou tensão é amostrado, surgirá um erro na amplitude da amostra. Para um sinal com forma de onda próxima a uma senóide, que estiver usando toda a faixa dinâmica do conversor A/D, o erro resultante da amostra será:

$$
e \approx \Delta t \frac{d u}{d t}=D \varpi \Delta t \cos (\varpi t) \leq D \varpi \Delta t \quad \text { Equação } 55
$$

O time-jitter causa um ruído na amplitude que depende da derivada do sinal medido.

\subsection{Normas de medidores de energia}

As normas estabelecidas para os medidores envolvem a metrologia. Esta, por sua vez, trata de medir e produzir grandezas corretamente que respondam a padrões secundários, os quais podem ser comparados a padrões primários.

Um instrumento de medição por características metrológicas possibilita julgar a conveniência do instrumento para realizar medições em uma faixa conhecida, com exatidão conhecida, para obter um valor mensurando e estimar sua incerteza [16]. 
Determinados por procedimento regulatório, os medidores de energia só podem ser comercializados e aplicados em instalações que tenham por objetivo medir o faturamento da energia consumida, quando suas propriedades metrológicas são bem conhecidas, as quais podem, em princípio, ser estabelecidas por duas metodologias [16].

$\mathrm{Na}$ primeira, determinam-se as características reais de certo instrumento por calibração. Na outra, as características metrológicas nominais e os desvios permissíveis das características reais em relação às características nominais. Estes desvios se apresentam como classe de exatidão. Trata-se da classe de instrumentos de medição que satisfazem a certas exigências metrológicas, destinadas a conservar os erros (desvios) dentro de limites especificados [15].

Conforme NBR 8377 [8] e NBR 14519 [12], a classe de exatidão é o número que define os limites de desvio admissível, ou seja, o erro relativo percentual para todos os valores de corrente entre 0,1 In (10\% da corrente nominal) e Imáx (corrente máxima), para o fator de potência unitário e cargas equilibradas, quando o medidor é ensaiado sob condições de um padrão de referência. Contudo, para que sejam inseridos no parque de medição das concessionárias, os instrumentos de medição devem ser submetidos a verificação amostral, após o processo de calibração do fabricante ou reparador. Clientes sorteados em campanhas de medição estabelecidas pela ANEEL também devem executar esse processo periodicamente. Se suas propriedades reais desviarem dos padrões estabelecidos, [16] o instrumento deve ser ajustado, reformado ou descartado, dependendo de cada caso.

Assim, a escolha das características nominais de instrumentos de medição e a especificação de desvios permissíveis de suas características reais são relevantes para a prática de medição.

Apesar de os projetos serem bem definidos em suas concepções, as características reais de instrumentos de medição dependem, de alguma forma, das condições ou fatores externos, como temperatura, tipo de carga não linear instalada, ruído eletromagnético etc. Estas condições são conhecidas como "condições de referência". Os desvios de medição apurados sob tais condições decorrem de fatores intrínsecos ao instrumento [16]. 
Desse modo, pequenas faixas de valores de todas as grandezas de influência são definidas, sob as quais o instrumento de medição de energia deve ser verificado e/ou calibrado.

Além das condições de referência, as condições normais de operação também são estabelecidas. Sob tal situação, as características dos instrumentos permanecem dentro de certos limites, apesar de o erro (desvio) poder ser superior ao erro (desvio) intrínseco, e o instrumento pode ser empregado como pretendido [16].

Estas condições são de extrema importância em qualquer tipo de medição e/ou procedimento de ensaio e constam nas normas brasileiras de medidores de energia elétrica, pertinentes ao assunto em questão [9,10,11,12,13 e 14].

A Tabela 11 contém um resumo das condições de referência, relativas aos medidores utilizados neste trabalho, que serão consideradas para os ensaios de laboratório, detalhados no Capítulo 3. 


\begin{tabular}{|c|c|c|c|}
\hline \multirow{2}{*}{$\begin{array}{l}\text { Grandeza de } \\
\text { influência }\end{array}$} & \multirow{2}{*}{$\begin{array}{l}\text { Condição de } \\
\text { referência }\end{array}$} & \multicolumn{2}{|l|}{ Variação permitida } \\
\hline & & Eletrônicos & Eletromecânicos \\
\hline $\begin{array}{l}\text { Temperatura } \\
\text { ambiente }\end{array}$ & $\begin{array}{l}\text { Temperatura de } \\
\text { referência ou, na } \\
\text { falta desta, } 23^{\circ} \mathrm{C} \text { para } \\
\text { eletrônicos e } \\
\text { entre } 20^{\circ} \mathrm{C} \text { e } 30^{\circ} \mathrm{C} \\
\text { para eletromecânicos }\end{array}$ & $\pm 2^{\circ} \mathrm{C}$ & $\pm 2^{\circ} \mathrm{C}$ \\
\hline Tensão & Tensão nominal & $\pm 2 \%$ & $\pm 2 \%$ \\
\hline Frequência & Frequência nominal & $\pm 0,5 \%$ & $\pm 0,5 \%$ \\
\hline Forma de onda & $\begin{array}{l}\text { Correntes e tensões } \\
\text { senoidais }\end{array}$ & $\begin{array}{l}\text { Fator de distorção n } \\
\qquad 1,0 \%\end{array}$ & $\begin{array}{l}\text { nor do que: } \\
5,0 \%\end{array}$ \\
\hline $\begin{array}{l}\text { Indução magnética } \\
\text { de } \\
\text { origem externa na } \\
\text { freqüência nominal }\end{array}$ & $\begin{array}{l}\text { Indução magnética } \\
\text { igual a zero }\end{array}$ & $\begin{array}{c}\text { Valor de indução qu } \\
\text { desvio não maior dc } \\
\pm 0,1 \% \\
\text { Deve ser } \\
\text { em qualquer } \\
\text { caso menor que } \\
0,05 \mathrm{mT}\end{array}$ & $\begin{array}{l}\text { causa variação de } \\
\text { ue: } \\
\text { - }\end{array}$ \\
\hline Posição & Vertical & - & $\pm 0,5^{\circ}$ \\
\hline
\end{tabular}

Tabela 11 - Condições de referência para medidores de energia elétrica - Fonte: ASSOCIAÇÃO BRASILEIRA DE NORMAS TÉCNICAS; NBR 14519 - 2000

A Associação Brasileira de Normas Técnicas (ABNT), por meio das normas brasileiras (NBR) já consolidadas, prescreve vários ensaios a serem realizados para aprovação de modelo [8 e 12] e/ou para aceitação, pelos compradores, de lotes de medidores novos [9 e 13]. 
A aprovação de novos modelos de medidores deve ser feita pelo Instituto Nacional de Metrologia e Qualidade Industrial (Inmetro), como consta da NBR 8378 [9] e da NBR 14520 [13]. Tais ensaios, apresentados de maneira detalhada nas referidas normas, são prescritos para serem realizados em laboratório.

Para a realização deste trabalho, as normas $[9,10,11,12,13$ e 14]. serão aplicadas ao que tange o desvio da potência medida em energia ativa. $O$ desvio relativo percentual (ou tendência ao desvio), que é uma expressão quantitativa do erro de medição, deve sempre ser entendido como o desvio de medição que o medidor sob teste apresenta em relação ao valor indicado pelo padrão de referência e referenciado a este.

Além das parametrizações estabelecidas em norma, esta pesquisa busca encontrar a possibilidade de desvios de grandezas medidas quando tais desvios são submetidos às condições mais severas. Essas condições, normalmente, são encontradas no parque de distribuição das concessionárias e serão mais detalhadas no Capítulo 3. 


\section{CAPÍTULO 3 - COMPORTAMENTO DOS MEDIDORES ELETRÔNICOS SUBMETIDOS A ONDAS DE TENSÃO E CORRENTE NÃO SENOIDAIS.}

Este estudo buscou comparar os resultados de medições obtidas com medidores eletrônicos de energia de dois fabricantes (A) e (B), com um padrão de referência, a fim de comprovar a existência ou não de erros decorrentes da influência de harmônicas em medidores de energia.
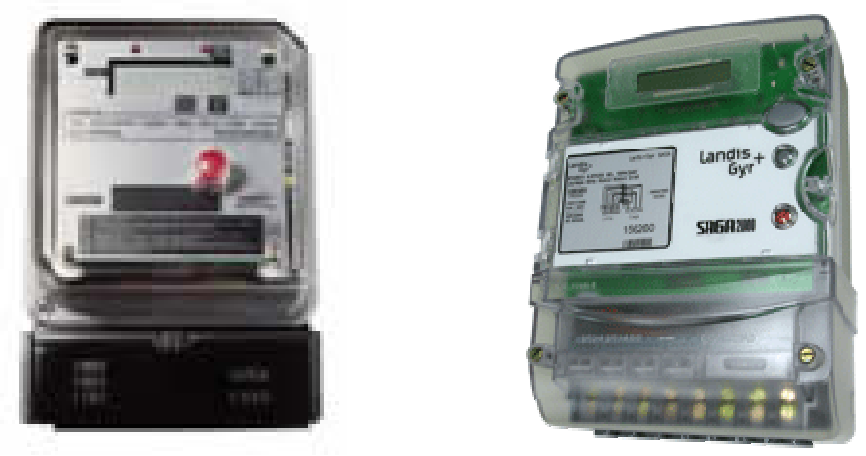

Foto 1 - Medidores Eletrônicos de Energia Fonte: AES - Eletropaulo - 2009

\subsection{Metodologia}

Por questão de limitação das fontes geradoras de padrões de sinais utilizados, nos ensaios, somente foi possível comparar os ensaios dos medidores com a distorção harmônica de tensão e corrente até a $10^{\text {a }}$ harmônica, ou seja, $600 \mathrm{~Hz}$. Optando-se por repetir o mesmo ensaio em 3 laboratórios de medição distintos, com padrões rastreados pela RBC - Rede Brasileira de Calibração.

Nos ensaios realizados na Eletropaulo empregou-se distorção até a $10^{\text {a }}$ harmônica, ou seja, $600 \mathrm{~Hz}$, gerados por uma carga artificial da mesa ZERA. Para tanto, comparou-se o padrão Callport 400 ao padrão Yokogawa, modelo WT2030, que foi a referência para os demais laboratórios (Foto 2). 


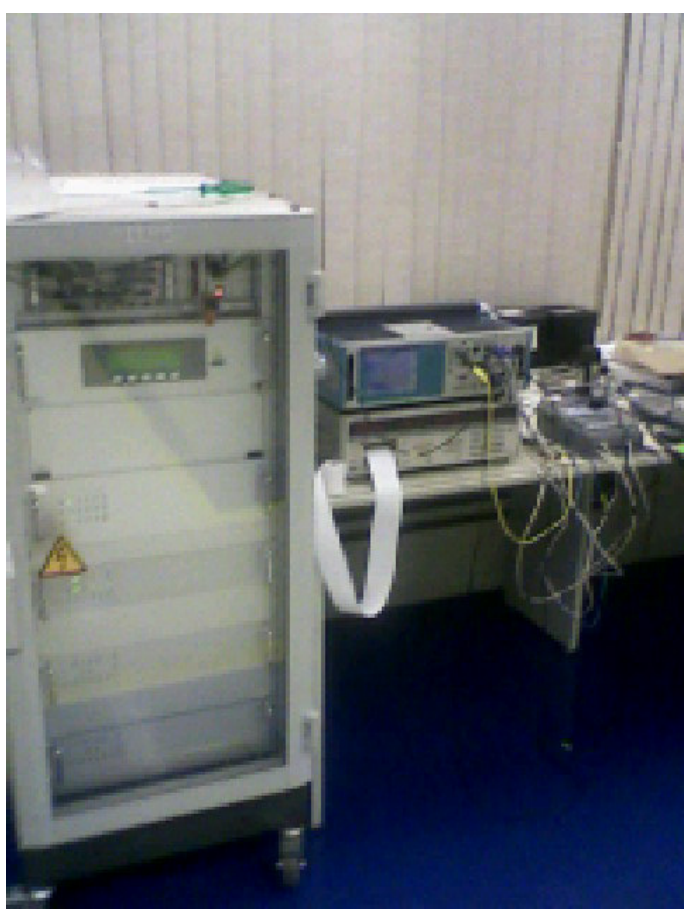

Foto 2 - Sistema de calibração Zera e padrões e Callport 400 WT2030 - Fonte: AES Eletropaulo-2009.

Nos ensaios realizados no Enerq - USP, 2 (dois) instrumentos de medição ficaram sob testes simultaneamente, ligados com em paralelo Foto 3, com o padrão Yokogawa modelo WT2030. Todos os ensaios foram realizados empregando-se um medidor eletrônico do Fabricante $A$ (M1) operando em paralelo com um medidor eletrônico do Fabricante B (M2), sendo que para estes ensaios foi possível gerar distorção harmônica de tensão e corrente até a 25ํㅗำ ordem. 


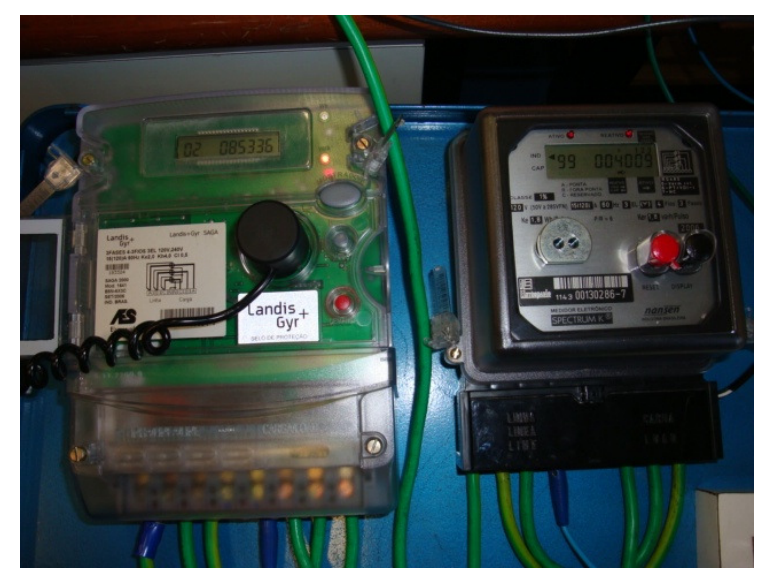

Foto 3 - Medidores eletrônicos (A) e (B) - Fonte: AES - Eletropaulo - 2009.

Uma montagem foi elaborada a partir da fonte de energia Pacific, modelo 390 AMX, conforme mostra a Foto 4, incluindo um transformador padrão para elevação dos níveis de corrente de ensaio e que serviu como referência de fonte dos sinais de corrente e de tensão para os medidores de energia.
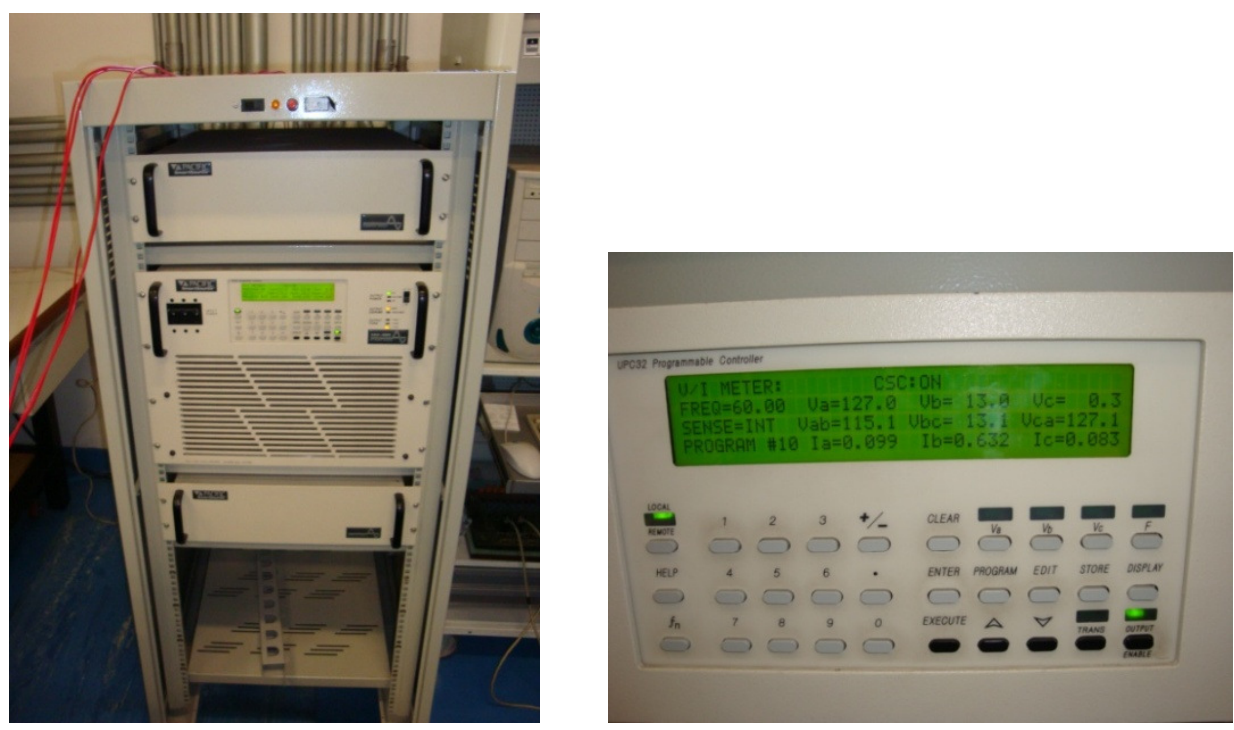

Foto 4 - Fonte de energia Pacific 390 AMX - Fonte: ENERQ - 2009

Foram utilizados sensores adequados para captação dos pulsos emitidos pelos medidores eletrônicos, por meio de porta ótica no modo "calibração", bem como uma placa de memória com saída serial, para o armazenamento temporário do conteúdo da memória de massa dos medidores através de leituras realizadas em intervalos de 5 minutos e cujos dados foram lidos em um programa padrão ABNT. Paralelamente 
foi instalado um osciloscópio Tektronix TDS 1002 de 60Mhz, ver Foto 5, para a confirmação da forma de onda programada.

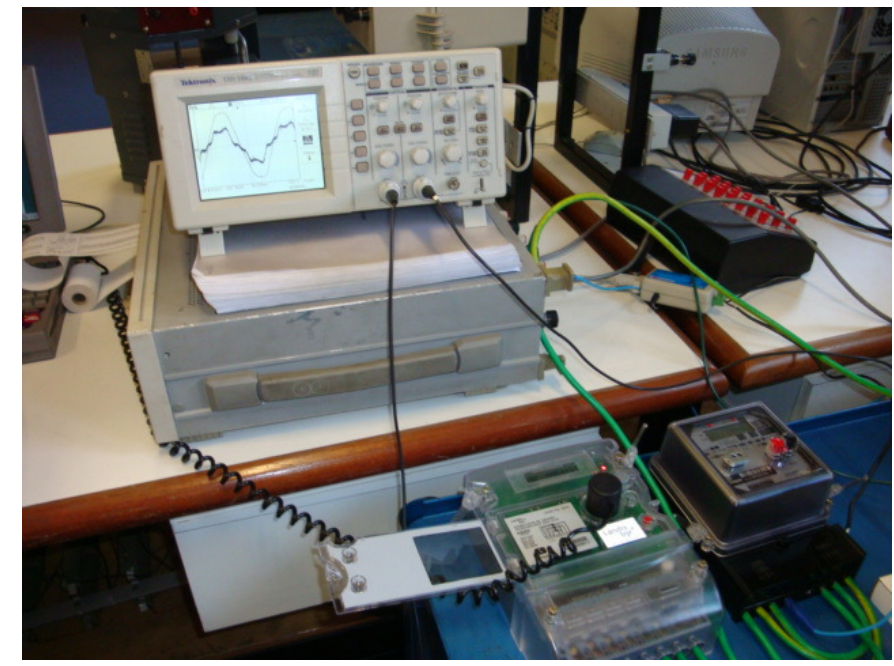

Foto 5 - Osciloscópio Tektronix TDS 1002 - Fonte: ENERQ - 2009

As formas de ondas programadas foram obtidas de resultados de medições realizadas em cargas reais de clientes da Eletropaulo, decorrentes de projetos de P\&D (Pesquisa e Desenvolvimento). Esses projetos foram realizados anteriormente pela Aneel, em parceria com concessionárias de energia, além de formas de onda calculadas.

Havia necessidade de uma fonte bifásica para a realização dos ensaios na condição de distorção harmônica de tensão e corrente acima da 10ª harmônica, ou seja, freqüência superior a $600 \mathrm{~Hz}$. Assim, conectaram-se os circuitos de potencial em paralelo e os circuitos de corrente em série de todos os medidores. As fases da fonte exerceram a função de gerador de tensão e corrente: uma das fases foi o gerador de tensão distorcida; a outra fase foi o gerador de corrente distorcida, como informa o circuito da Figura 13. 


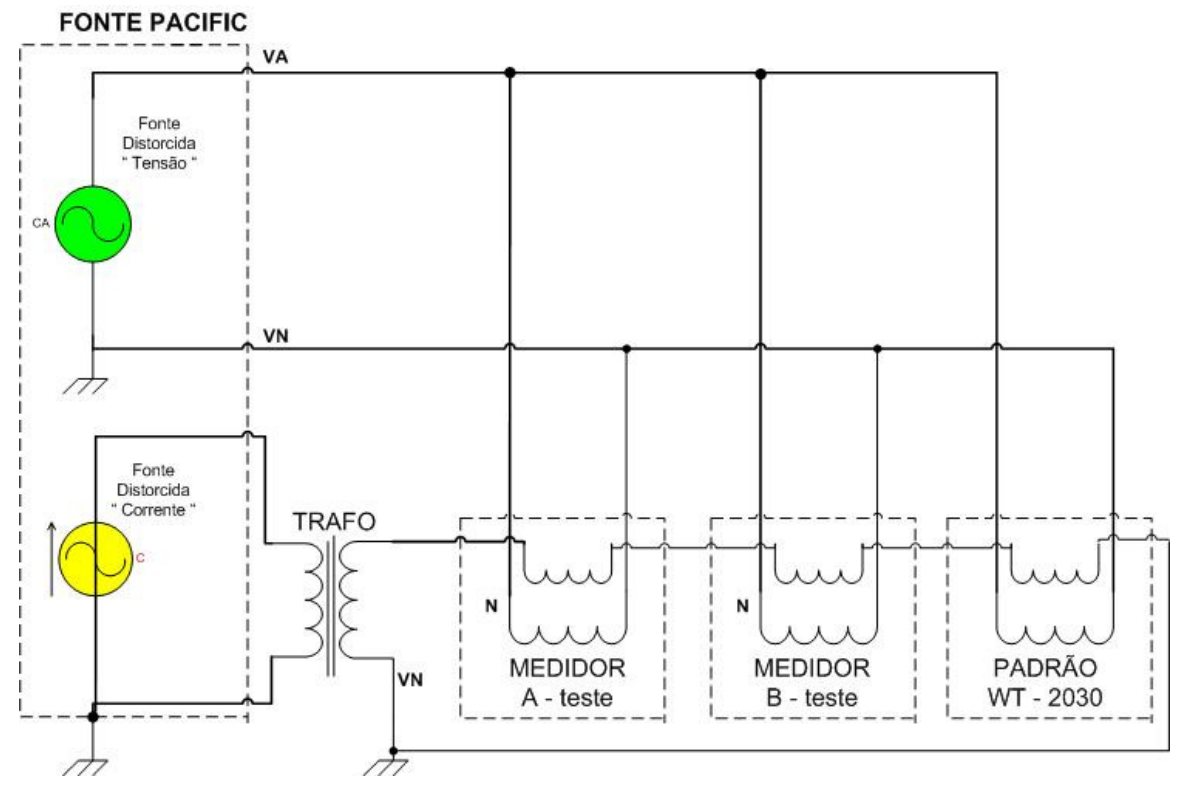

Figura 13 - Circuito para testes laboratoriais dos medidores - Fonte: Elaborado pelo autor (2009).

Este procedimento foi analisado, concluindo-se que os resultados não seriam afetados, uma vez que os elementos de medição são construídos de maneira independente, Foto 6 . Seguindo a recomendação de norma e procedimentos adotados pelos laboratórios, foi estabelecido que o calibrador permaneceria ligado por 30 (trinta) minutos anteriormente ao início dos ensaios, para proporcionar a estabilização térmica do sistema.

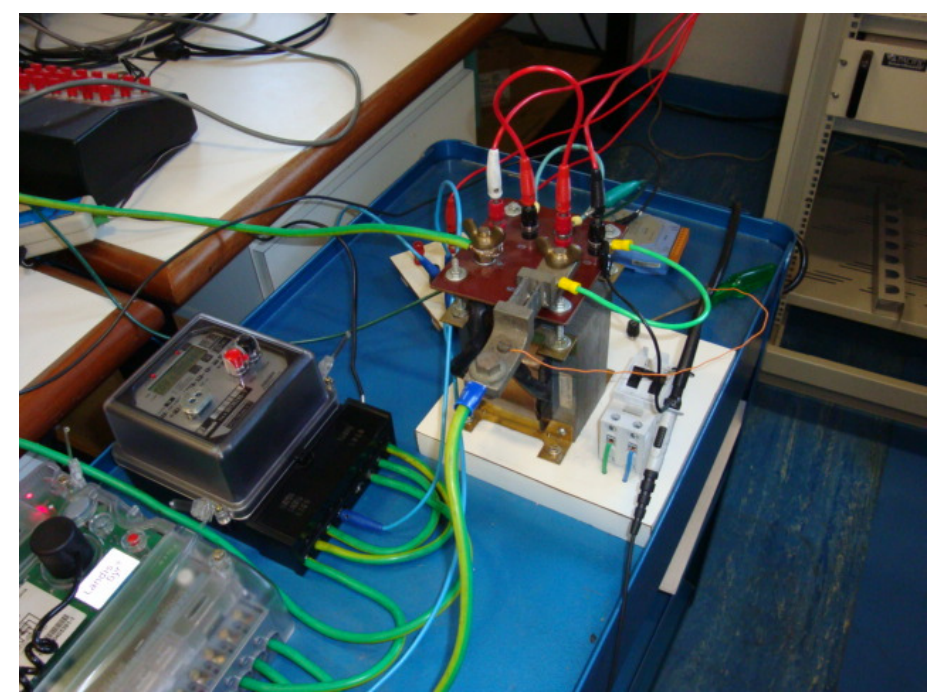

Foto 6- Circuito de ensaios - Fonte: ENERQ - 2009 
De forma similar a medidores eletromecânicos de energia sob teste em literatura, foi adotado um tempo de estabilização térmica de 5 (cinco) minutos, ao iniciar cada ensaio, em condição diferente da anterior. Após esse período, o primeiro pulso recebido em cada entrada do calibrador sinaliza o início do ensaio propriamente dito para o respectivo medidor.

Desse modo, os referidos medidores medem e sinalizam para o calibrador em Wh ou VArh, em cada condição de teste, dependendo do canal da grandeza calibrada. Conseqüentemente, para medir a mesma energia que os anteriores, foi definido um número mínimo de pulsos dos medidores eletrônicos.

Todos os medidores foram submetidos a ensaios sob condições de distorções harmônicas de tensão e corrente, com base em medições reais conforme exposto nos itens a seguir:

3.2 Comparativo e característica dos medidores submetidos a sinais de ondas de tensão e corrente não senoidais.

Os ensaios realizados buscaram obter grandezas idênticas medidas em todos os medidores. Para tanto, tiveram como referência o padrão de medição, fazendo com que os resultados diferentes desse modelo fossem considerados desvio. Este, portanto, foi entendido como o erro da exatidão dos medidores.

3.2.1 Valores das componentes harmônicas aplicados nos ensaios realizados.

Como observado no item 3.1, os equipamentos foram ligados em paralelo com o padrão, alimentados pela fonte geradora de harmônicas. Eles seguiram os programas de parâmetros levantados pelas medições encontradas em cargas reais, demonstradas nas (Tabelas 12; 14; 16; 18; 21; 23; 25; 27; 29; 31).

Estas medições possuem características de espectros harmônicos superiores aos estabelecidos por norma.

As (Tabelas 13; 15; 17; 19; 22; 24; 26; 28; 30; 32) apresentam os valores de corrente e tensão rms, inseridos nos medidores durante os ensaios efetuados.

3.2.1.1 Dados de medições feitas em um prédio comercial, no secundário do transformador MT/BT.

A seguir são apresentados os resultados das medições realizadas em um prédio comercial. As medições foram realizadas no secundário do transformador 
abaixador de MT/BT. Estas medições estão agrupadas por medidor, isto é, medição $A$, medição $B$ e medição $C$. Os elementos para estes ensaios são apresentados nas tabelas 12,14 e 16.

\section{Medição "A"}

A Tabela 12 apresenta os resultados das medições do grupo $A$, realizadas no prédio comercial. As medições foram realizadas no secundário do transformador alimentador (MT/BT).

\begin{tabular}{|c|c|c|c|c|c|c|}
\hline \multirow{2}{*}{\multicolumn{2}{|c|}{$\frac{\mathrm{V}}{\text { DHT - TOTAL } \%}$}} & \multirow[b]{3}{*}{$\begin{array}{l}\text { Ângulo } \\
\text { (graus) } \\
\end{array}$} & \multirow{2}{*}{\multicolumn{2}{|c|}{$\frac{\text { I }}{\text { DHT - TOTAL \% }}$}} & \multirow[b]{3}{*}{$\begin{array}{l}\text { Ângulo } \\
\text { (graus) }\end{array}$} & \multirow[b]{3}{*}{ 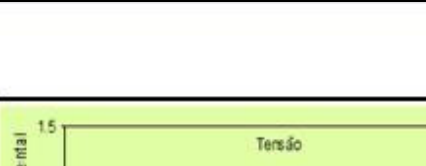 } \\
\hline & & & & & & \\
\hline $\begin{array}{c}\text { Ordem } \\
\text { Harmônica }\end{array}$ & 4.13 & & \begin{tabular}{|c|} 
Ordem \\
Harmônica
\end{tabular} & 21.96 & & \\
\hline 0 & 0.25 & 0 & 0 & 0.08 & 0 & \multirow{7}{*}{ 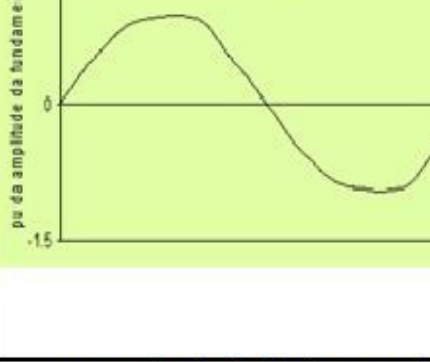 } \\
\hline 1 & 100 & 0.47 & 1 & 100 & 7.01 & \\
\hline 2 & 0.1 & 183.97 & 2 & 0.25 & 182.75 & \\
\hline 3 & 2.72 & 57.1 & 3 & 14.21 & 165.61 & \\
\hline 4 & 0.13 & 75.94 & 4 & 0.33 & 43.24 & \\
\hline 5 & 2.47 & 202.18 & 5 & 12.68 & 233.44 & \\
\hline 6 & 0.06 & 184.06 & 6 & 0.09 & 318.8 & \\
\hline 7 & 1.53 & 329.61 & 7 & 7.79 & 20.8 & pu amplitude da fundamental \\
\hline 8 & 0.09 & 191.75 & 8 & 0.16 & 235.8 & \multirow{9}{*}{ 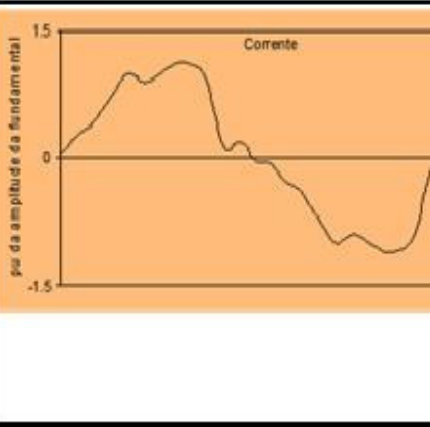 } \\
\hline 9 & 0.42 & 2.06 & 9 & 3.43 & 54.75 & \\
\hline 10 & 0.01 & 147.58 & 10 & 0.09 & 89.77 & \\
\hline 11 & 0.78 & 156.22 & 11 & 5.16 & 176.53 & \\
\hline 12 & 0.05 & 292.81 & 12 & 0.08 & 38.61 & \\
\hline 13 & 0.48 & 210.59 & 13 & 3.16 & 245.53 & \\
\hline 14 & 0.04 & 298.82 & 14 & 0.02 & 127.17 & \\
\hline 15 & 0.04 & 239.97 & 15 & 2.82 & 294.46 & \\
\hline 16 & 0.05 & 321.37 & 16 & 0.06 & 324.27 & \\
\hline
\end{tabular}

Tabela 12 - Elementos para o ensaio laboratorial 1, Programa 10, Medição A.

\begin{tabular}{|c|c|c|c|}
\hline Ensaios & I $A_{\text {ef }}$ & $\mathrm{V} 1-\mathrm{V}_{\text {ef }}$ & $\mathrm{I}-\mathrm{A}_{\mathrm{ef}}$ \\
\hline $\mathrm{A}$ & 15 & 127 & 14,65 \\
\hline $\mathrm{B}$ & 25 & 127 & 24,42 \\
\hline $\mathrm{C}$ & 1,5 & 127 & 1,465 \\
\hline
\end{tabular}

Tabela 13 - Elementos para o ensaio 1, Programa 10, Pacific 390 AMX, Seqüências A, B e C. 


\section{Medição "B"}

A Tabela 14 apresenta os resultados das medições do grupo B realizadas no prédio comercial. As medições foram realizadas no secundário do transformador alimentador (MT/BT).

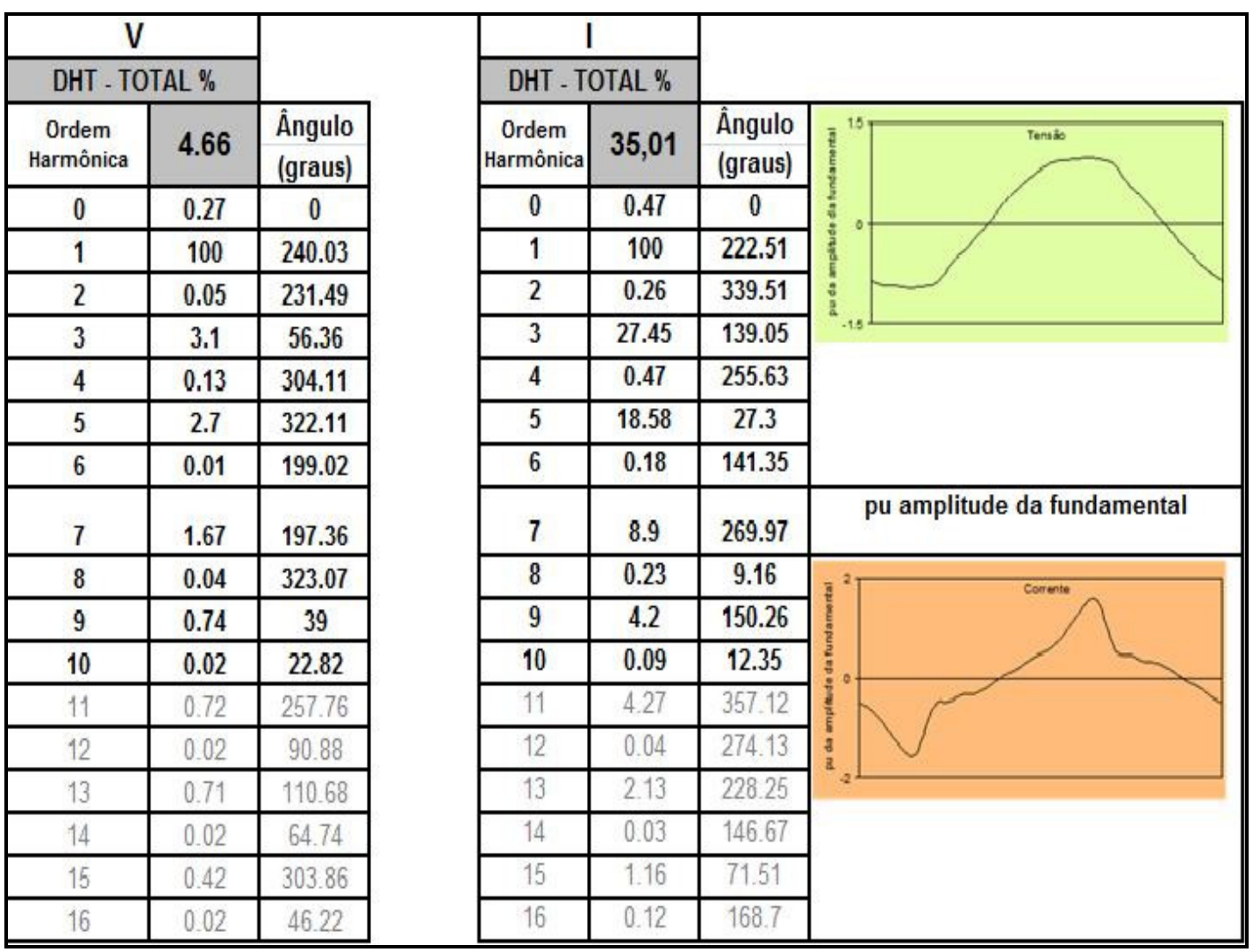

Tabela 14 - Elementos para o ensaio laboratorial 2, Programa 11, Medição B

\begin{tabular}{|c|c|c|c|}
\hline Ensaios & $\mathrm{I} \mathrm{A}_{\mathrm{ef}}$ & $\mathrm{V} 1-\mathrm{V}_{\mathrm{ef}}$ & $\mathrm{I} 1-\mathrm{A}_{\mathrm{ef}}$ \\
\hline $\mathrm{A}$ & 15 & 127 & 14,16 \\
\hline $\mathrm{B}$ & 25 & 127 & 23,59 \\
\hline $\mathrm{C}$ & 1,5 & 127 & 1,416 \\
\hline
\end{tabular}

Tabela 15 - Elementos para o ensaio 2, Programa 11, Pacific 390 AMX, Seqüências A, B e C. 


\section{Medição "C"}

A Tabela 16 apresenta os resultados das medições do grupo $C$, realizadas no prédio comercial. As medições foram realizadas no secundário do transformador alimentador (MT/BT).

\begin{tabular}{|c|c|c|c|c|c|c|}
\hline \multicolumn{2}{|c|}{ V } & & \multicolumn{2}{|c|}{ I } & & \\
\hline \multicolumn{2}{|c|}{ DHT - TOTAL \% } & & \multicolumn{2}{|c|}{ DHT - TOTAL \% } & & \\
\hline $\begin{array}{l}\text { Ordem } \\
\text { Harmônica }\end{array}$ & 4.51 & $\begin{array}{l}\text { Ângulo } \\
\text { (graus) }\end{array}$ & $\begin{array}{c}\text { Ordem } \\
\text { Harmônica }\end{array}$ & 18,32 & $\begin{array}{l}\text { Ângulo } \\
\text { (graus) }\end{array}$ & $\overline{8}^{-15}$ \\
\hline 0 & 0.31 & 0 & 0 & 1.06 & 0 & $\frac{2}{3}$ \\
\hline 1 & 100 & 120.01 & 1 & 100 & 122.56 & \\
\hline 2 & 0.05 & 339.11 & 2 & 0.21 & 98.53 & 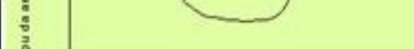 \\
\hline 3 & 3.11 & 56.41 & 3 & 9.77 & 184.76 & \\
\hline 4 & 0.15 & 199.62 & 4 & 0.23 & 263.62 & \\
\hline 5 & 2.58 & 78.45 & 5 & 9.06 & 173.73 & \\
\hline 6 & 0.01 & 188.25 & 6 & 0.26 & 112.11 & \\
\hline 7 & 1.54 & 86.56 & 7 & 9.89 & 208.92 & pu amplitude da fundamental \\
\hline 8 & 0.05 & 57 & 8 & 0.16 & 286.57 & $=18$. \\
\hline 9 & 0.63 & 14.61 & 9 & 5.68 & 294.15 & \\
\hline 10 & 0.06 & 232.08 & 10 & 0.16 & 286.57 & $\frac{2}{g}$ \\
\hline 11 & 0.93 & 9.72 & 11 & 3.44 & 53.21 & \\
\hline 12 & 0.07 & 181.58 & 12 & 0.12 & 278.69 & 8 \\
\hline 13 & 0.33 & 316.2 & 13 & 2.32 & 126.05 & \\
\hline 14 & 0.05 & 307.2 & 14 & 0.22 & 301.26 & \\
\hline 15 & 0.3 & 271.34 & 15 & 1.88 & 161.66 & \\
\hline 16 & 0.02 & 325.69 & 16 & 0.19 & 45.4 & \\
\hline
\end{tabular}

Tabela 16 - Elementos para o ensaio laboratorial 3, Programa 12, Medição C

\begin{tabular}{|c|c|c|c|}
\hline Ensaios & $\mathrm{I} \mathrm{A}_{\mathrm{ef}}$ & $\mathrm{V} 1-\mathrm{V}_{\mathrm{ef}}$ & $\mathrm{I}-\mathrm{A}_{\mathrm{ef}}$ \\
\hline $\mathrm{A}$ & 15 & 127 & 14,75 \\
\hline $\mathrm{B}$ & 25 & 127 & 24,59 \\
\hline $\mathrm{C}$ & 1,5 & 127 & 1,475 \\
\hline
\end{tabular}

Tabela 17 - Elementos para o ensaio 3, Programa 12, Pacific 390 AMX, Seqüências A, B e C. 
3.2.1.2. Dados de medições feitas em uma instalação residencial

A seguir são apresentados na Tabela 18 os resultados obtidos na medição de consumo em uma instalação residencial.

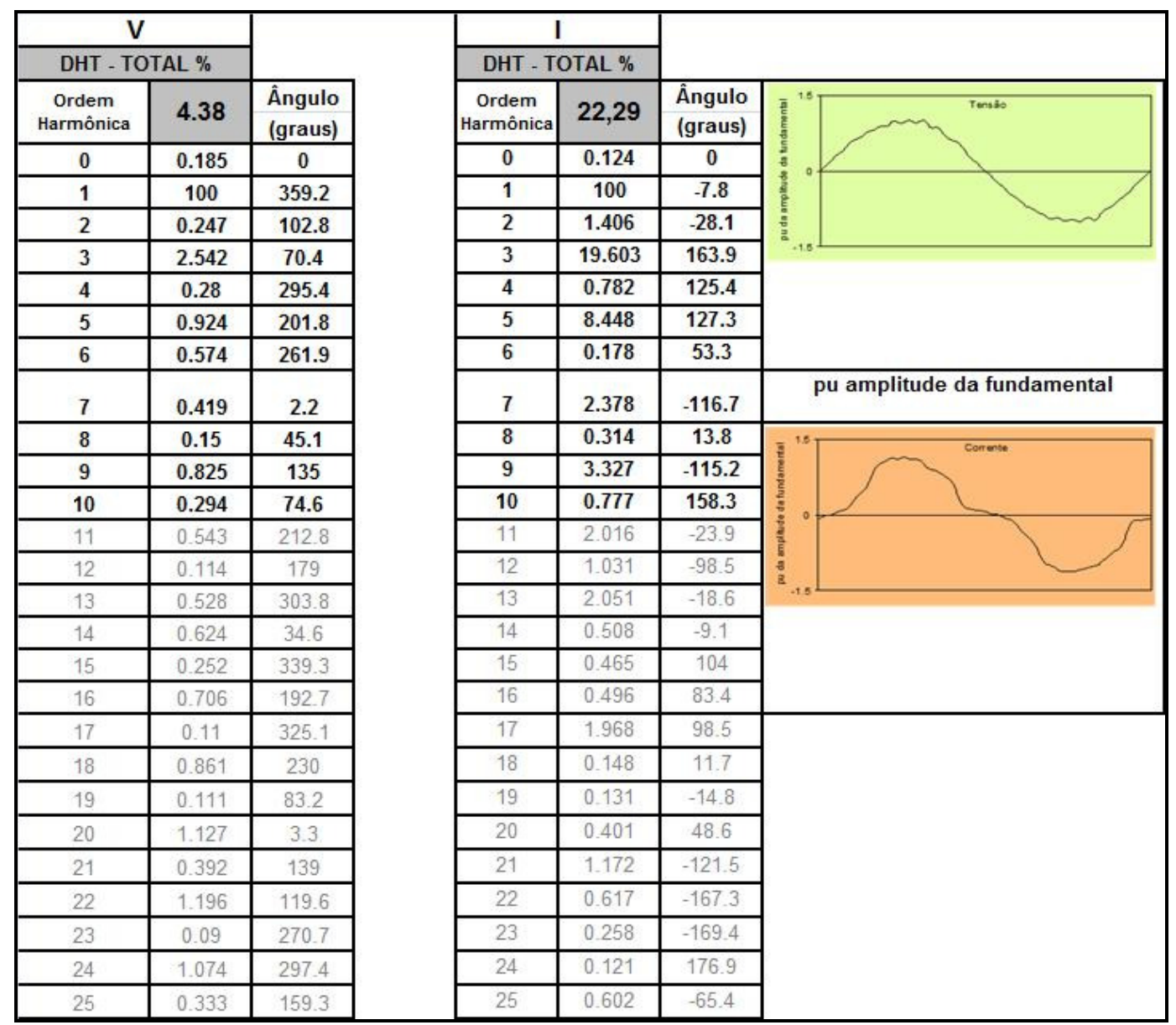

Tabela 18 - Elementos para o ensaio 4, Programa 13, Medição em Instalação Residencial

A Tabela 19 contém os padrões de corrente e tensão adotados neste ensaio. $\mathrm{Na}$ Tabela 20, são relacionados os elementos presentes da instalação.

\begin{tabular}{|c|c|c|c|}
\hline Ensaios & I $A_{\text {ef }}$ & V1- $\mathrm{V}_{\text {ef }}$ & $\mid 1-\mathrm{A}_{\mathrm{ef}}$ \\
\hline $\mathrm{A}$ & 15 & 127 & 14,64 \\
\hline $\mathrm{B}$ & 25 & 127 & 24,4 \\
\hline C & 1,5 & 127 & 1,464 \\
\hline
\end{tabular}

Tabela 19 - Elementos para o ensaio 4, Programa 13, Pacific 390 AMX, Seqüências A, B e C. 


\begin{tabular}{|l|c|}
\hline \multicolumn{1}{|c|}{ Elementos de consumo } & Quantidade \\
\hline Computador & 1 \\
\hline Televisor & 3 \\
\hline Lâmpada PL20W & 4 \\
\hline Lâmpada PL15W & 4 \\
\hline Lâmpada Fluorescente & 1 \\
\hline Forno microondas & 1 \\
\hline
\end{tabular}

Tabela 20 - Cargas Elétricas da Instalação Residencial

3.2.1.5. Ensaios com ondas teóricas

A seguir são apresentados o resultados de medições nos quais foram adotados padrões teóricos para as ondas de tensão e corrente conforme segue. 


\section{Onda Teórica "A"}

Para a onda teórica A tomou-se o ângulo da onda de tensão harmônica em relação a onda de corrente harmônica o valor $0^{\circ}$.

A Tabela 21 apresenta os resultados obtidos para este ensaio.

\begin{tabular}{|c|c|c|c|c|c|c|}
\hline \multirow{2}{*}{\multicolumn{2}{|c|}{$\frac{\mathrm{V}}{\text { DHT - TOTAL \% }}$}} & \multirow[b]{3}{*}{$\begin{array}{l}\text { Ângulo } \\
\text { (graus) }\end{array}$} & \multirow{2}{*}{\multicolumn{2}{|c|}{$\frac{\text { I }}{\text { DHT - TOTAL \% }}$}} & \multirow[b]{3}{*}{$\begin{array}{l}\text { Ângulo } \\
\text { (graus) }\end{array}$} & \multirow[b]{3}{*}{ Tersio } \\
\hline & & & & & & \\
\hline $\begin{array}{c}\text { Ordem } \\
\text { Harmônica }\end{array}$ & 7,14 & & \multirow{2}{*}{\begin{tabular}{|c|}
$\begin{array}{c}\text { Ordem } \\
\text { Harmônica }\end{array}$ \\
0 \\
\end{tabular}} & 111,15 & & \\
\hline 1 & 0 & 0 & & 0 & 0 & \\
\hline 1 & 100 & 0 & 1 & 100 & 0 & \\
\hline 2 & 0 & 0 & 2 & 0 & 0 & $\vdots$ of \\
\hline 3 & 5 & 0 & 3 & 80 & 0 & \\
\hline 4 & 0 & 0 & 4 & 0 & 0 & $:$ \\
\hline 5 & 3 & 0 & 5 & 48 & 0 & 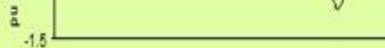 \\
\hline 6 & 0 & 0 & 6 & 0 & 0 & \\
\hline 7 & 2.14 & 0 & 7 & 34.29 & 0 & pu amplitude da fundamental \\
\hline 8 & 0 & 0 & 8 & 0 & 0 & \\
\hline 9 & 1.67 & 0 & 9 & 26.67 & 0 & \\
\hline 10 & 0 & 0 & 10 & 0 & 0 & toriente \\
\hline 11 & 1.36 & 0 & 11 & 21.82 & 0 & \\
\hline 12 & 0 & 0 & 12 & 0 & 0 & : \\
\hline 13 & 1.15 & 0 & 13 & 18.46 & 0 & 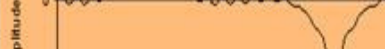 \\
\hline 14 & 0 & 0 & 14 & 0 & 0 & 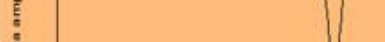 \\
\hline 15 & 1 & 0 & 15 & 16 & 0 & 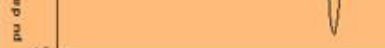 \\
\hline 16 & 0 & 0 & 16 & 0 & 0 & \\
\hline 17 & 1.88 & 0 & 17 & 14.12 & 0 & \\
\hline 18 & 0 & 0 & 18 & 0 & 0 & \\
\hline 19 & 0.79 & 0 & 19 & 12.63 & 0 & \\
\hline 20 & 0 & 0 & 20 & 0 & 0 & \\
\hline 21 & 0.71 & 0 & 21 & 11.43 & 0 & \\
\hline 22 & 0 & 0 & 22 & 0 & 0 & \\
\hline 23 & 0.65 & 0 & 23 & 10.43 & 0 & \\
\hline 24 & 0 & 0 & 24 & 0 & 0 & \\
\hline 25 & 0.6 & 0 & 25 & 9.6 & 0 & \\
\hline
\end{tabular}

Tabela 21 - Elementos para o ensaio 5, Programa 14, Medição com Onda Teórica A

\begin{tabular}{|c|c|c|c|}
\hline Ensaios & I A ef & V1- $\mathrm{V}_{\text {ef }}$ & $\mathrm{I} 1-\mathrm{A}_{\text {ef }}$ \\
\hline $\mathrm{A}$ & 15 & 127 & 10,3 \\
\hline $\mathrm{B}$ & 25 & 127 & 16,72 \\
\hline $\mathrm{C}$ & 1,5 & 127 & 1,003 \\
\hline
\end{tabular}

Tabela 22 - Elementos para o ensaio 5, Programa 14,Onda Teórica A-Âng oㅡ, Seq A, B e C 


\section{Onda Teórica "B"}

Para a onda teórica B tomou-se o ângulo da onda de tensão harmônica em relação a onda de corrente harmônica o valor $180^{\circ}$.

A Tabela 23 apresenta os resultados obtidos para este ensaio.

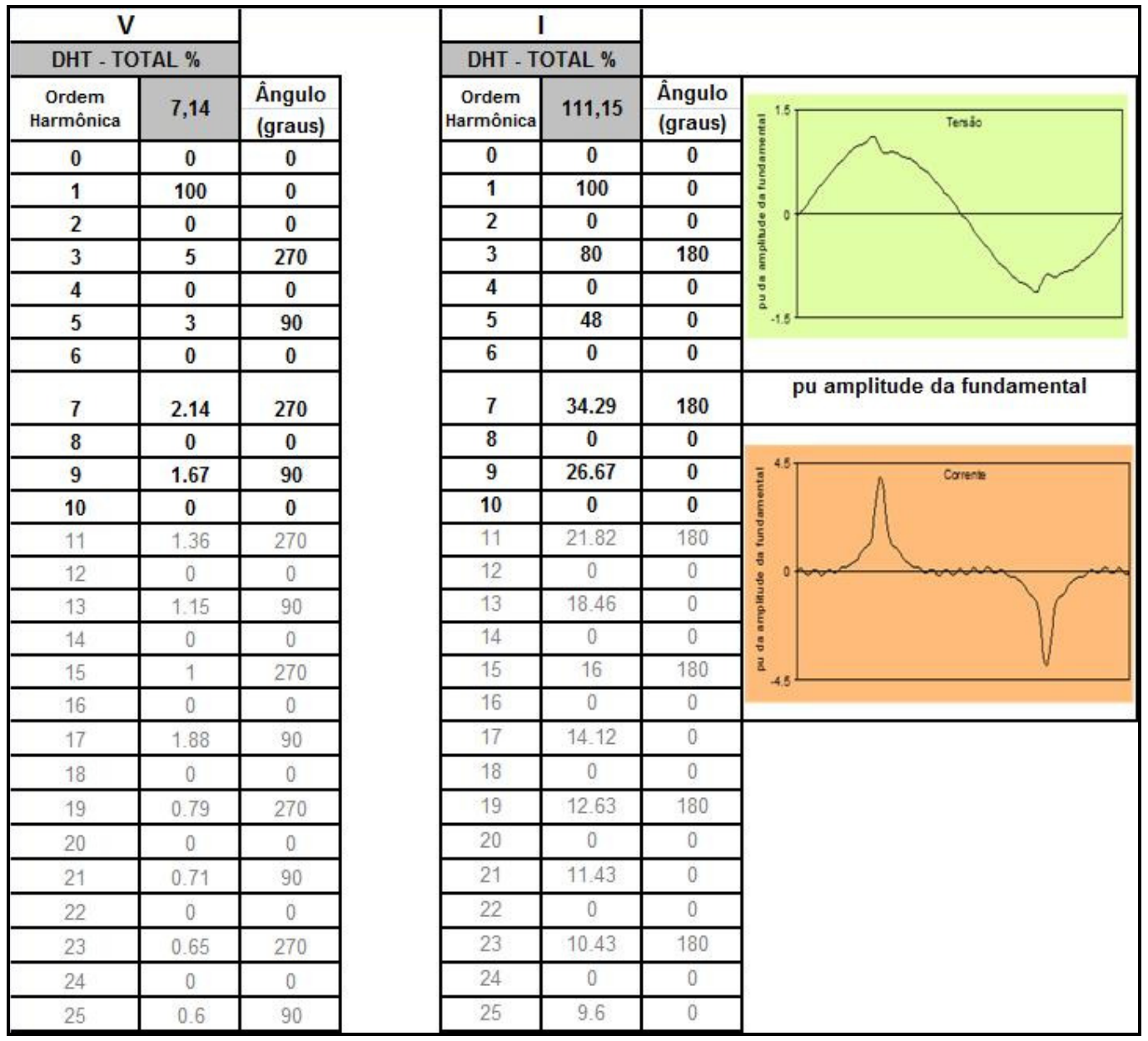

Tabela 23 - Elementos para o ensaio 6, Programa 15, Medição com Onda Teórica B

\begin{tabular}{|c|c|c|c|}
\hline Ensaios & $\mathrm{I} \mathrm{A}_{\mathrm{ef}}$ & $\mathrm{V} 1-\mathrm{V}_{\mathrm{ef}}$ & $\mathrm{I} 1-\mathrm{A}_{\mathrm{ef}}$ \\
\hline $\mathrm{A}$ & 15 & 127 & 10,3 \\
\hline $\mathrm{B}$ & 25 & 127 & 16,72 \\
\hline $\mathrm{C}$ & 1,5 & 127 & 1,003 \\
\hline
\end{tabular}

Tabela 24 - Elementos para o ensaio 6, Programa 15,Onda Teórica B-Âng 180ํ, Seq A, B e C. 


\section{Onda Teórica "C"}

Para a onda teórica $\mathrm{C}$ tomou-se o ângulo da onda de tensão harmônica em relação a onda de corrente harmônica o valor $180^{\circ}$.

A Tabela 25 apresenta os resultados obtidos para este ensaio.

\begin{tabular}{|c|c|c|c|c|c|c|}
\hline \multicolumn{2}{|c|}{ V } & \multirow[b]{3}{*}{$\begin{array}{l}\text { Ângulo } \\
\text { (graus) }\end{array}$} & \multicolumn{2}{|c|}{ I } & \multirow[b]{3}{*}{$\begin{array}{l}\text { Ângulo } \\
\text { (graus) }\end{array}$} & \multirow[b]{3}{*}{ Tenso } \\
\hline \multicolumn{2}{|c|}{ DHT - TOTAL \% } & & \multicolumn{2}{|c|}{ DHT - TOTAL \% } & & \\
\hline $\begin{array}{c}\text { Ordem } \\
\text { Harmônica }\end{array}$ & 7,14 & & \begin{tabular}{|c|} 
Ordem \\
Harmônica
\end{tabular} & 111,15 & & \\
\hline 0 & 0 & 0 & 0 & 0 & 0 & \\
\hline 1 & 100 & 0 & 1 & 100 & 0 & \\
\hline 2 & 0 & 0 & 2 & 0 & 0 & \\
\hline 3 & 5 & 0 & 3 & 80 & 180 & \\
\hline 4 & 0 & 0 & 4 & 0 & 0 & \\
\hline 5 & 3 & 180 & 5 & 48 & 0 & \\
\hline 6 & 0 & 0 & 6 & 0 & 0 & \\
\hline 7 & 2.14 & 0 & 7 & 34.29 & 180 & pu amplitude da fundamental \\
\hline 8 & 0 & 0 & 8 & 0 & 0 & \\
\hline 9 & 1.67 & 180 & 9 & 26.67 & 0 & \\
\hline 10 & 0 & 0 & 10 & 0 & 0 & \\
\hline 11 & 1.36 & 0 & 11 & 21.82 & 180 & \\
\hline 12 & 0 & 0 & 12 & 0 & 0 & \\
\hline 13 & 1.15 & 180 & 13 & 18.46 & 0 & \\
\hline 14 & 0 & 0 & 14 & 0 & 0 & \\
\hline 15 & 1 & 0 & 15 & 16 & 180 & \\
\hline 16 & 0 & 0 & 16 & 0 & 0 & \\
\hline 17 & 1.88 & 180 & 17 & \begin{tabular}{|l|l|}
4.12 \\
\end{tabular} & 0 & \\
\hline 18 & 0 & 0 & 18 & 0 & 0 & \\
\hline 19 & 0.79 & 0 & 19 & 12.63 & 180 & \\
\hline 20 & 0 & 0 & 20 & 0 & 0 & \\
\hline 21 & 0.71 & 180 & 21 & 11.43 & 0 & \\
\hline 22 & 0 & 0 & 22 & 0 & 0 & \\
\hline 23 & 0.65 & 0 & 23 & 10.43 & 180 & \\
\hline 24 & 0 & 0 & 24 & 0 & 0 & \\
\hline 25 & 0.6 & 180 & 25 & 9.6 & 0 & \\
\hline
\end{tabular}

Tabela 25 - Elementos para o ensaio 8, Programa 15-Pacific 390 AMX - Medição com Onda Teórica C

\begin{tabular}{|c|c|c|c|}
\hline Ensaios & $\mathrm{I} \mathrm{A}_{\mathrm{ef}}$ & $\mathrm{V} 1-\mathrm{V}_{\mathrm{ef}}$ & $\mathrm{I} 1-\mathrm{A}_{\mathrm{ef}}$ \\
\hline $\mathrm{A}$ & 15 & 127 & 10,3 \\
\hline $\mathrm{B}$ & 25 & 127 & 16,72 \\
\hline $\mathrm{C}$ & 1,5 & 127 & 1,003 \\
\hline
\end{tabular}

Tabela 26 - Elementos para o ensaio 8, Programa 15,Onda Teórica C-Âng 180ํㅗ Seq $A, B$ e $C$. 


\section{Onda Teórica "E"}

Para a onda teórica E, com harmônicos pares e ímpares, tomou-se o ângulo da onda de tensão harmônica em relação a onda de corrente harmônica o valor 180․

A Tabela 27 apresenta os resultados obtidos para este ensaio.

\begin{tabular}{|c|c|c|c|c|c|c|}
\hline \multicolumn{2}{|c|}{ V } & \multirow[b]{3}{*}{$\begin{array}{l}\text { Ângulo } \\
\text { (graus) }\end{array}$} & \multicolumn{2}{|c|}{ I } & \multirow[b]{3}{*}{$\begin{array}{l}\text { Ângulo } \\
\text { (graus) }\end{array}$} & \multirow{4}{*}{$\sqrt{1.5}{ }^{\text {Terabo }}$} \\
\hline \multicolumn{2}{|c|}{ DHT - TOTAL \% } & & \multicolumn{2}{|c|}{ DHT - TOTAL \% } & & \\
\hline $\begin{array}{c}\text { Ordem } \\
\text { Harmônica }\end{array}$ & 8,09 & & \begin{tabular}{|c|} 
Ordem \\
Harmônica
\end{tabular} & 113,93 & & \\
\hline 0 & 0.00 & 0 & 0 & 0.0 & 0 & \\
\hline 1 & 100.00 & 0 & 1 & 100.0 & 0 & \\
\hline 2 & 3.00 & 0 & 2 & 20.0 & 180 & 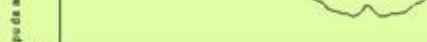 \\
\hline 3 & 5.00 & 0 & 3 & 80.0 & 180 & \\
\hline 4 & 1.50 & 0 & 4 & 10.0 & 180 & \\
\hline 5 & 3.00 & 180 & 5 & 48.0 & 0 & \\
\hline 6 & 1.00 & 0 & 6 & 6.7 & 180 & \\
\hline 7 & 2.14 & 0 & 7 & 34.3 & 180 & pu amplitude da fundamental \\
\hline 8 & 0.75 & 0 & 8 & 5.0 & 180 & \\
\hline 9 & 1.67 & 180 & 9 & 26.7 & 0 & \\
\hline 10 & 0.60 & 0 & 10 & 4.0 & 180 & \\
\hline 11 & 1.40 & 0 & 11 & 21.8 & 180 & \\
\hline 12 & 0.50 & 0 & 12 & 3.3 & 180 & \\
\hline 13 & 1.20 & 180 & 13 & 18.5 & 0 & \\
\hline 14 & 0.40 & 0 & 14 & 2.9 & 180 & \\
\hline 15 & 1.00 & 0 & 15 & 16.0 & 180 & \\
\hline 16 & 0.40 & 0 & 16 & 2.5 & 180 & \\
\hline 17 & 1.90 & 180 & 17 & 14.1 & 0 & \\
\hline 18 & 0.30 & 0 & 18 & 2.2 & 180 & \\
\hline 19 & 0.80 & 0 & 19 & 12.6 & 180 & \\
\hline 20 & 0.30 & 0 & 20 & 2.0 & 180 & \\
\hline 21 & 0.70 & 180 & 21 & 11.4 & 0 & \\
\hline 22 & 0.30 & 0 & 22 & 1.8 & 180 & \\
\hline 23 & 0.70 & 0 & 23 & 10.4 & 180 & \\
\hline 24 & 0.30 & 0 & 24 & 1.7 & 180 & \\
\hline 25 & 0.60 & 180 & 25 & 9.6 & 0 & \\
\hline
\end{tabular}

Tabela 27 - Elementos para o ensaio 10, Programa 16-Pacific 390 AMX - Medição com Onda Teórica E

\begin{tabular}{|c|r|r|r|}
\hline Ensaios & \multicolumn{1}{|c|}{$\mathrm{I} \mathrm{A}_{\mathrm{ef}}$} & \multicolumn{1}{c|}{$\mathrm{V} 1-\mathrm{V}_{\text {ef }}$} & \multicolumn{1}{c|}{$\mathrm{I}-\mathrm{A}_{\mathrm{ef}}$} \\
\hline $\mathrm{A}$ & 15 & 127 & 9,89 \\
\hline $\mathrm{B}$ & 25 & 127 & 16,49 \\
\hline $\mathrm{C}$ & 1,5 & 127 & 0,989 \\
\hline
\end{tabular}

Tabela 28 - Elementos para o ensaio 10, Programa 16,Onda Teórica E-Âng 180, Seq A, B e C. 
Onda Teórica "F"

Para a onda teórica $F$, com espectros de harmônicos iguais para tensão e corrente. No caso 1 os ângulos de fase são de $180^{\circ}$ ou $0^{\circ}$.

A Tabela 29 Apresenta os resultados obtidos para este ensaio.

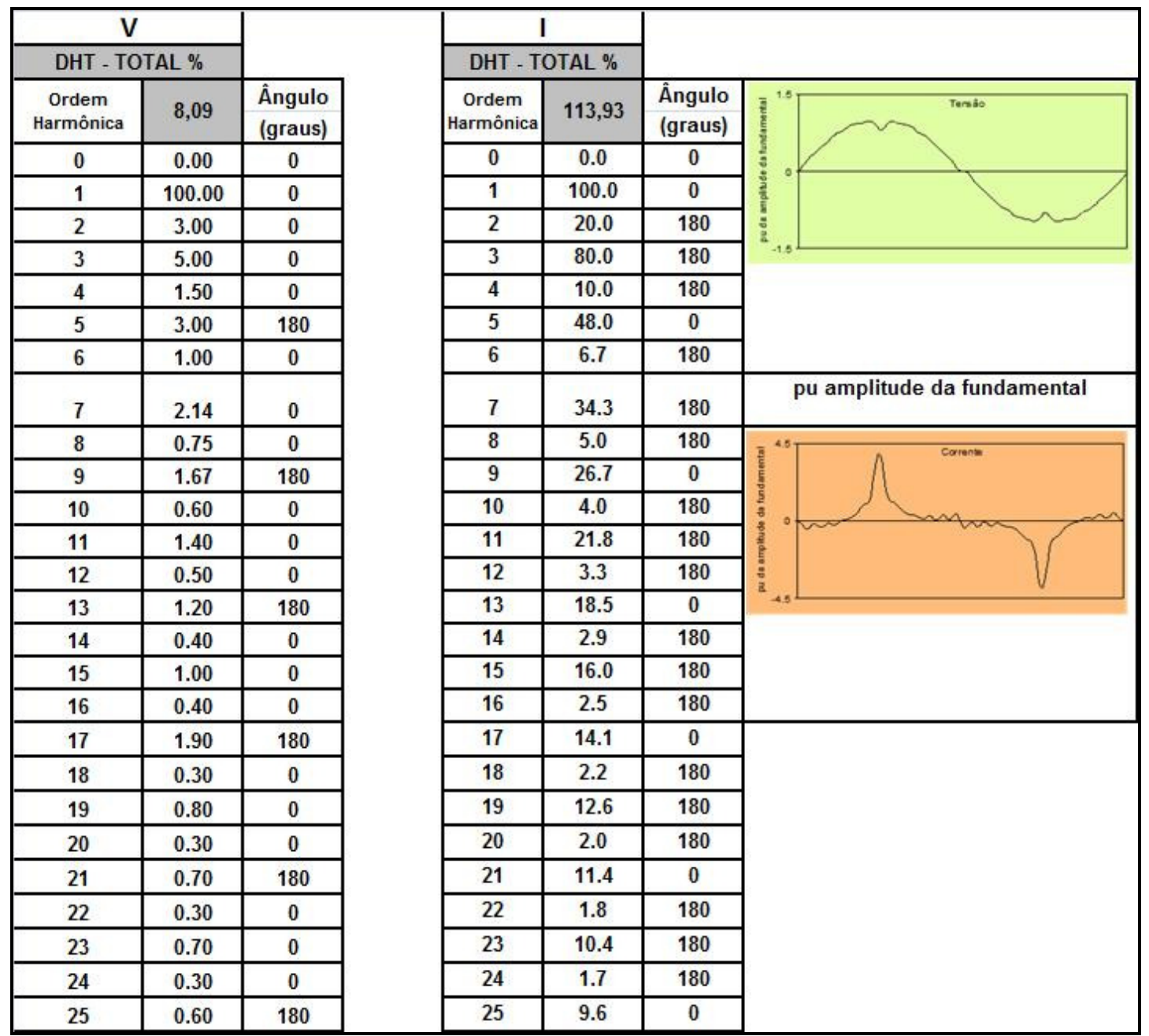

Tabela 29 - Elementos para o ensaio 12, Programa 17-Pacific 390 AMX - Medição com Onda Teórica F

\begin{tabular}{|c|c|c|c|}
\hline Ensaios & I $\mathrm{A}_{\text {ef }}$ & $\mathrm{V} 1-\mathrm{V}_{\mathrm{ef}}$ & $\mathrm{I}-\mathrm{A}_{\mathrm{ef}}$ \\
\hline $\mathrm{A}$ & 15 & 127 & 14,44 \\
\hline $\mathrm{B}$ & 25 & 127 & 24,08 \\
\hline $\mathrm{C}$ & 1,5 & 127 & 1,444 \\
\hline
\end{tabular}

Tabela 30 - Elementos para o ensaio 12, Programa 17,Onda Teórica F-Âng $180^{\circ}$ ou $0^{0}$ 


\begin{tabular}{|c|c|c|c|c|c|c|}
\hline 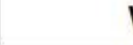 & & & I & & & \\
\hline DHT - T & AL \% & & DHT - TC & TAL \% & & \\
\hline $\begin{array}{c}\text { Ordem } \\
\text { Harmônica }\end{array}$ & 27,95 & $\begin{array}{l}\text { Ángulo } \\
\text { (graus) }\end{array}$ & $\begin{array}{c}\text { Ordem } \\
\text { Harmônica }\end{array}$ & 27,95 & $\begin{array}{c}\text { Ângulo } \\
\text { (graus) }\end{array}$ & Tensão \\
\hline 0 & 0 & 0 & 0 & 0 & 0 & E \\
\hline 1 & 100 & 0 & 1 & 100 & 0 & c \\
\hline 2 & 0 & 0 & 2 & 0 & 0 & $\frac{\pi}{0}$ \\
\hline 3 & 0 & 0 & 3 & 0 & 0 & \pm 0 \\
\hline 4 & 0 & 0 & 4 & 0 & 0 & 产 \\
\hline 5 & 0 & 0 & 5 & 0 & 0 & $\begin{array}{ll}0 \\
0 \\
0\end{array}$ \\
\hline 6 & 0 & 0 & 6 & 0 & 0 & $\mathrm{a}_{-1,5}$ \\
\hline 7 & 0 & 0 & 7 & 0 & 0 & \\
\hline 8 & 0 & 0 & 8 & 0 & 0 & \\
\hline 9 & 0 & 0 & 9 & 0 & 0 & 1,5 \\
\hline 10 & 0 & 0 & 10 & 0 & 0 & छ్ \\
\hline$\overline{11}$ & 0 & 0 & 11 & 0 & 0 & 号 \\
\hline 12 & 0 & 0 & 12 & 0 & 0 & : \\
\hline$\overline{13}$ & 0 & 0 & 13 & 0 & 0 & "ू. \\
\hline 14 & 0 & 0 & 14 & 0 & 0 & हे \\
\hline 15 & 0 & 0 & 15 & 0 & 0 & vi \\
\hline 16 & 0 & 0 & 16 & 0 & 0 & \\
\hline
\end{tabular}

Tabela 31 - Onda teórica fundamental - Com espectros de harmônicos iguais a zero para tensão e corrente

\begin{tabular}{|l|l|l|}
\hline Ensaios & I Aef & V1- Vef \\
\hline A & 15 & 127 \\
\hline B & 25 & 127 \\
\hline C & 1,5 & 127 \\
\hline
\end{tabular}

Tabela 32 - Elementos para o ensaio (12. Programa 17)-Onda teórica F - Âng.-180ํำ

$$
\text { ou } 0 \text {-seq. A, B e C }
$$

Para a validação das metodologias de ensaios realizadas foi aplicado um teste laboratorial contrapondo dois padrões: o padrão ZERA, que compara a energia medida por meio da contagem de pulsos - trata-se de uma metodologia utilizada pela maioria das concessionárias e pelos fabricantes de medidores e o padrão Yokogawa, que realiza as medições pelo método de tensão e corrente. 
Os fatores de influência dos medidores [80] determinam que a forma de onda deve ter, no máximo, 10\% de distorção da corrente na terceira harmônica. O fator de distorção da tensão deve ser menor do que $1 \%$ e não pode ser aplicado para medidores de energia reativa.

Os ensaios no laboratório do Enerq-USP foram realizados em três condições de carga, sendo registrados pelos 3 medidores instalados no circuito, conforme aponta a Figura 13. Eles seguiram os programas de ensaio implantados na Fonte de energia Pacific Foto 6. Essas correntes foram determinadas obedecendo às normas ABNT e Inmetro, limitadas às condições de carga da fonte comparando-se os ensaios realizados na AES Eletropaulo Tabela 33.

$\mathrm{Na}$ Tabela 34, apresentam-se os resultados comparativos dos ensaios com a corrente nominal dos medidores dos fabricantes $(A)$ e $(B)$.

Os resultados comparativos dos ensaios com $25 \%$ da corrente nominal dos medidores dos fabricantes $(A)$ e $(B)$ são apresentados na Tabela 35.

A Tabela 36 expõe os resultados comparativos dos ensaios com 10\% da corrente nominal dos medidores dos fabricantes $(A)$ e $(B)$.

Por meio da Tabela 37, dispõe-se um resumo de consolidação dos resultados obtidos em função dos ensaios medidores submetidos a ondas de tensão e corrente não senoidais. Destacam-se os erros com desvio superior ao definido pelo fabricante do instrumento. 


\begin{tabular}{|c|c|c|c|c|c|c|c|c|c|c|c|c|c|c|c|c|c|}
\hline \multirow{2}{*}{ CURVA } & \multicolumn{5}{|c|}{ WT2030 } & \multicolumn{5}{|c|}{ CAL PORT 400} & \multicolumn{5}{|c|}{ SAGA 2000} & \multicolumn{2}{|c|}{ HORA } \\
\hline & v & 1 & ATIVO & REATIVO & WH & v & 1 & ATIVO & REATIVO & WH & v & 1 & ATIVO & \begin{tabular}{|l|} 
REATIVO \\
\end{tabular} & WH & inico & fim \\
\hline senoide & 119,94 & 5,02 & 602,50 & 1,30 & 150,62 & 119,98 & 5,00 & 599,80 & $-0,13$ & 151,20 & & & $\begin{array}{l}599,20 \\
599,20 \\
599,20\end{array}$ & $\begin{array}{l}0,80 \\
0,80 \\
0,80\end{array}$ & 149,8 & 09:00 & 09:15 \\
\hline $60 \mathrm{hz}_{-} 3$ & 120,42 & 5,04 & 606,90 & 2,20 & 151,76 & 120,47 & 5,01 & 603,86 & 0,11 & 151,22 & & & $\begin{array}{l}604,80 \\
604,40 \\
604,80 \\
\end{array}$ & $\begin{array}{l}0,00 \\
0,00 \\
0,00\end{array}$ & 151,0 & 10:15 & $10: 30$ \\
\hline $60 \mathrm{hz} \_5$ & 120,81 & 5,05 & 610,10 & 5,30 & 152,59 & 120,85 & 5,03 & 607,35 & $-0,94$ & 152,05 & $\begin{array}{c}\text { sem } \\
\text { dados }\end{array}$ & $\begin{array}{c}\text { sem } \\
\text { dados }\end{array}$ & $\begin{array}{l}607,20 \\
607,20 \\
607,20 \\
\end{array}$ & $\begin{array}{l}2,40 \\
0,00 \\
2,40 \\
\end{array}$ & 151,8 & $10: 40$ & $10: 55$ \\
\hline 60hz 2_10 & 122,20 & 5,11 & 624,20 & 9,60 & 155,97 & 122,24 & 5,08 & 620,99 & $-1,40$ & 155,57 & & & $\begin{array}{l}619,20 \\
621,60 \\
621,60\end{array}$ & $\begin{array}{l}2,40 \\
2,40 \\
2,40\end{array}$ & 155,2 & 11:15 & $11: 30$ \\
\hline ENSAIO 3.8 & 126,95 & 7,90 & 1003,10 & 579,70 & 204,66 & 126,98 & 7,89 & 813,52 & $-575,93$ & 204,70 & & & $\begin{array}{l}811,20 \\
813,60 \\
813,60\end{array}$ & $\begin{array}{l}578,40 \\
576,00 \\
578,40\end{array}$ & 203,4 & 11:45 & $12: 00$ \\
\hline
\end{tabular}

Tabela 33 - Ensaios comparativos de metodologia contagem de pulso X tensão e corrente 
O Gráfico 3 demonstra o comportamento do medidor, com classe de exatidão de $1 \%$ em relação aos ensaios com ondas de tensão e corrente não senoidais.

O comportamento do medidor, com classe de exatidão de $0,5 \%$ em relação aos ensaios com ondas de tensão e corrente não senoidais, é ilustrado no Gráfico 4. 


\begin{tabular}{|c|c|c|c|c|c|c|c|c|c|c|c|c|c|c|c|c|c|c|c|c|c|c|c|c|}
\hline \multirow{2}{*}{ CURVA } & \multicolumn{6}{|c|}{ WT2030 } & \multicolumn{8}{|c|}{ NANSEN } & \multicolumn{8}{|c|}{ SAGA 2000 (MEDIÇÃO INDIRETA CORRENTE 15(120) A } & \multicolumn{2}{|c|}{ HORA (real) } \\
\hline & V & 1 & ATIVO & ATIV0(3f) & VAR & WH (1F) & v & 1 & ATIVO(1f) A & ATIVO(3f) & IND & CAP & WH & ARQUIVO & V & 1 & ATIVO & ATIVO (3f) & IND & CAP & WH(1F) & ARQUIVO & inicio & fim \\
\hline \multirow{3}{*}{ ENSAIO 1-PROGRAMA 10} & \multirow{3}{*}{126,92} & \multirow{3}{*}{23,908} & \multirow{3}{*}{2954,3} & \multirow{3}{*}{8862,9} & \multirow{3}{*}{693,0} & \multirow{3}{*}{739,08} & \multirow{3}{*}{$x$} & \multirow{3}{*}{$x$} & 2944,80 & 8834,40 & 1036,8 & 0 & \multirow{3}{*}{735,60} & \multirow{3}{*}{$x$} & \multirow{3}{*}{126.9} & \multirow{3}{*}{23,74} & 2944,00 & 8832,00 & 1080,00 & 0,00 & \multirow{3}{*}{734,67} & \multirow{3}{*}{ GL.ESO } & \multirow{3}{*}{ 12:50 } & \multirow{3}{*}{ 13:05 } \\
\hline & & & & & & & & & 2937,60 & 8812,80 & 1036,8 & 0 & & & & & 2936,00 & 8808,00 & 1056,00 & 0,00 & & & & \\
\hline & & & & & & & & & 2944,80 & 8834,40 & 1036,8 & 0 & & & & & 2936,00 & 8808,00 & 1080,00 & 0,00 & & & & \\
\hline & & & & & & & & & 2692,80 & 8078,40 & 0 & 2656,8 & & & & & 2696,00 & 8088,00 & 3816,00 & 0,00 & & & & \\
\hline ENSAI0 2-PROGRAMA 11 & 126,95 & 23,574 & 2706,4 & 8119,2 & 1277,2 & 676,19 & $x$ & $x$ & 2692,80 & 8078,40 & 0 & 2635,2 & 672,60 & $x$ & 127 & 23,48 & 2688,00 & 8064,00 & 3792,00 & 0,00 & 673,33 & GL.ESO & 13:10 & 13:25 \\
\hline & & & & & & & & & 2685,60 & 8056,80 & 0 & 2656,8 & & & & & 2696,00 & 8088,00 & 3792,00 & 0,00 & & & & \\
\hline & & & & & & & & & 2952,00 & 8856,00 & 208,8 & 0 & & & & & 2952,00 & 8856,00 & 336,00 & 0,00 & & & & \\
\hline ENSAIO 3 PROGRAMA 12 & 126,94 & 23,846 & 2970,6 & 8911,8 & 581,6 & 741,81 & $x$ & $x$ & 2952,00 & 8856,00 & 302,4 & 0 & 738,00 & $x$ & 126,9 & 23,7 & 2952,00 & 8856,00 & 336,00 & 0,00 & 738,67 & GLIBN & 13:30 & 13:45 \\
\hline & & & & & & & & & 2952,00 & 8856,00 & 208,8 & 0 & & & & & 2960,00 & 8880,00 & 312,00 & 0,00 & & & & \\
\hline & & & & & & & & & 2923,20 & 8769,60 & 0 & 1274,4 & & & & & 2920,00 & 8760,00 & 1248,00 & 0,00 & & & & \\
\hline ENSAIO 4 PROGRAMA 13 & 126,89 & 23,915 & 2934,9 & 8804,7 & 771,1 & 734,65 & $x$ & $x$ & 2923,20 & 8769,60 & 0 & 1252,8 & 730,80 & $x$ & 127 & 23,76 & 2920,00 & 8760,00 & 1248,00 & 0,00 & 730,67 & GL.LI & 13:50 & 14:05 \\
\hline & & & & & & & & & 2923,20 & 8769,60 & 0 & 1252,8 & & & & & 2928,00 & 8784,00 & 1124,00 & 0,00 & & & & \\
\hline & & & & & & & & & 1627,20 & 4881,60 & 0 & 64,8 & & & & & 1632,00 & 4896,00 & 72,00 & 0,00 & & & & \\
\hline ENSAIO6 - PROGRAMA 14 & 126,85 & 17,839 & 1637 & 4911 & 1562,4 & 408,91 & $x$ & $x$ & 1634,40 & 4903,20 & 0 & 64,8 & 407,40 & $x$ & 127,6 & 20,6 & 1624,00 & 4872,00 & 48,00 & 0,00 & 406,67 & GL.NQI & 14:10 & 14:25 \\
\hline & & & & & & & & & 1627,20 & 4881,60 & 0 & 64,8 & & & & & 1624,00 & 4872,00 & 72,00 & 0,00 & & & & \\
\hline & & & & & & & & & 1404,00 & 4212,00 & 0 & 86,4 & & & & & 1392,00 & 4176,00 & 48,00 & 0,00 & & & & \\
\hline ENSAI08 -PROGRAMA 15 & 126,88 & 17,809 & 1404,1 & 4212,3 & 1770,4 & 351,54 & $x$ & $x$ & 1404,00 & 4212,00 & 0 & 64,8 & 351,00 & $x$ & 128,3 & 12,16 & 1400,00 & 4200,00 & 72,00 & 0,00 & 348,67 & GLQPQ & $14: 30$ & 14:45 \\
\hline & & & & & & & & & 1404,00 & 4212,00 & 0 & 86,4 & & & & & 1392,00 & 4176,00 & 72,00 & 0,00 & & & & \\
\hline & & & & & & & & & 1728,00 & 5184,00 & 0 & 108 & & & & & 1712,00 & 5136,00 & 120,00 & 0,00 & & & & \\
\hline ENSAI010 -PROGRAMA 16 & 126,86 & 21,003 & 1726,1 & 5178,3 & 2029,8 & 431,92 & $x$ & $x$ & 1728,00 & 5184,00 & 0 & 108 & 431,39 & $x$ & 126,9 & 20,76 & 1728,00 & 5184,00 & 96,00 & 0,00 & 430,00 & GM.BFS & $14: 50$ & 15:05 \\
\hline & & & & & & & & & 1720,67 & 5162,00 & 0 & 129,6 & & & & & 1720,00 & 5160,00 & 120,00 & 0,00 & & & & \\
\hline & & & & & & & & & 2995,20 & 8985,60 & 0 & 108 & & & & & 3000,00 & 9000,00 & 120,00 & 0,00 & & & & \\
\hline ENSAIO - PROGRAMA 17 & 126,94 & 23,337 & 2961,9 & 8885,7 & 55,1 & 752,99 & $x$ & $x$ & 2995,20 & 8985,60 & 0 & 129,6 & 751,80 & $x$ & 127 & 23,17 & 2992,00 & 8976,00 & 96,00 & 0,00 & 749,33 & GM.DCK & 15:10 & 15:25 \\
\hline & & & & & & & & & 3031,20 & 9093,60 & 0 & 129,6 & & & & & 3000,00 & 9000,00 & 120,00 & 0,00 & & & & \\
\hline & & & & & & & & & 3052,80 & 9158,40 & 0 & 129,6 & & & & & 3056,00 & 9168,00 & 120,00 & 0,00 & & & & \\
\hline ENSAIO - PROGRAMA 18 & 126,96 & 24,202 & 3072,4 & 9217,2 & 39,3 & 767,80 & $x$ & $x$ & 3060,00 & 9180,00 & 0 & 129,6 & 763,80 & $A G . D D B$ & 127 & 24,07 & 3056,00 & 9168,00 & 120,00 & 0,00 & 764,03 & GM.FHP & $15: 30$ & 15:45 \\
\hline & & & & & & & & & 3052,80 & 9158,40 & 0 & 151,2 & & & & & 3056,33 & 9169,00 & 120,00 & 0,00 & & & & \\
\hline
\end{tabular}

Tabela 34 - Resultado do ensaio (A) com corrente nominal - 15 Ampéres 


\begin{tabular}{|c|c|c|c|c|c|c|c|c|c|c|c|c|c|c|c|c|c|c|c|c|c|c|c|c|}
\hline \multirow{2}{*}{ CURVA } & \multicolumn{6}{|c|}{ WT2030 } & \multicolumn{8}{|c|}{ NANSEN } & \multicolumn{8}{|c|}{ SAGA 2000 (MEDIÇÃO INDIRETA CORRENTE 15(120) A } & \multicolumn{2}{|c|}{ HORA (real) } \\
\hline & V & 1 & ATIV0 & ATIV0(3f) & VAR & WH(IF) & $\mathrm{V}$ & 1 & ATIV0(1f) & ATIV0(3f) & IND & CAP & WH & ARQUIVO & $\mathrm{v}$ & 1 & ATIV0 & ATIVO (3f) & IND & CAP & WH(IF) & ARQUIVO & inicio & fim \\
\hline \multirow{3}{*}{ ENSAIO 1-PROGRAMA 10} & \multirow{3}{*}{126,92} & \multirow{3}{*}{23,908} & \multirow{3}{*}{2954,3} & \multirow{3}{*}{8862,9} & \multirow{3}{*}{693,0} & \multirow{3}{*}{739,08} & \multirow{3}{*}{$x$} & \multirow{3}{*}{$x$} & 2944,80 & 8834,40 & 1036,8 & 0 & \multirow{3}{*}{735,60} & \multirow{3}{*}{$x$} & \multirow{3}{*}{126.9} & \multirow{3}{*}{23,74} & 2944,00 & 8832,00 & 1080,00 & 0,00 & \multirow{3}{*}{734,67} & \multirow{3}{*}{ GL.ESO } & \multirow{3}{*}{ 12:50 } & \multirow{3}{*}{ 13:05 } \\
\hline & & & & & & & & & \begin{tabular}{|l|}
2937,60 \\
\end{tabular} & 8812,80 & 1036,8 & 0 & & & & & 2936,00 & 8808,00 & 1056,00 & 0,00 & & & & \\
\hline & & & & & & & & & 2944,80 & 8834,40 & 1036,8 & 0 & & & & & 2936,00 & 8808,00 & 1080,00 & 0,00 & & & & \\
\hline & & & & & & & & & 2692,80 & 8078,40 & 0 & 2656,8 & & & & & 2696,00 & 8088,00 & 3816,00 & 0,00 & & & & \\
\hline ENSAIO 2-PROGRAMA 11 & 126,95 & 23,574 & 2706,4 & 8119,2 & 1277,2 & 676,19 & $x$ & $x$ & 2692,80 & 8078,40 & 0 & 2635,2 & 672,60 & $x$ & 127 & 23,48 & 2688,00 & 8064,00 & 3792,00 & 0,00 & 673,33 & GL.ESO & 13:10 & 13:25 \\
\hline & & & & & & & & & 2685,60 & 8056,80 & 0 & 2656,8 & & & & & 2696,00 & 8088,00 & 3792,00 & 0,00 & & & & \\
\hline & & & & & & & & & 2952,00 & 8856,00 & 208,8 & 0 & & & & & 2952,00 & 8856,00 & 336,00 & 0,00 & & & & \\
\hline ENSAIO 3 PROGRAMA 12 & 126,94 & 23,846 & 2970,6 & 8911,8 & 581,6 & 741,81 & $x$ & $x$ & 2952,00 & 8856,00 & 302,4 & 0 & 738,00 & $x$ & 126,9 & 23,7 & 2952,00 & 8856,00 & 336,00 & 0,00 & 738,67 & GL.IBN & $13: 30$ & 13:45 \\
\hline & & & & & & & & & 2952,00 & 8856,00 & 208,8 & 0 & & & & & 2960,00 & 8880,00 & 312,00 & 0,00 & & & & \\
\hline & & & & & & & & & 2923,20 & 8769,60 & 0 & 1274,4 & & & & & 2920,00 & 8760,00 & 1248,00 & 0,00 & & & & \\
\hline ENSAIO 4 PROGRAMA 13 & 126,89 & 23,915 & 2934,9 & 8804,7 & 771,1 & 734,65 & $x$ & $x$ & \begin{tabular}{|l|}
2923,20 \\
\end{tabular} & 8769,60 & 0 & 1252,8 & 730,80 & $x$ & 127 & 23,76 & 2920,00 & 8760,00 & 1248,00 & 0,00 & 730,67 & GL.LI & $13: 50$ & 14:05 \\
\hline & & & & & & & & & 2923,20 & 8769,60 & 0 & 1252,8 & & & & & 2928,00 & 8784,00 & 1124,00 & 0,00 & & & & \\
\hline & & & & & & & & & 1627,20 & 4881,60 & 0 & 64,8 & & & & & 1632,00 & 4896,00 & 72,00 & 0,00 & & & & \\
\hline ENSAIO6 - PROGRAMA 14 & 126,85 & 17,839 & 1637 & 4911 & 1562,4 & 408,91 & $x$ & $x$ & 1634,40 & 4903,20 & 0 & 64,8 & 407,40 & $x$ & 127,6 & 20,6 & 1624,00 & 4872,00 & 48,00 & 0,00 & 406,67 & GL.NQI & 14:10 & $14: 25$ \\
\hline & & & & & & & & & 1627,20 & 4881,60 & 0 & 64,8 & & & & & 1624,00 & 4872,00 & 72,00 & 0,00 & & & & \\
\hline & & & & & & & & & \begin{tabular}{|l|}
1404,00 \\
\end{tabular} & 4212,00 & 0 & 86,4 & & & & & 1392,00 & 4176,00 & 48,00 & 0,00 & & & & \\
\hline ENSAIO8 - PROGRAMA 15 & 126,88 & 17,809 & 1404,1 & 4212,3 & 1770,4 & 351,54 & $x$ & $x$ & 1404,00 & 4212,00 & 0 & 64,8 & 351,00 & $x$ & 128,3 & 12,16 & 1400,00 & 4200,00 & 72,00 & 0,00 & 348,67 & GL.QPQ & $14: 30$ & $14: 45$ \\
\hline & & & & & & & & & 1404,00 & 4212,00 & 0 & 86,4 & & & & & 1392,00 & 4176,00 & 72,00 & 0,00 & & & & \\
\hline & & & & & & & & & 1728,00 & 5184,00 & 0 & 108 & & & & & 1712,00 & 5136,00 & 120,00 & 0,00 & & & & \\
\hline ENSAI010-PROGRAMA 16 & 126,86 & 21,003 & 1726,1 & 5178,3 & 2029,8 & 431,92 & $x$ & $x$ & 1728,00 & 5184,00 & 0 & 108 & 431,39 & $x$ & 126,9 & 20,76 & 1728,00 & 5184,00 & 96,00 & 0,00 & 430,00 & GM.BFS & $14: 50$ & 15:05 \\
\hline & & & & & & & & & 1720,67 & 5162,00 & 0 & 129,6 & & & & & 1720,00 & 5160,00 & 120,00 & 0,00 & & & & \\
\hline & & & & & & & & & \begin{tabular}{|l|}
2995,20 \\
\end{tabular} & 8985,60 & 0 & 108 & & & & & 3000,00 & 9000,00 & 120,00 & 0,00 & & & & \\
\hline ENSAIO-PROGRAMA 17 & 126,94 & 23,337 & 2961,9 & 8885,7 & 55,1 & 752,99 & $x$ & $x$ & \begin{tabular}{|l|}
2995,20 \\
\end{tabular} & 8985,60 & 0 & 129,6 & 751,80 & $x$ & 127 & 23,17 & 2992,00 & 8976,00 & 96,00 & 0,00 & 749,33 & GM.DCK & $15: 10$ & $15: 25$ \\
\hline & & & & & & & & & 3031,20 & 9093,60 & 0 & 129,6 & & & & & 3000,00 & 9000,00 & 120,00 & 0,00 & & & & \\
\hline & & & & & & & & & \begin{tabular}{|l|}
3052,80 \\
\end{tabular} & 9158,40 & 0 & 129,6 & & & & & 3056,00 & 9168,00 & 120,00 & 0,00 & & & & \\
\hline ENSAIO-PROGRAMA 18 & 126,96 & 24,202 & 3072,4 & 9217,2 & 39,3 & 767,80 & $x$ & $x$ & \begin{tabular}{|l|}
3060,00 \\
\end{tabular} & 9180,00 & 0 & 129,6 & 763,80 & AG.DDB & 127 & 24,07 & 3056,00 & 9168,00 & 120,00 & 0,00 & 764,03 & GM.FHP & $15: 30$ & $15: 45$ \\
\hline & & & & & & & & & 3052,80 & 9158,40 & 0 & 151,2 & & & & & 3056,33 & 9169,00 & 120,00 & 0,00 & & & & \\
\hline
\end{tabular}

Tabela 35 - Resultado do ensaio (B) com corrente a 25\% da corrente máxima - 25 Ampéres 


\begin{tabular}{|c|c|c|c|c|c|c|c|c|c|c|c|c|c|c|c|c|c|c|c|c|c|c|c|c|}
\hline \multirow{2}{*}{ CURVA } & \multicolumn{6}{|c|}{ WT2030 } & \multicolumn{8}{|c|}{ NANSEN } & \multicolumn{8}{|c|}{ SAGA 2000 (MEDIÇÃOO INDIRETA CORRENTE 15(120) A } & \multicolumn{2}{|c|}{ HORA (real) } \\
\hline & $\mathrm{v}$ & 1 & ATIV0 & ATIV0(3f) & var & WH (1F) & v & 1 & ATIV0(1f) & ATIV0(3f) & IND & CAP & WH & ARQUIVO & v & 1 & ATIV0 & ATIVO (3f) & IND & CAP & WH(1F) & ARQUIVO & inicio & fim \\
\hline \multirow{3}{*}{ ENSAI0 1-PROGRAMA 10} & \multirow{3}{*}{126,8} & \multirow{3}{*}{1,422} & \multirow{3}{*}{175,4} & \multirow{3}{*}{526,2} & \multirow{3}{*}{42,0} & \multirow{3}{*}{45,07} & \multirow{3}{*}{$x$} & \multirow{3}{*}{$x$} & 180,00 & 540,00 & 64,8 & 0 & \multirow{3}{*}{45,00} & \multirow[b]{3}{*}{$x$} & \multirow{3}{*}{127} & \multirow{3}{*}{1,43} & 176,00 & 528,00 & 72,00 & 0,00 & \multirow{3}{*}{44,00} & \multirow{3}{*}{ GM.JSD } & \multirow{3}{*}{$15: 50$} & \multirow{3}{*}{$16: 0$} \\
\hline & & & & & & & & & 180,00 & 540,00 & 64,8 & 0 & & & & & 176,00 & 528,00 & 48,00 & 0,00 & & & & \\
\hline & & & & & & & & & 180,00 & 540,00 & 64,8 & 0 & & & & & 176,00 & 528,00 & 72,00 & 0,00 & & & & \\
\hline & & & & & & & & & 158,40 & 475,20 & 0 & 151,2 & & & & & 160,00 & 480,00 & 240,00 & 0,00 & & & & \\
\hline ENSAIO 2-PROGRAMA 11 & 126,81 & 1,44 & 165,6 & 496,8 & 77,0 & 41,49 & $x$ & $x$ & 165,60 & 496,80 & 0 & 151,2 & 40,80 & & 126,9 & 1,42 & 168,00 & 504,00 & 216,00 & 0,00 & 40,67 & GM.MDT & 16:10 & $16: 25$ \\
\hline & & & & & & & & & 165,60 & 496,80 & 0 & 151,2 & & $x$ & & & 160,00 & 480,00 & 216,00 & 0,00 & & & & \\
\hline & & & & & & & & & 180,00 & 540,00 & 21,6 & 0 & & & & & 176,00 & 528,00 & 24,00 & 0,00 & & & & \\
\hline ENSAIO 3 PROGRAMA 12 & 126,8 & 1,497 & 186,2 & 558,6 & 37,1 & 45,77 & $x$ & $x$ & 187,20 & 561,60 & 21,6 & 0 & 45,60 & & 126,8 & 1,47 & 184,00 & 552,00 & 24,00 & 0,00 & 45,33 & GM.0IK & $16: 30$ & 16:45 \\
\hline & & & & & & & & & 180,00 & 540,00 & 21,6 & 0 & & $x$ & & & 184,00 & 552,00 & 24,00 & 0,00 & & & & \\
\hline & & & & & & & & & 180,00 & 540,00 & 64,8 & 0 & & & & & 176,00 & 528,00 & 72,00 & 0,00 & & & & \\
\hline ENSAIO 4 PROGRAMA 13 & 126,76 & 1,462 & 179,38 & 538,14 & 46,5 & 44,89 & $x$ & $x$ & 172,67 & 518,00 & 64,8 & 0 & 44,39 & & 126,9 & 1,48 & 176,00 & 528,00 & 48,00 & 0,00 & 44,67 & GM.SID & $16: 50$ & 17:05 \\
\hline & & & & & & & & & 180,00 & 540,00 & 64,8 & 0 & & $x$ & & & 184,00 & 552,00 & 72,00 & 0,00 & & & & \\
\hline & & & & & & & & & 100,80 & 302,40 & 0 & 0 & & & & & 104,00 & 312,00 & 0,00 & 0,00 & & & & \\
\hline ENSAIO6 - PROGRAMA 14 & 126,84 & 1,126 & 102,7 & 308,1 & 99,1 & 25,63 & $x$ & $x$ & 100,80 & 302,40 & 0 & 0 & 25,20 & & 128,7 & 1,38 & 96,00 & 288,00 & 0,00 & 0,00 & 25,33 & GJ.BAI & 8:10 & $8: 25$ \\
\hline & & & & & & & & & 100,80 & 302,40 & 0 & 0 & & $x$ & & & 104,00 & 312,00 & 0,00 & 0,00 & & & & \\
\hline & & & & & & & & & 86,40 & 259,20 & 0 & 0 & & & & & 88,00 & 264,00 & 24,00 & 0,00 & & & & \\
\hline ENSAIO8 - PROGRAMA 15 & 126,81 & 1,132 & 89,26 & 267,78 & 112,5 & 22,44 & $x$ & $x$ & 93,60 & 280,80 & 0 & 0 & 22,20 & & 125,9 & 1,3 & 88,00 & 264,00 & 0,00 & 0,00 & 22,00 & GJ.DDI & $8: 30$ & $8: 45$ \\
\hline & & & & & & & & & 86,40 & 259,20 & 0 & 0 & & $x$ & & & 88,00 & 264,00 & 0,00 & 0,00 & & & & \\
\hline & & & & & & & & & 108,00 & 324,00 & 0 & 0 & & & & & 104,00 & 312,00 & 0,00 & 0,00 & & & & \\
\hline ENSAI010 - PROGRAMA 16 & 126,84 & 1,292 & 106,64 & 319,92 & 124,5 & 27,28 & $x$ & $x$ & 108,00 & 324,00 & 0 & 0 & 27,00 & & 126,1 & 1,3 & 104,00 & 312,00 & 0,00 & 0,00 & 26,67 & GJ.JEH & $8: 50$ & 9:05 \\
\hline & & & & & & & & & 108,00 & 324,00 & 0 & 0 & & $x$ & & & 112,00 & 336,00 & 0,00 & 0,00 & & & & \\
\hline & & & & & & & & & 194,40 & 583,20 & 0 & 0 & & & & & 184,00 & 552,00 & 0,00 & 0,00 & & & & \\
\hline ENSAIO - PROGRAMA 17 & 126,84 & 1,476 & 187,19 & 561,57 & 2,8 & 47,68 & $x$ & $x$ & 187,20 & 561,60 & 0 & 0 & 47,40 & & 126,6 & 1,54 & 192,00 & 576,00 & 0,00 & 0,00 & 46,67 & GJ.JEH & 9:10 & 9:25 \\
\hline & & & & & & & & & 187,20 & 561,60 & 0 & 0 & & $x$ & & & 184,00 & 552,00 & 0,00 & 0,00 & & & & \\
\hline & & & & & & & & & 187,20 & 561,60 & 0 & 0 & & & & & 184,00 & 552,00 & 0,00 & 0,00 & & & & \\
\hline ENSAIO - PROGRAMA 18 & 126,83 & 1,486 & 188,49 & 565,47 & 1,6 & 47,48 & $x$ & $x$ & 187,20 & 561,60 & 0 & 0 & 46,80 & & 126,9 & 1,46 & 192,00 & 576,00 & 0,00 & 0,00 & 46,67 & GJ.LOT & 9:30 & 9:45 \\
\hline & & & & & & & & & 187,20 & 561,60 & 0 & 0 & & $x$ & & & 184,00 & 552,00 & 0,00 & 0,00 & & & & \\
\hline
\end{tabular}

Tabela 36 - Resultado do ensaio (C) com corrente a 10\% da corrente nominal - 1,5 Ampéres 


\begin{tabular}{|c|c|c|c|c|c|c|c|}
\hline CORRENTE & $1,5 \mathrm{~A}$ & 15A & $25 \mathrm{~A}$ & RTM & RTM & CLASSE & CLASSE \\
\hline WT- $2030 \times$ MEDIDOR (A)CLASSE $1 \%$ & $\operatorname{ERRO}(\%)$ & $\operatorname{ERRO}(\%)$ & ERRO $(\%)$ & ERRO +(\%) & ERRO - $(\%)$ &.$+1(\%)$ & $-1(\%)$ \\
\hline PROGRAMA 10 & $-2,37$ & $-0,53$ & $-0,60$ & 1,60 & $-1,60$ & 1,00 & $-1,00$ \\
\hline PROGRAMA 12 & $-0,95$ & $-0,40$ & $-0,42$ & 1,60 & $-1,60$ & 1,00 & $-1,00$ \\
\hline PROGRAMA 13 & $-0,49$ & $-0,69$ & $-0,54$ & 1,60 & $-1,60$ & 1,00 & $-1,00$ \\
\hline PROGRAMA 14 & $-1,14$ & $-2,48$ & $-0,55$ & 1,60 & $-1,60$ & 1,00 & $-1,00$ \\
\hline PROGRAMA 16 & $-2,25$ & $-0,70$ & $-0,44$ & 1,60 & $-1,60$ & 1,00 & $-1,00$ \\
\hline PROGRAMA 17 & $-2,13$ & 0,08 & $-0,49$ & 1,60 & $-1,60$ & 1,00 & $-1,00$ \\
\hline PROGRAMA 18 & $-1,71$ & $-0,64$ & $-0,49$ & 1,60 & $-1,60$ & 1,00 & $-1,00$ \\
\hline CORRENTE & $1,5 \mathrm{~A}$ & $15 \mathrm{~A}$ & $25 \mathrm{~A}$ & RTM & RTM & CLASSE $+0,5 \%$ & CLASSE - $0,5 \%$ \\
\hline WT2030 $\times$ MEDIDOR (A)CLASSE 0,5\% & $\operatorname{ERRO}(\%)$ & $\operatorname{ERRO}(\%)$ & $\operatorname{ERRO}(\%)$ & ERRO $+(\%)$ & ERRO - $(\%)$ & $\mathrm{ERRO}+(\%)$ & ERRO - $(\%)$ \\
\hline PROGRAMA 14 & 0,00 & $-0,34$ & $-0,37$ & 0,60 & $-0,60$ & 0,50 & $-0,50$ \\
\hline PROGRAMA 15 & $-1,07$ & $-0,23$ & $-0,15$ & 0,60 & $-0,60$ & 0,50 & $-0,50$ \\
\hline PROGRAMA 16 & $-1,03$ & 0,01 & $-0,12$ & 0,60 & $-0,60$ & 0,50 & $-0,50$ \\
\hline PROGRAMA 17 & $-0,59$ & $-0,49$ & $-0,16$ & 0,60 & $-0,60$ & 0,50 & $-0,50$ \\
\hline PROGRAMA 18 & $-1,43$ & $-0,50$ & $-0,52$ & 0,60 & $-0,60$ & 0,50 & $-0,50$ \\
\hline
\end{tabular}

Tabela 37 - Erros apresentados nos medidores submetidos a ondas de tensão e corrente não senoidais 


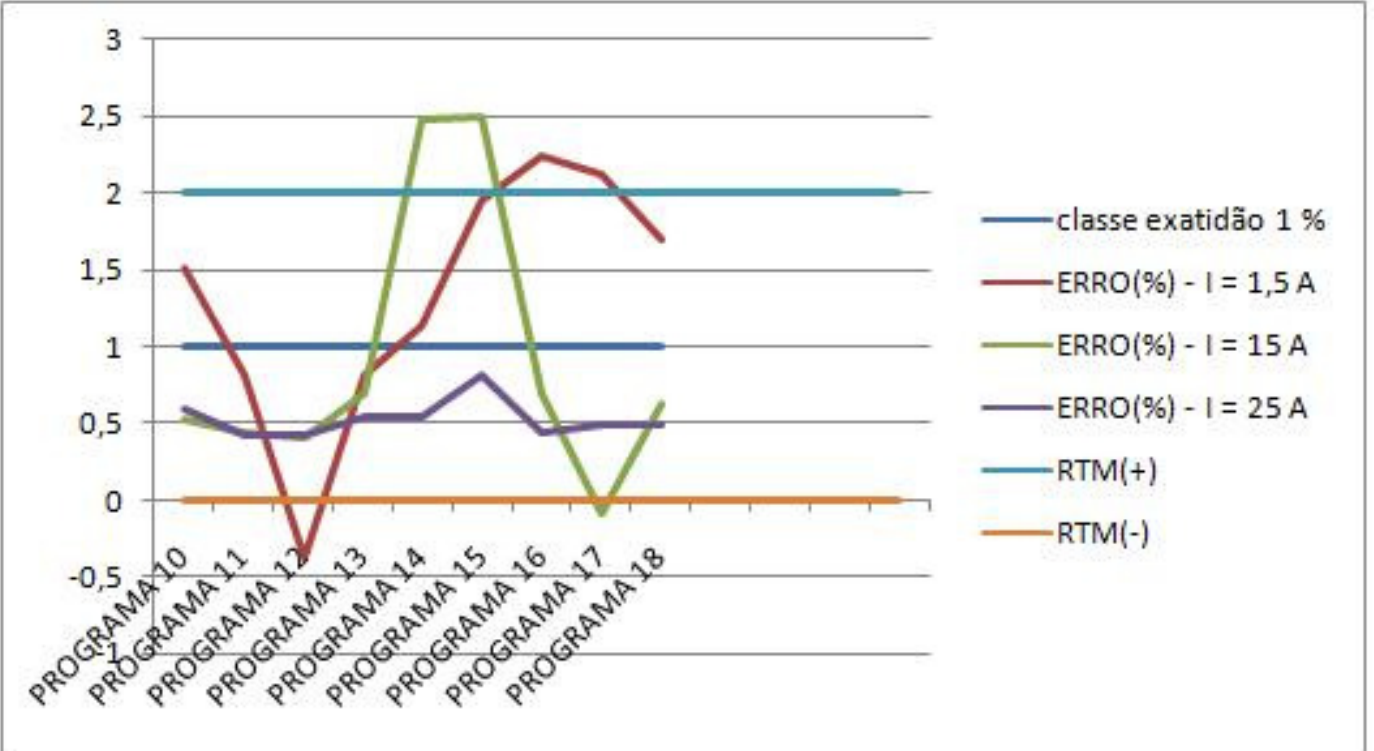

Gráfico 3 - Comportamento do medidor (A) comparado ao WT-2030

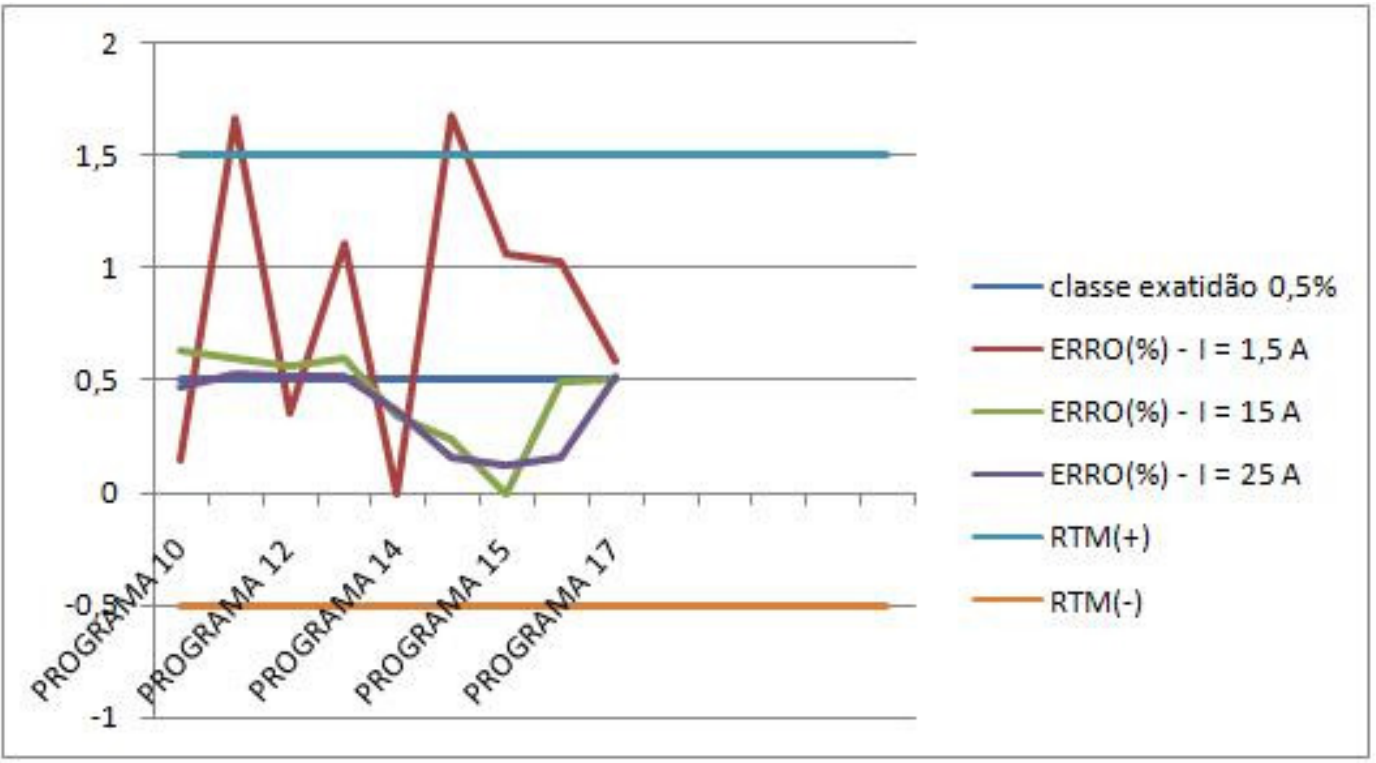

Gráfico 4 - Comportamento do medidor (B) comparado ao WT-2030 


\section{CAPÍTULO 4 - CONSIDERAÇÕES FINAIS}

Este estudo foi realizado nos laboratórios da Eletropaulo, do Instituto de Eletrotécnica e Energia da Universidade de São Paulo, e no Laboratório do Centro de Estudos em Regulação e Qualidade de Energia (Enerq), USP. Participaram das análises dos resultados pesquisadores da Universidade Estadual Paulista (Unesp), Campus Bauru, além de profissionais dos laboratórios anteriormente citados.

Utilizaram-se medidores de dois fabricantes com área fabril instalada no Brasil, ambos os medidores atendem às especificações de normas ABNT e Inmetro.

Este estudo faz parte de um projeto maior de Pesquisa e Desenvolvimento aprovado pela Aneel. Tal projeto foi apresentado pela concessionária de distribuição de energia AES Eletropaulo e pela Unesp - Bauru, com o título de "Projeto de um Dispositivo para Caracterização de Harmônicas nas Medições de Faturamento Ciclo 2006/2007- P\&D”.

O referido trabalho originou-se das seguintes necessidades:

a) busca da confiabilidade do medidor de energia em situações não senoidais;

b) busca do aumento de qualidade no faturamento de energia elétrica, com foco na medição mais justa e melhor relacionamento entre concessionária e consumidor;

c) busca de equipamentos de medição eletrônica confiáveis para a substituição do parque de medidores eletromecânicos.

As condições de ensaio foram estabelecidas no Capítulo 3, distribuídas em condições senoidais padrão $(60 \mathrm{~Hz})$, grandezas de influência normatizadas (freqüência e forma de onda), condições não senoidais ou distorcidas, em situações reais de cargas. Nestas circunstâncias, as correntes distorcidas chegam a ultrapassar os limites estabelecidos em norma para a fabricação dos medidores.

As principais conclusões que podem ser extraídas dos resultados do experimento em questão são:

- Os ensaios normatizados para a verificação e/ou calibração da função VArh dos medidores de energia não são os mais adequados, por se tratar de instrumentos que operam em unidades consumidoras, com FP próximo do unitário. 
Trata-se de uma condição de operação na qual alguns medidores apresentam desempenho pior do que outros;

- O presente estudo constatou que os instrumentos ensaiados em condições normatizadas, quando parametrizados para não considerar a potência de distorção no cálculo de reativo, atendem à freqüência de $60 \mathrm{~Hz}$, dentro dos parâmetros de exatidão. Esses dados são válidos tanto para as funções de VArh quanto Wh.

- A medição da potência ativa de todos os componentes harmônicos é aceita quando é realizada com potência útil;

- Os medidores eletrônicos sob testes não tiveram desempenho tão bom quanto se esperava, quando operando sob condições não senoidais, especialmente na função VArh. Nessas circunstâncias, chegaram a ter erros de medição adicionais superiores a 1,5\% do que normalmente é estabelecido em norma para a classe de exatidão a qual foi especificado.

A Tabela 37 identifica os erros apresentados nos medidores submetidos a ondas de tensão e corrente não senoidais. O Gráfico 3 demonstra o comportamento do medidor do fabricante $A$, que possui classe de exatidão de 1\%. O Gráfico 4 indica o comportamento do medidor do fabricante $\mathrm{B}$, que possui classe de exatidão de 0,5\%. Ambos os gráficos são comparados ao padrão WT-2030, da Yokogawa. 
As Tabelas 38, 39 e 40 demonstram os erros decorrentes das condições de tensão e corrente não senoidais. O processo foi executado com medidores testados em laboratório, comparados à faixa de erro estabelecida pelo Regulamento Técnico Metrológico (RTM).

\begin{tabular}{|c|c|c|}
\hline CORRENTE & $1,5 \mathrm{~A}$ & mínimo até máximo - RTM \\
\hline WT-2030 x MEDIDOR (A)CLASSE $1 \%$ & ERRO(\%) & $\begin{array}{c}\text { ERRO(\%) } \\
\end{array}$ \\
\hline PROGRAMA 10 & $-2,37$ & $(-1,60$ a 1,60$)$ \\
\hline PROGRAMA 11 & $-1,98$ & $(-1,60$ a 1,60$)$ \\
\hline PROGRAMA 12 & $-0,95$ & $(-1,60$ a 1,60$)$ \\
\hline PROGRAMA 13 & $-0,49$ & $(-1,60$ a 1,60$)$ \\
\hline PROGRAMA 14 & $-1,14$ & $(-1,60$ a 1,60$)$ \\
\hline PROGRAMA 14 & $-1,16$ & $(-1,60$ a 1,60$)$ \\
\hline PROGRAMA 15 & $-1,96$ & $(-1,60$ a 1,60$)$ \\
\hline PROGRAMA 16 & $-2,25$ & $(-1,60$ a 1,60$)$ \\
\hline PROGRAMA 17 & $-2,13$ & $(-1,60$ a 1,60$)$ \\
\hline PROGRAMA 18 & $-1,71$ & $(-1,60$ a 1,60$)$ \\
\hline CORRENTE & $1,5 \mathrm{~A}$ & mínimo até máximo-RTM \\
\hline WT2030 x MEDIDOR (A)CLASSE 0,5\% & ERRO(\%) & ERRO(\%) \\
\hline PROGRAMA 10 & $-0,34$ & $(-0,60$ a 0,60$)$ \\
\hline PROGRAMA 11 & 0,00 & $(-0,60$ a 0,60$)$ \\
\hline PROGRAMA 12 & 0,00 & $(-0,60$ a 0,60$)$ \\
\hline PROGRAMA 13 & 0,00 & $(-0,60$ a 0,60$)$ \\
\hline PROGRAMA 14 & 0,00 & $(-0,60$ a 0,60$)$ \\
\hline PROGRAMA 15 & $-1,07$ & $(-0,60$ a 0,60$)$ \\
\hline PROGRAMA 16 & $-1,03$ & $(-0,60$ a 0,60$)$ \\
\hline PROGRAMA 17 & $-0,59$ & $(-0,60$ a 0,60$)$ \\
\hline PROGRAMA 18 & $-1,43$ & $(-0,60$ a 0,60$)$ \\
\hline
\end{tabular}

Tabela 38 - Comparativo dos erros apresentados para faixa de corrente de 1,5 ampéres

Os ensaios foram realizados em uma seqüência de cargas não senoidais de programa, denominadas "Programa (x)".

No ensaio do Programa 10, consideraram-se as medições realizadas em um prédio comercial: o medidor apresentava classe de exatidão de 1\%, e o desvio em corrente era de 1,5 ampéres, conforme indica a Tabela 36. O desvio chegou à ordem de $0,77 \%$, superior ao mínimo estabelecido, o que não ocorreu para as correntes de 15 ampéres Tabela 34 e 25 ampéres Tabela 35. Tais índices denotam que, para medidores submetidos à tensão não senoidal, com distorção de $4,13 \%$ e com 
corrente não senoidal de distorção $21,96 \%$, o maior erro concentra-se nas pequenas cargas instaladas nos consumidores com esse nível de distorção no sistema.

\begin{tabular}{|c|c|c|}
\hline CORRENTE & 15A & mínimo até máximo - RTM \\
\hline WT-2030 M MEDIDOR (A)CLASSE 1\% & ERRO(\%) & ERRO(\%) \\
\hline PROGRAMA 10 & $-0,53$ & $(-1,60$ a 1,60$)$ \\
\hline PROGRAMA 11 & $-0,44$ & $(-1,60$ a 1,60$)$ \\
\hline PROGRAMA 12 & $-0,40$ & $(-1,60$ a 1,60$)$ \\
\hline PROGRAMA 13 & $-0,69$ & $(-1,60$ a 1,60$)$ \\
\hline PROGRAMA 14 & $-2,48$ & $(-1,60$ a 1,60$)$ \\
\hline PROGRAMA 15 & $-2,49$ & $(-1,60$ a 1,60$)$ \\
\hline PROGRAMA 16 & $-0,70$ & $(-1,60$ a 1,60$)$ \\
\hline PROGRAMA 17 & 0,08 & $(-1,60$ a 1,60$)$ \\
\hline PROGRAMA 18 & $-0,64$ & $(-1,60$ a 1,60$)$ \\
\hline CORRENTE & $\mathbf{1 5 A}$ & mínimo até máximo- RTM \\
\hline PROGRAMA 10 & ERRO(\%) & ERRO(\%) \\
\hline PROGRAMA 11 & $-0,63$ & $(-0,60$ a 0,60$)$ \\
\hline PROGRAMA 12 & $-0,59$ & $(-0,60$ a 0,60$)$ \\
\hline PROGRAMA 13 & $-0,56$ & $(-0,60$ a 0,60$)$ \\
\hline PROGRAMA 14 & $-0,59$ & $(-0,60$ a 0,60$)$ \\
\hline PROGRAMA 15 & $-0,34$ & $(-0,60$ a 0,60$)$ \\
\hline PROGRAMA 16 & $-0,23$ & $(-0,60$ a 0,60$)$ \\
\hline PROGRAMA 17 & 0,01 & $(-0,60$ a 0,60$)$ \\
\hline PROGRAMA 18 & $-0,49$ & $(-0,60$ a 0,60$)$ \\
\hline & $-0,50$ & $(-0,60$ a 0,60$)$ \\
\hline
\end{tabular}

Tabela 39 - Comparativo dos erros apresentados para faixa de corrente de 15 ampéres

O ensaio do Programa 11 considerou as medições realizadas em um prédio comercial: o medidor apresentava classe de exatidão de 1\%, o desvio em corrente era de 1,5 ampéres, como expõe a Tabela 36. O processo chegou à ordem de 0,38\%, superior ao mínimo estabelecido, o que não ocorreu para as correntes de 15 ampéres Tabela 34 e 25 ampéres Tabela 35. Tais dados revelam que, para medidores submetidos à tensão não senoidal, com distorção de 4,66\% e com corrente não senoidal de $35,01 \%$, o maior erro concentra-se nas pequenas cargas instaladas nos consumidores com esse nível de distorção no sistema.

O ensaio do Programa 12 considerou as mesmas condições, com os seguintes índices: o medidor possuía classe de exatidão de $1 \%$, e o desvio em 
corrente era de 1,5 ampéres Tabela 36 . O desvio chegou à ordem de $0,65 \%$ superior ao mínimo estabelecido, o que não ocorreu para as correntes de 15 ampéres Tabela 34 e 25 ampéres Tabela 35. Esses dados indicam que, para medidores submetidos à tensão não senoidal, com distorção de $4,51 \%$ e corrente não senoidal de distorção $18,32 \%$, o maior erro concentra-se nas pequenas cargas.

\begin{tabular}{|c|c|c|}
\hline CORRENTE & 25A & mínimo até máximo-RTM \\
\hline WT-2030 $\times$ MEDIDOR (A)CLASSE 1\% & ERRO(\%) & ERRO $(\%)$ \\
\hline PROGRAMA 10 & $-0,60$ & $(-1,60$ a 1,60$)$ \\
\hline PROGRAMA 11 & $-0,42$ & $(-1,60$ a 1,60$)$ \\
\hline PROGRAMA 12 & $-0,42$ & $(-1,60$ a 1,60$)$ \\
\hline PROGRAMA 13 & $-0,54$ & $(-1,60$ a 1,60$)$ \\
\hline PROGRAMA 14 & $-0,55$ & $(-1,60$ a 1,60$)$ \\
\hline PROGRAMA 15 & $-0,82$ & $(-1,60$ a 1,60$)$ \\
\hline PROGRAMA 16 & $-0,44$ & $(-1,60$ a 1,60$)$ \\
\hline PROGRAMA 17 & $-0,49$ & $(-1,60$ a 1,60$)$ \\
\hline PROGRAMA 18 & $-0,49$ & $(-1,60$ a 1,60$)$ \\
\hline CORRENTE & $25 A$ & mínimo até máximo- RTM \\
\hline MEDIDOR (A)CLASSE 0,5\% & ERRO(\%) & ERRO(\%) \\
\hline PROGRAMA 10 & $-0,47$ & $(-0,60$ a 0,60$)$ \\
\hline PROGRAMA 11 & $-0,53$ & $(-0,60$ a 0,60$)$ \\
\hline PROGRAMA 12 & $-0,51$ & $(-0,60$ a 0,60$)$ \\
\hline PROGRAMA 13 & $-0,52$ & $(-0,60$ a 0,60$)$ \\
\hline PROGRAMA 14 & $-0,37$ & $(-0,60$ a 0,60$)$ \\
\hline PROGRAMA 16 & $-0,15$ & $(-0,60$ a 0,60$)$ \\
\hline PROGRAMA 17 & $-0,12$ & $(-0,60$ a 0,60$)$ \\
\hline PROGRAMA 18 & $-0,16$ & $(-0,60$ a 0,60$)$ \\
\hline
\end{tabular}

Tabela 40 - Comparativo dos erros apresentados para faixa de corrente de 25 ampéres 
O Programa 13 considerou o medidor com classe de exatidão de $1 \%$. Os dados de medições realizadas em uma residência continham cargas que provocavam distorções de tensão da ordem de 4,38\% e, de corrente, em torno de $22,29 \%$. Para este nível de distorção, os testes com a corrente nominal do medidor, ou seja, 15 ampéres Tabela 34, tiveram o maior desvio: chegaram a 1,11\% superior ao desvio mínimo estabelecido no regulamento técnico metrológico. Para as demais correntes, o comportamento foi dentro do especificado no RTM.

Os ensaios realizados com o programa 14 consideraram o cálculo de uma onda teórica com distorção de tensão na ordem de $7,14 \%$ e com distorção de corrente na ordem de $111,15 \%$. Nessa condição de distorção para a corrente nominal Tabela 35, o desvio chegou a ser $0,88 \%$ superior ao desvio mínimo estabelecido no regulamento técnico metrológico. Para as demais correntes, o comportamento foi dentro do especificado no RTM.

Os ensaios realizados no programa 15, para o medidor de classe $1 \%$, consideraram uma onda teórica com a onda de tensão defasada de 180․ Esses dados foram comparados em relação à corrente, para uma distorção de tensão de $7,14 \%$ e, de corrente, de $111,15 \%$. O comportamento do medidor, tanto para a corrente nominal Tabela 34 quanto para a corrente mínima Tabela 36, teve distorções de 0,36\% e 0,89\%, consecutivamente. Ambas apresentaram-se superiores ao desvio mínimo estabelecido no regulamento técnico metrológico. Para as demais correntes, o comportamento manteve-se dentro do que é especificado pelo RTM.

O ensaio 16 considerou o medidor de classe 1\%, em uma onda teórica de harmônicos pares e impares, com ângulo de $180^{\circ}$ da onda de tensão em relação à onda de corrente. A distorção harmônica oscilava em 8,09\% para tensão e 113,93\% para corrente. O desvio encontrado para a corrente nominal Tabela 34 foi $0,65 \%$ superior ao desvio mínimo especificado pelo RTM. No ensaio do programa 17, foram consideradas ondas teóricas com espectros harmônicos iguais para tensão e corrente, em ângulos de 180ำ ou 0ํㅡ, e com distorções de 27,95\%. O desvio para a corrente de 1,5 ampéres Tabela 36 foi de 0,53\% superior ao mínimo especificado no RTM. Para as correntes nominal e máxima, os parâmetros ficaram dentro do estabelecido. 
O ensaio realizado no programa 18 considerou uma onda teórica com espectros de harmônicos iguais a zero, tanto para tensão como para a corrente, ou seja, uma forma de onda de tensão e corrente fundamental. Nesta condição, o desvio para a corrente mínima Tabela 36 foi de $0,11 \%$ superior à distorção mínima permitida para o medidor de classe de exatidão de $1 \%$.

Nos ensaios realizados com o medidor de classe de exatidão de 0,5\%, 0 comportamento do medidor foi mais compatível com a norma. Apresentou desvios, para a corrente mínima, de 1,5 ampéres Tabela 36 e na faixa de 0,47\% do valor mínimo especificado no RTM. Tais informações evidenciam que, quanto melhor a classe de exatidão do medidor, menor será a tendência do desvio. Assim, conservam-se os desvios sempre para o valor negativo, causando impacto para o fornecedor de energia, quando o nível de distorção é superior ao padrão estabelecido no RTM.

Avaliando esses resultados, considera-se que os valores estabelecidos em norma não são suficientes para garantir a exatidão do medidor em condições de ondas de tensão e corrente não senoidais, encontradas no sistema elétrico. Portanto, é necessário rever os parâmetros para os ensaios.

É muito importante, com base nos medidores testados, realizar a escolha certa para a utilização dos instrumentos nos sistemas de medição.

A dúvida que as concessionárias têm quanto ao desempenho dos medidores eletrônicos pode ser esclarecida pelo fato de esses equipamentos atenderem às normas vigentes. Quando os medidores são colocados em condições de distorção não previstas em norma, suas especificações podem adotar limites aceitáveis de erros na exatidão. Neste caso, é necessário adequar o tipo de medidor para o que realmente se deseja medir.

Os resultados encontrados e discutidos no contexto acima revelam que os sistemas de medição eletrônicos vêm se apresentando como a melhor alternativa para os propósitos de medição. Compreende-se, no entanto, que os parâmetros estabelecidos por norma necessitam de revisões para garantir a exatidão dos medidores submetidos a ondas de tensão e corrente não senoidais.

Entendemos que este assunto não foi esgotado neste trabalho e que o mesmo servirá como base para outras pesquisas referente a comportamento de harmônicas em medidores de energia e parâmetros para normas técnicas. 
Para os medidores eletromecânicos tem-se que:

- Pesquisas anteriores de um medidor eletromecânico [70], indicam que tal equipamento mede, com erro, a menor do que a classe de exatidão estabelecida, para os ângulos de potência harmônica no sentido direto (potência consumida), e a maior do que a classe de exatidão estabelecida, nos casos de fluxo de potência harmônica no sentido reverso (potência gerada).

- Os medidores eletromecânicos de energia ativa (Wh), de acordo com estudos anteriores [70], revelam resultados de medição dentro dos limites admissíveis para as condições normatizadas em $(60 \mathrm{~Hz})$; 


\section{ANEXOS}

A NEXO 1 - Análise geral da presença de harmônicas no sistema elétrico

\subsection{Harmônicas de tensão e corrente no sistema elétrico}

Segundo [1] a presença de harmônicas de corrente em sistemas de alimentação industrial e residencial é inevitável. As características construtivas dos equipamentos e seu modo de funcionamento têm provocado distorções na forma de onda, tanto em tensão como de corrente.

Cargas elétricas - como conversores estáticos e equipamentos com elemento saturado, encontrados, sobretudo, em parques siderúrgicos - são consideradas as "vilãs" no sistema elétrico industrial. Destinadas ao acionamento de máquinas e a unidades de alimentação ininterruptas de energia - UPS -, são, de longe, as que mais contribuem para a ocorrência de distorção harmônica nos sistemas de alimentação de plantas industriais. Já as lâmpadas fluorescentes, LFC, televisores, entre outras, são os grandes poluidores nas parcelas residencial e comercial.

Os efeitos da presença de harmônicas são sentidos por todos os equipamentos conectados ao sistema. Mesmo sendo geradores de harmônicas (como os conversores estáticos), eles sofrem com a distorção na tensão. Esses efeitos são sentidos também por aparelhos coligados aos notches.

De modo geral, é possível descrever alguns dos efeitos nos equipamentos mais usuais. Serão apresentados, a seguir, os tópicos considerados mais importantes, referentes aos efeitos provocados em alguns equipamentos. Posteriormente, será feita uma análise mais aprofundada sobre os efeitos em medidores de energia elétrica.

Motores: aumento de temperatura, diminuição da vida útil, diminuição do rendimento, aumento de ruídos, danificação de mancais devido a batimentos e torque.

Transformadores: aumento da temperatura, aumento das perdas no ferro e no cobre, diminuição da vida útil.

Efeito nos condutores: aumento da perda Joule. 
Acionamentos/UPS: anomalia de operação, usualmente, causada por múltiplas passagens em zero das tensões e correntes, falhas nos circuitos de comutação.

Fusíveis/disjuntores/chaves seccionadoras: atuação indevida.

Capacitores: aumento de temperatura, aumento de perdas, diminuição da vida útil; sobretensões e ressonância podem causar a ruptura do dielétrico.

É preciso, contudo, salientar que, na presença de elevado conteúdo de harmônica, as perdas são maiores em todos os dispositivos (circulação de energia reativa). As paradas por falha de operação são mais frequentes, e a identificação do defeito passa a ser mais uma arte do que uma ciência.

\subsection{Efeito das harmônicas nos equipamentos elétricos}

\subsubsection{Efeito nos motores e geradores}

O principal efeito das harmônicas em máquinas elétricas de corrente alternada é o aumento da temperatura de operação, devido ao aumento das perdas no ferro e no cobre. Em conseqüência, o rendimento da máquina diminui. As componentes harmônicas afetam o torque da máquina, podendo gerar um ruído audível. Ainda que a contribuição para o torque médio seja pequena, podem ocorrer batimentos de torque. Também é possível que haja excitação de ressonâncias mecânicas da máquina, pela criação de oscilações mecânicas.

Como conseqüência direta desta elevação de temperatura verifica-se a redução da expectativa de vida útil dos motores, visto que o material isolante sofre uma deterioração mais acentuada com a presença de elevadas temperaturas nos enrolamentos.

Outro fato gerado por esse processo refere-se à proporção entre distorção e torque, indicado no Gráfico 5, quanto maior o valor da distorção harmônica de tensão, maior será a redução do torque do motor. 


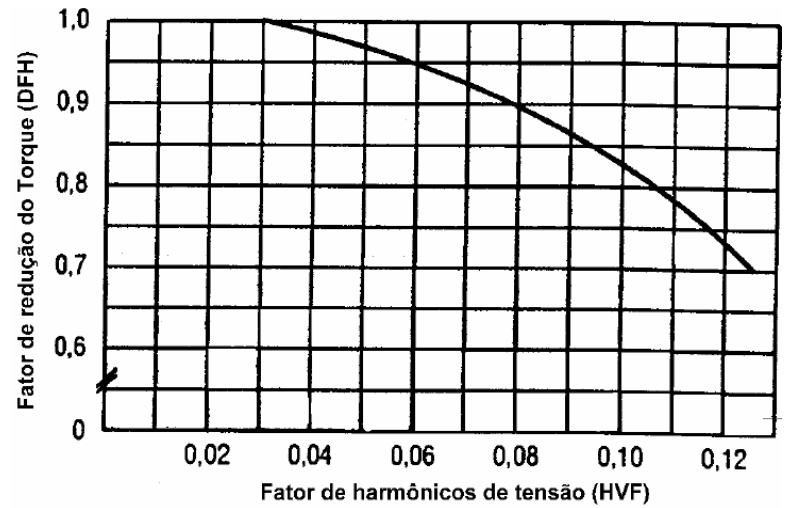

Gráfico 5 - Relação entre distorção de harmônicas e torque do motor elétrico- Fonte:

SAIDEL, M.A. (2007)

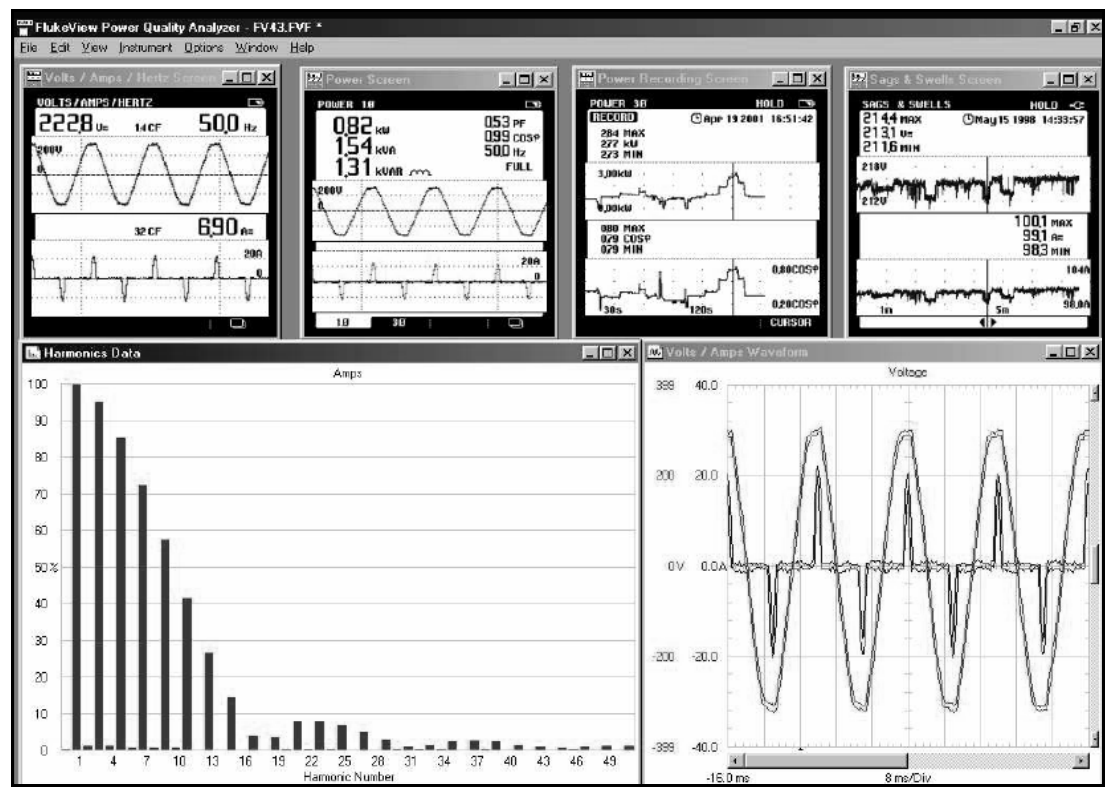

Gráfico 6 - Medição com medidor FLUKE 43B de distorções harmônicas em motores - Fonte: SAIDEL, M.A. (2007)

De acordo com alguns pesquisadores [2]: "em máquinas girantes os pares de

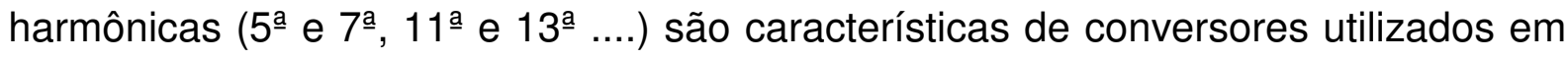
acionamento de motores elétricos apresentam sequências opostas, introduzindo no rotor correntes na frequência da harmônica intermediária $\left(6^{\underline{a}}, 12^{\underline{a}}, \ldots\right)$ ". Harmônicas de sequência positiva induzem correntes cuja frequência é a diferença entre a 
frequência da harmônica considerada e a frequência do campo girante fundamental do rotor. Isso acontece porque os campos girantes da harmônica e da fundamental do rotor giram no mesmo sentido.

Para as harmônicas de sequência negativa, a frequência resultante é a soma entre a frequência da harmônica considerada e a frequência do campo girante fundamental do rotor, pois os campos girantes da harmônica e da fundamental do rotor giram em sentido oposto. Para conversores de 6 pulsos, a $5^{\underline{a}}$ harmônica é de sequência negativa e a $7^{\underline{a}}$ é de sequência positiva; a $11^{\underline{a}}$ harmônica é de sequência negativa, a $13^{\text {a }}$ é de sequência positiva e assim por diante. No Gráfico 4 podemos observar algumas dessas harmônicas.

\subsubsection{Efeito nos transformadores}

As harmônicas são responsáveis pelo aumento da temperatura dos transformadores, podendo também resultar em geração de ruído audível.

Efeitos como perda no cobre e perdas devido ao fluxo de dispersão são decorrentes de harmônicas de corrente. Já as harmônicas de tensão causam o aumento das perdas no ferro por histereses.

As correntes harmônicas circulam nos transformadores, provocando um aumento das perdas nas bobinas, pelo efeito Joule, além de perdas no ferro, pelas correntes de Foucault.

Em transformadores ligados em delta, as harmônicas múltiplas impares de 3 que circulam nos enrolamentos podem levar à sobrecarga destes enrolamentos, caso a presença dessas harmônicas seja ignorada.

Também se tem notado um aumento nas perdas. Harmônicas na tensão aumentam as perdas no ferro, enquanto harmônicas na corrente elevam as perdas no cobre. A elevação das perdas no cobre deve-se principalmente ao efeito pelicular, que implica numa redução da área efetivamente condutora, à medida que se eleva a freqüência da corrente.

Conceitualmente, podemos considerar que a perda nas bobinas tem a sua variação, sendo o quadrado da distorção harmônica total THD, para as correntes. Adicionalmente, as perdas no núcleo são lineares, em função da THD em tensão. 


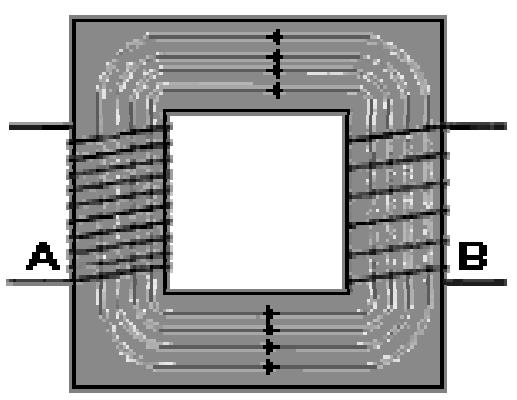

Figura 14 Fluxo magnético em um transformador - Fonte: MORAES, C.C. (1978)

Segundo [2], muitos transformadores possuem resposta de frequência limitada. Estas afirmações também podem ser aplicadas à tensão e à corrente.

A perda depende da carga e possui duas componentes:

$$
P_{L L}=I^{2} R+P_{E C} \quad \text { Equação } 56
$$

Onde $P_{E C}$ é a perda causada pela corrente parasita, provocada pelo fluxo magnético Figura 14. 


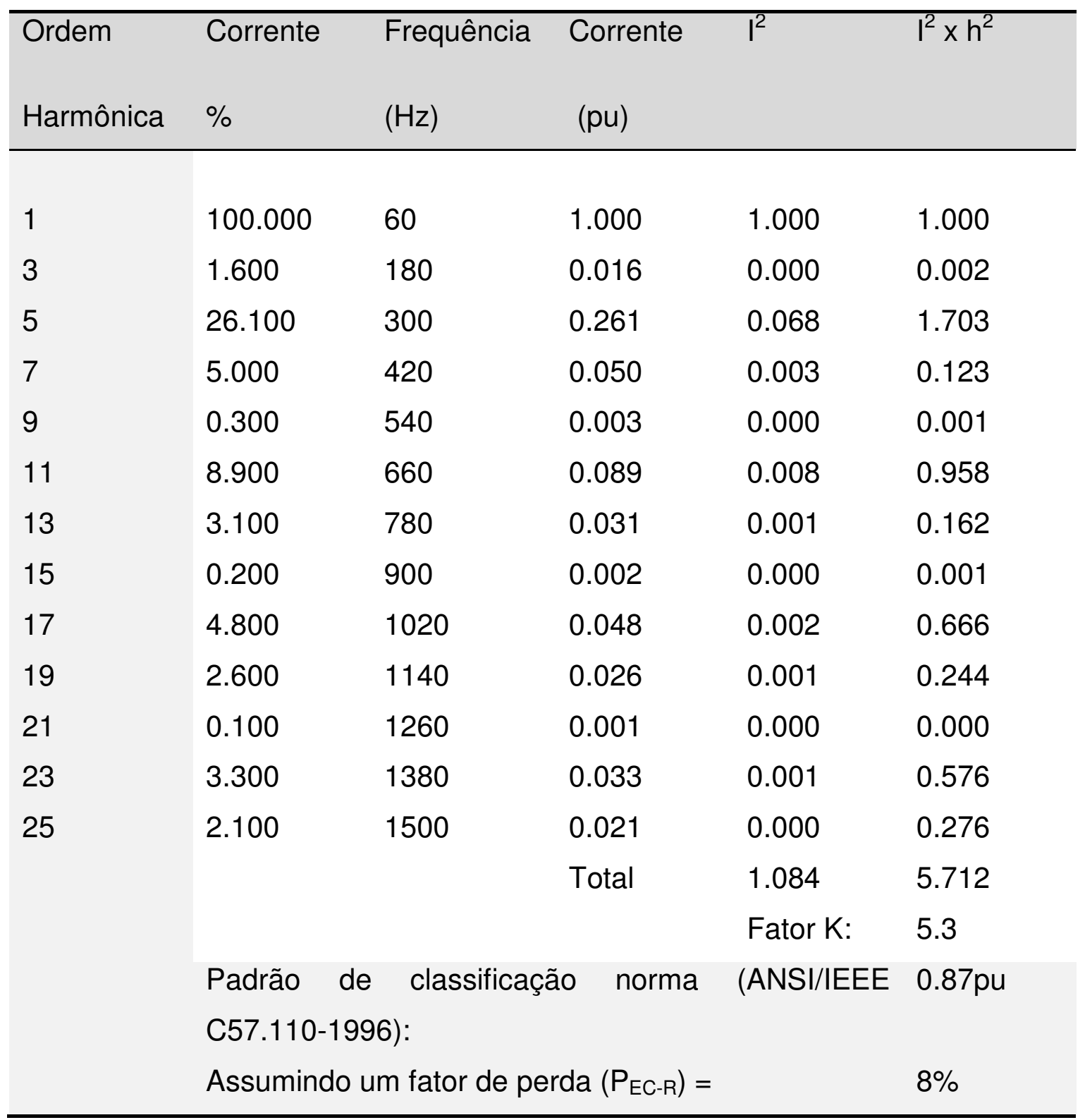

Tabela 41 - Distribuição da corrente harmônica no transformador - Fonte: MORAES, C.C. (1978)

A perda relativa à corrente parasita é proporcional à corrente e à frequência: 


$$
P_{E C}=K_{E C} \times I^{2} \times h^{2} \quad \text { Equação } 57
$$

Onde $\mathrm{K}_{\mathrm{EC}}=$ constante de proporcionalidade. A perda a plena carga em $p u$, sob condições de correntes harmônicas, é:

$$
P_{L L}=\sum I_{h}^{2}+\left(\sum I_{h}^{2} \times h^{2}\right) P_{E C-R} \quad \text { Equação } 58
$$

Onde $\mathrm{P}_{\mathrm{EC}-\mathrm{R}}$ é o fator de corrente parasita sob condições normais.

O fator $^{2} \quad \mathrm{~K}$ difundido em literaturas de Power Quality é definido exclusivamente em termos de correntes harmônicas:

$$
K=\frac{\Sigma\left(L_{h}^{\Sigma} x h^{2}\right)}{\sum I_{h}^{n}} \quad \text { Equação } 59
$$

Em termos de fator $\mathrm{K}$, o valor rms da corrente distorcida em pu é obtido de:

$$
\sqrt{\sum I_{h}^{2}}=\sqrt{\frac{1+P_{E C-R}}{1+R \cdot P_{E C-R}}}(\text { pu }) \quad \text { Equação } 60
$$

Onde:

$$
\begin{aligned}
& \mathrm{P}_{\mathbf{E} C-\mathbb{R}}=\text { corrente parasita (foucault) } \\
& \mathrm{h}=\text { número da harmônica } \\
& \mathrm{I}_{\mathrm{h}}=\text { harmônica de corrente }
\end{aligned}
$$

Essa equação revela a redução de corrente e da capacidade do transformador, devido à presença de correntes harmônicas. 
Tendo também k como:

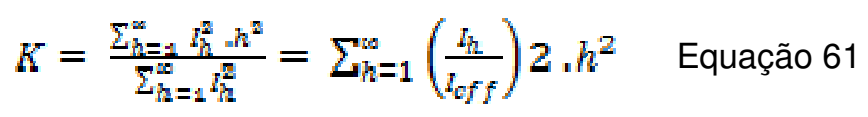

\subsubsection{Efeito nos condutores}

De modo geral, na presença de harmônicas, a resistência em corrente alternada RCA, nos condutores, aumenta, elevando também as perdas Joule ( $P=$ RCA $x$ lef 2). Com a ocorrência de ressonância, os condutores podem ficar submetidos a grandes esforços de tensão e efeito corona, que podem levar a falhas no isolamento.

Cabos e condutores, submetidos a níveis de distorções harmônicas "ordinárias", têm sua temperatura aumentada, devido à circulação de reativos de distorção e em função da frequência, com efeitos peculiares e de proximidade.

O efeito causado em condutores neutro, de sistemas trifásicos, direciona-se a cargas lineares equilibradas. Nessas cargas, normalmente, é empregado condutor de bitola inferior em relação ao condutor de linha, pois as correntes de linha, estando defasadas de $120^{\circ}$, cancelam-se no neutro.

Para o caso de cargas não-lineares, ou seja, quando a corrente absorvida não tem a mesma forma de tensão que a alimenta, mesmo que equilibradas, a corrente de neutro pode atingir tipicamente o valor de 1.57 vezes a corrente de fase. As harmônicas de ordem 3 e suas múltiplas ímpares das três fases são componentes de sequência zero, estando em fase entre si. Esse processo resulta na soma do condutor de neutro em instalações, contendo cargas não-lineares, mesmo que sejam cargas trifásicas equilibradas.

As cargas não lineares adotam a eletrônica de potência, a qual é cada vez mais utilizada, contribuindo para um acréscimo do consumo de energia em equipamentos como: máquinas de solda, inversores de frequência para motores, computadores, máquinas copiadoras, fax, televisores, fornos de microondas, iluminação neon, entre outros. Esses são apenas alguns exemplos de cargas que imputam efeitos de distorção harmônica dos circuitos de distribuição.

A tensão harmônica é causada pela circulação da corrente harmônica nas impedâncias dos circuitos de alimentação. Esta impedância aumenta em função da 
frequência da corrente. Podemos afirmar que, a cada corrente harmônica de ordem h, corresponde uma impedância de circuito de potência.

Aplicando-se a Lei de $\mathrm{Ohm}^{11}$ em um circuito de alimentação, a corrente harmônica de ordem h gera uma tensão harmônica em função da impedância ao longo deste circuito. Em um determinado ponto, a tensão passa a ser deformada, e todo o equipamento, alimentado a partir deste ponto, receberá uma tensão perturbada.

Podemos considerar que a circulação das correntes harmônicas nas redes é retro-alimentada por cargas não-lineares. Essas correntes deterioram a qualidade de energia, sendo a origem de numerosos prejuízos.

\subsubsection{Efeito em acionamentos/UPS}

Fontes de Alimentação em Sistemas de Energia Ininterruptos e acionamentos de dispositivos eletroeletrônicos com processadores têm, cada vez mais, seu funcionamento prejudicado por cargas não lineares no sistema de potência. As evoluções dos semicondutores vêm proporcionando uma revolução na indústria eletrônica. Assim, existe uma grande tendência de que continue evoluindo. Entre esses dispositivos, incluem-se acionadores de velocidade de motores, fontes eletrônicas, carregadores de bateria, retificadores, inversor, entre outros.

Os modelos fabricados com tecnologia mais antiga faziam uso de transformadores para reduzir a tensão e levá-la aos barramentos dos circuitos internos nos equipamentos, e a indutância destes transformadores era benéfica para os circuitos de potência.

É possível que o efeito resultante da redução da tensão pelos chaveamentos alcance um bom resultado. Contudo, durante a comutação, ele também pode provocar distorções, prejudicando o funcionamento de diversos sistemas.

\subsubsection{Efeito em fusíveis/disjuntores/chaves seccionadoras}

A presença de harmônicas causa o aumento da temperatura de trabalho e das perdas nos dispositivos de proteção em todos os equipamentos, reduzindo a

\footnotetext{
${ }^{11}$ Georg Simon Ohm - Nasceu em 16 de Março de 1789 e faleceu em 6 de Julho de 1854 foi um físico e matemático alemão. Entre 1825 e 1827, Ohm desenvolveu a primeira teoria matemática da condução eléctrica nos circuitos, baseando-se no estudo da condução do calor de Fourier.
} 
capacidade da corrente nominal, que é fundamental em regime permanente. Tal situação pode reduzir a vida útil destes equipamentos.

Podemos dizer que as operações dos dispositivos de proteção, na presença de distorção harmônica, prejudicam sua atuação como:

A velocidade de atuação dos relés de proteção fica reduzida e/ou com valores de atuação mais elevados do que em uma atuação mais rápida ou ajustes para valores de proteção menores;

Em casos em que a THD fica na faixa de $5 \%$, a mudança das operações de relês não é muito relevante;

Dependendo do conteúdo de harmônicas, os torques de atuação dos dispositivos de proteção podem aparecer em sentido contrário ao da atuação normal;

Em geral, as harmônicas podem causar problemas de operação em dispositivos de proteção como relés. Isso acontece quando o THD for superior à faixa de $10 \%$ a $20 \%$, dependendo do fabricante e do modelo dos relés.

\subsubsection{Efeito em capacitores}

Os impactos das harmônicas em capacitores, segundo a norma ANSI/IEEE 18-1980 [72], definem a especificação do fluxo contínuo de operação do capacitor, sendo:

$135 \%$ da potência nominal;

$110 \%$ da tensão nominal rms (incluindo-se as harmônicas, mas excluindo-se os transientes);

$120 \%$ do pico de tensão (incluindo-se as harmônicas);

As recomendações para a aplicação prática de capacitores em situação não senoidal de tensão definida na norma [72] têm o seguinte banco de dados apresentado na Tabela 42: 


\begin{tabular}{lll}
\hline Descrição & Valor & Unidade \\
\hline Potência nominal do Banco & 1.200 & KVAr \\
Tensão nominal do Banco & 13.800 & $\mathrm{~V}$ (fase / fase) \\
Tensão de operação & 13.800 & $\mathrm{~V}$ (fase / fase) \\
Corrente nominal fundamental & 50.2 & $\mathrm{~A}$ \\
Frequência fundamental & 60 & $\mathrm{~Hz}$ \\
Reatância capacitiva & 158.700 & $\Omega$ \\
\hline
\end{tabular}

Tabela 42 - Banco de dados do capacitor - Fonte: IEEE-18-1980(1980) 


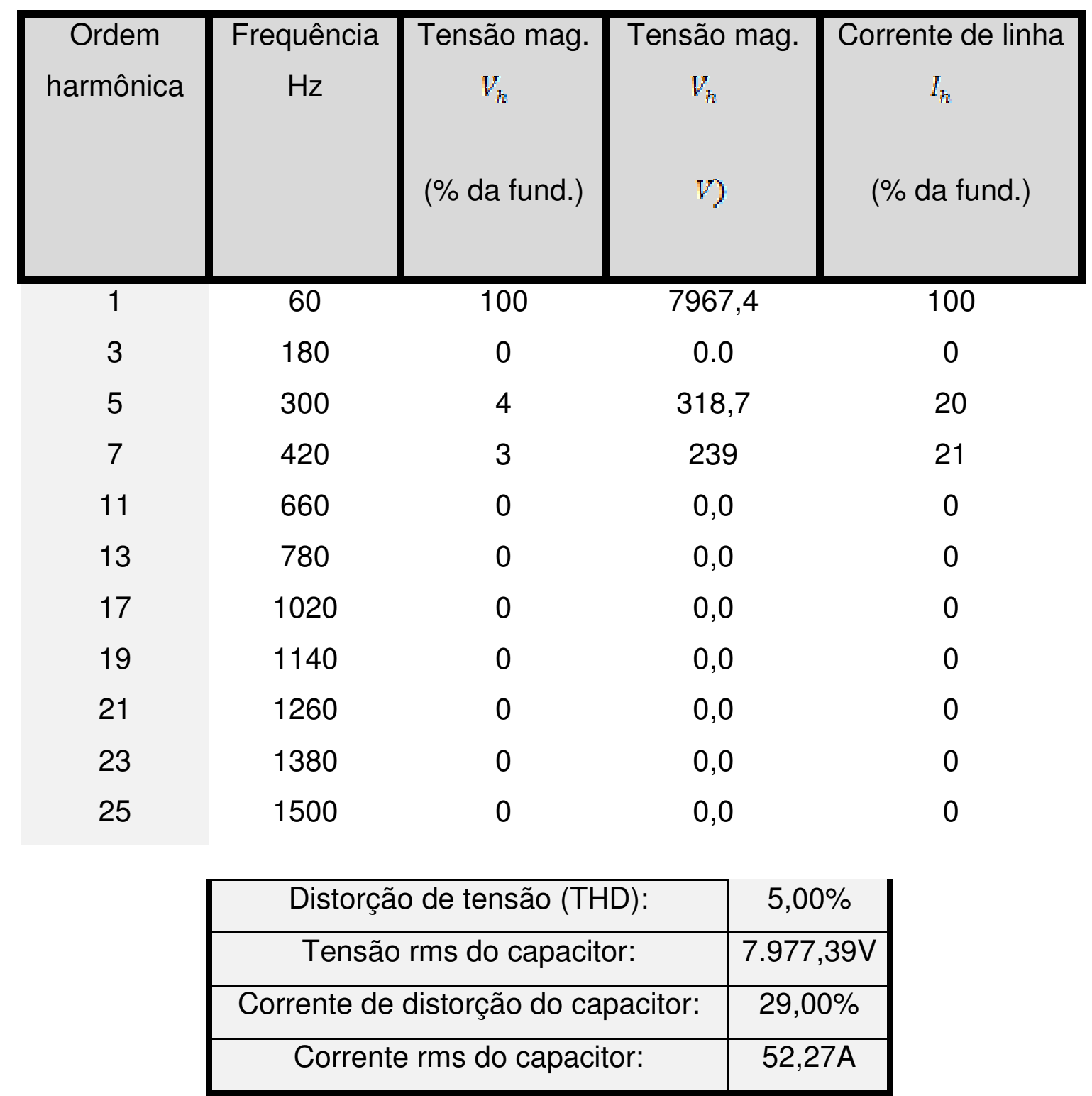

Tabela 43 - Distribuição harmônica da tensão - Fonte: IEEE-18-1980(1980) 


\begin{tabular}{llll}
\hline & \% calculada & Limite \% & Limite excedido \\
\hline Tensão de pico & 107,0 & 120 & Não \\
Tensão rms & 100,1 & 110 & Não \\
Corrente rms & 104,1 & 180 & Não \\
kvar & 104,3 & 135 & Não \\
\hline
\end{tabular}

Tabela 44 - Limites do banco de capacitores - Fonte: IEEE-18-1980(1980)

A corrente de carga máxima de um capacitor de 1200 kvar é determinada pela seguinte forma:

$$
I_{\sigma}=\frac{\text { kvar }_{\mathrm{z \phi}}}{\sqrt{3} \times \mathrm{kv} V_{\phi \phi}}=\frac{1200}{\sqrt{3} \times 13.3}=50,2 \mathrm{~A} \quad \text { Equação } 62
$$

\subsection{Efeito das harmônicas no sistema elétrico}

As cargas do sistema elétrico eram basicamente lineares e possuíam características indutivas, capacitivas e resistivas. Este conceito perdurou até o inicio da década de 1980. Após este período, com o surgimento de novas tecnologias e o emprego cada vez mais intenso de equipamentos que fazem uso de microprocessadores nos sistemas elétricos, têm sido constatados diversos problemas na tensão, na corrente ou na freqüência. Tal quadro resulta na falha ou no funcionamento inadequado de equipamentos de medição, de controle e de proteção. Estas falhas atingem consumidores industriais, comerciais e residenciais, caracterizando-se como um problema na Qualidade de Energia (QE).

Em resposta a este cenário, diversos estudos buscam atenuar estes efeitos, por meio de métodos corretivos mais eficientes, novos materiais ou mesmo desenvolvimento de equipamentos para atender aos propósitos das concessionárias, com um foco direcionado aos clientes.

O principal interesse pela qualidade do suprimento de energia elétrica está na procura do aumento da produtividade pelos consumidores. Assim, as concessionárias de energia encorajam estas medidas, para propiciar redução de seus investimentos em ampliações de linhas, subestações e unidades geradoras. 
A necessidade de utilização de maquinários modernos para aceleração da produtividade gera redução de perdas e aumento da eficiência energética. Assim, o perfil de carga industrial caracteriza-se com equipamentos mais sensíveis às falhas e distúrbios dos sistemas de potência.

Do ponto de vista dos consumidores industriais, os problemas de qualidade da energia tornaram-se abundantes. Esse público, preocupado com as possibilidades de queda na produção de seus insumos por falha ou operação indevida de seus equipamentos elétricos, tem cada vez mais pressionado as concessionárias para que forneçam energia de qualidade às suas plantas.

Dessa forma, existe um risco de diminuição da produtividade e do aumento das ocorrências de interrupções nas linhas de produção e nos setores de serviços em geral. Esse risco justifica a divulgação de metodologias e soluções adequadas ao tratamento destes fenômenos.

Neste caso, destacam-se um dos problemas mais negligenciados pelos fabricantes de equipamentos elétricos, denominado de "distorções harmônicas". Tal fenômeno, além de caracterizar uma qualidade de tensão distorcida, pode, em primeira instância, produzir falhas parciais, redução de vida útil ou mesmo a queima dos equipamentos eletro-eletrônicos.

Nas instalações atuais, grande parte das cargas elétricas instaladas no sistema produz correntes não proporcionais à tensão de alimentação, resultando formas de ondas distorcidas diferentes da fundamental, denominadas "distorções harmônicas".

Considerando-se que a tensão gerada pelas usinas é puramente senoidal, podemos verificar que a distorção de tensão presente em qualquer ponto do sistema é oriunda da interação da impedância de série do sistema, bem como de sua corrente harmônica que circula pelo mesmo.

Entende-se que, quanto maior a quantidade de cargas não lineares instaladas e/ou quanto maior a impedância de curto circuito na fonte geradora, mais elevada será a distorção da forma de onda de tensão e, como consequência, maior ainda será a distorção na forma de onda da corrente.

Uma carga não linear, quando instalada em pontos diferentes no sistema elétrico, terá valores diferentes de distorção de tensão. Esses valores dependem de 
cada tipo de carga. Porém, podemos dizer que este tipo de característica é proveniente de fenômenos contínuos, ou seja, de longa duração.

Podemos notar também estas características em cargas não lineares, observando o comportamento similar nos semi-ciclos positivo e negativo, em quase todos os tipos de cargas. As harmônicas de ordem impar e múltiplas de três são as mais freqüentes e de maior intensidade, cargas indutivas. Trata-se, normalmente, dos maiores causadores de problemas. Assim, quanto maior a ordem ou frequência da harmônica, menor será a sua intensidade.

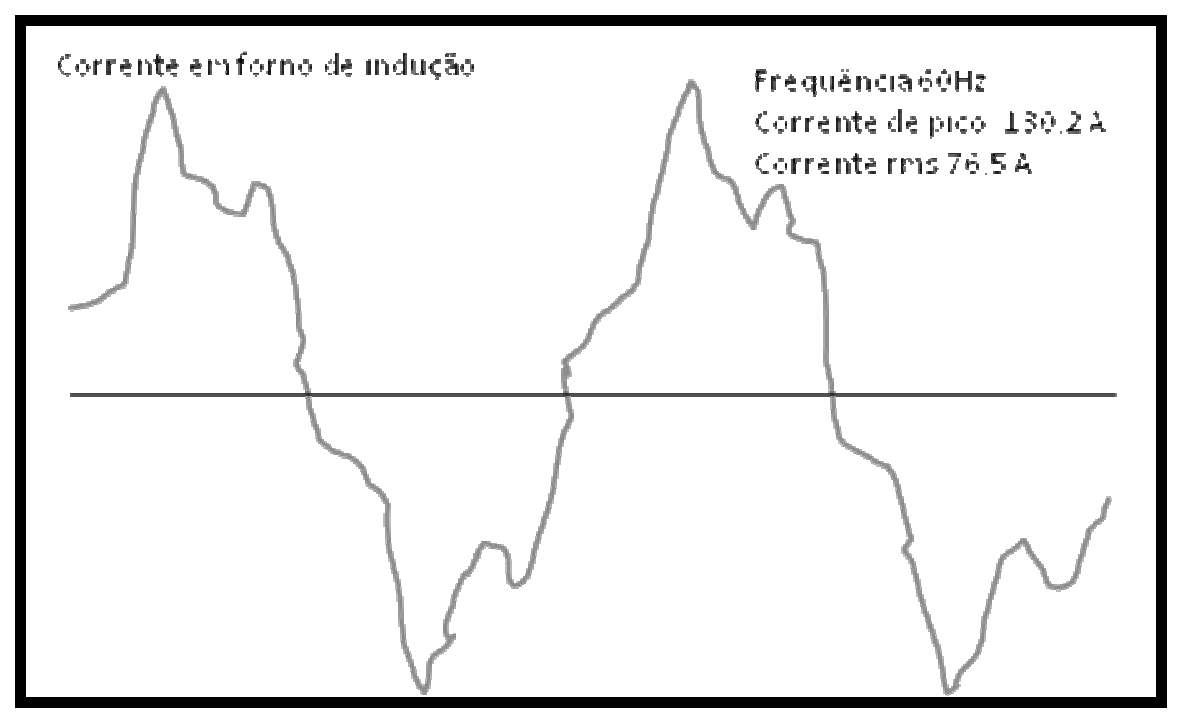

Figura 15 - Distorção harmônica em forno de indução -

Fonte: JÚNIOR, H.F(2004)

Na Figura 16 podemos observar o efeito das harmônicas, causado pela distorção de corrente de um forno de indução.

Já as harmônicas de tensão podem ser encontradas no forno de indução, como aquelas criadas pela saturação de circuitos magnéticos e conexão de transformadores.

Portanto, espera-se que o desempenho dos medidores seja alterado, quando operam dentro de sistemas com componentes harmônicas. Esse fato compromete de maneira significante a medição do faturamento de energia pelas concessionárias. Desta maneira, verifica-se a intensidade de esforços para diminuir os efeitos das harmônicas nos sistemas de energia, sobretudo, na medição de faturamento. Esta observação constata que a identificação e a classificação do processo precisam dos 
erros de medição, os quais se originam do fenômeno das harmônicas. Nestas circunstâncias, as falhas poderão ser mitigadas significativamente, explicando, assim, a utilidade desta pesquisa.

Conforme alguns pesquisadores [54] "Categorias e características típicas de fenômenos que provocam distorção na forma de onda e que contribuem para a perda de qualidade da energia elétrica". A Tabela 45 expõe alguns dados do IEEE Std 1159-1995/ ABNT.

\begin{tabular}{|l|l|l|l|}
\hline Categoria & $\begin{array}{l}\text { Conteúdo } \\
\text { Espectral } \\
\text { Típico }\end{array}$ & Duração Típica & $\begin{array}{l}\text { Amplitude } \\
\text { de Tensão } \\
\text { Típica }\end{array}$ \\
\hline Distorção da Forma de Onda & Regime Permanente & $0,0-0,1 \%$ \\
\hline - Nível CC & & Regime Permanente & $0,0-20 \%$ \\
\hline - Harmônicos & $0-\mathbf{1 0 0}^{a} \mathrm{H}$ & Regime Permanente & $0,0-2,0 \%$ \\
\hline - Interharmônicos & $0-6 \mathrm{kHz}$ & Regime Permanente & \\
\hline - "Notching" & & Regime permanente & $0,0-1 \%$ \\
\hline - Ruídos & Faixa ampla & & \\
\hline
\end{tabular}

Tabela 45 - Categorias e características típicas de fenômenos de distorção da forma de onda - Fonte:IEEE Std 1159-1995

NOTA: Os valores de amplitude de tensão mencionados na Tabela 45, dependendo da carga de variação de corrente, ficam em torno de $30 \%$ de distorção em relação à fundamental.

A principal razão pela qual existe um interesse mundial sobre os problemas de qualidade da energia é, sem dúvida, o aspecto financeiro. Grandes impactos econômicos envolverão as concessionárias, seus consumidores e os fabricantes de equipamentos elétricos.

Nesta mesma linha de pesquisa, segundo [46] "constata-se que as primeiras observações dos fenômenos harmônicos nas formas de onda de tensão e de corrente em sistemas elétricos datam do surgimento das primeiras fontes de corrente alternada". Porém, um interesse maior no estudo desses fenômenos surgiu 
na literatura técnica a partir das décadas de 1930 e 1940, quando foi verificado que tais distorções são responsáveis por distúrbios na Qualidade de Energia fornecida pelas concessionárias.

Em diversos trabalhos, verifica-se que as correntes e tensões harmônicas produzem efeitos danosos, que podem ser instantâneos ou de longa duração. Em [68] "As correntes distorcidas se propagam pelo sistema, provocando distorções de tensão em vários pontos, podendo afetar assim, todo o sistema elétrico, bem como causar a inadequada operação de equipamentos (medidores)".

Para alguns estudiosos [47] "O grau com que harmônicas podem ser toleradas em um sistema de alimentação depende da susceptibilidade da carga (ou da fonte de potência). Os equipamentos menos sensíveis, geralmente, são os de aquecimento (carga resistiva), para os quais a forma de onda não é relevante. Os mais sensíveis são aqueles que, em seu projeto, assumem a existência de uma alimentação senoidal como, por exemplo, equipamentos de comunicação e processamento de dados."

Mesmo para as cargas de baixa susceptibilidade, porém, a presença de harmônicas (de tensão ou de corrente) pode ser prejudicial, produzindo mais esforços nos componentes e isolantes. Normalmente, as componentes harmônicas possuem amplitude reduzida, o que colabora para não tornar esses aumentos de perdas excessivos. No entanto, podem surgir situações específicas (ressonâncias, por exemplo) em que surjam componentes de alta freqüência e amplitude elevada. Além disso, o efeito das reatâncias de dispersão fica ampliado, uma vez que seu valor aumenta com a frequência.

\subsection{Cargas causadoras de harmônicas}

A realização de instalações elétricas teve um aumento considerável nos últimos anos, bem como seus efeitos. Assim, é importante citar os vários tipos de cargas elétricas, com características não lineares, que têm sido implantadas:

cargas de aquecimento controladas por tiristores;

circuitos de iluminação com lâmpadas de descarga;

compensadores estáticos tipo reator saturado;

computadores; 
eletrodomésticos com fontes chaveadas;

fornos a arco;

fornos de indução controlados por reatores saturados;

fornos de indução de alta freqüência;

motores de corrente contínua controlados por retificadores;

motores de indução controlados por inversores, com comutação forçada;

motores síncronos controlados por ciclo-conversores;

processos de eletrólise, por meio de retificadores não-controlados;

reguladores de tensão, com núcleo saturado.

As distorções harmônicas causam muitos prejuízos às plantas industriais. A perda de produtividade e vendas é um item de grande importância, devido a paradas de produção causadas por inesperadas falhas em motores, acionamentos, fontes ou simplesmente "repique" de disjuntores. A seguir, destacamos algumas características de projeto de alguns desses equipamentos.

\subsubsection{Retificadores controlados}

Os retificadores, historicamente, são projetados com a utilização de diodos. Esse fato decorre da facilidade de operação e manutenção dos equipamentos.

Possuem como característica de saída (V.I), provocando aumento maior das perdas Joule $\left(I^{2} \cdot R\right)$ a jusante do retificador, para cargas do tipo potência constante.

O conteúdo harmônico depende da topologia dos retificadores e da natureza da instalação.

$\mathrm{Na}$ busca de alternativas para economia de energia ou melhoria de desempenho, os projetistas têm optado por retificadores controlados (tiristores).

Sua operação e sua manutenção são mais complexas; têm como característica de saída ( V.I) constante. Assim, reduz a quantidade das perdas Joule $\left(I^{2} \cdot R\right)$, a jusante do retificador, para cargas do tipo potência constante. O conteúdo harmônico depende da topologia dos retificadores, do ângulo de controle (disparo) e da natureza da instalação.

O fator de potência é muito influenciado pelo ângulo de disparo. Podemos comparar o perfil (típico) das ondas de tensão na Figura 17 para grupos de 
retificadores a diodos de 12 pulsos e, na figura 18, o perfil (típico) de tensão retificada em grupos retificadores tiristorizados.

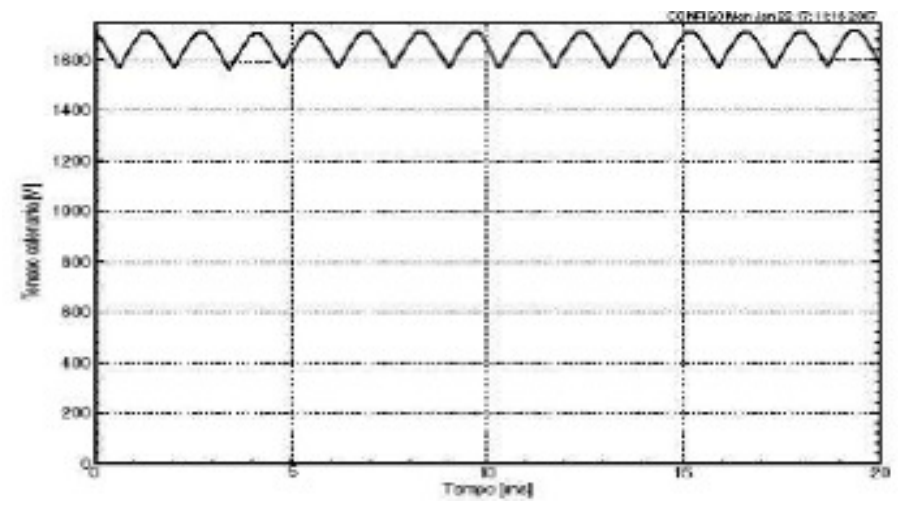

Figura 16 - Retificador a diodos de 12 pulsos - Fonte: V.E. Wagner, et al.(1993)

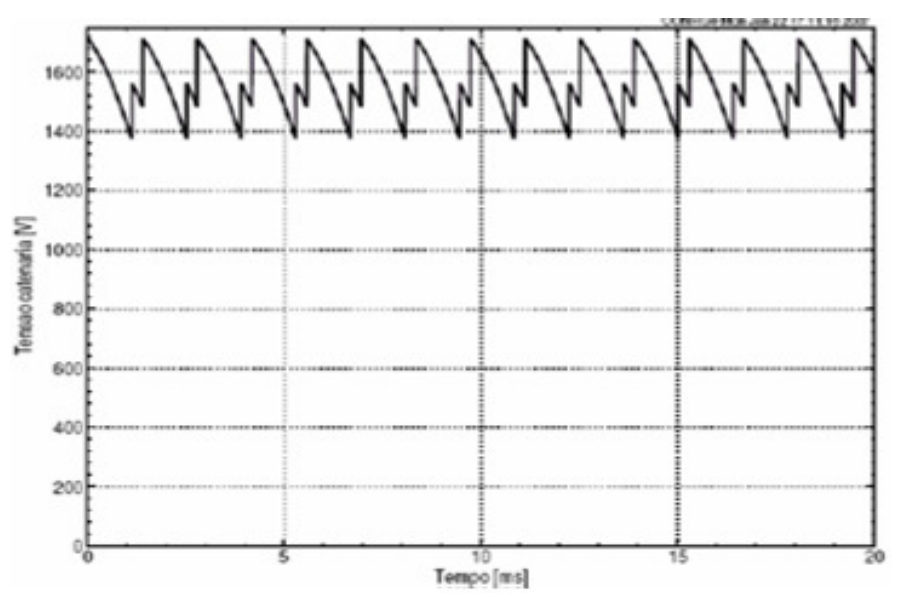

Figura 17 - Retificador a tiristorizado de 12 pulsos - Fonte: V.E. Wagner, et al.(1993)

Podemos notar a influência da ação dos tiristores sobre o perfil de tensão, com consequente aumento de distorção harmônica.

Genericamente, quanto mais distante de uma fonte senoidal, a interferência da linha de alimentação torna-se mais sujeita à tensão.

Contudo, em função da característica da impedância da linha visualizada por cada carga não senoidal, os efeitos de correntes harmônicas em cada freqüência podem ser mantidos, atenuados ou amplificados. 


\subsubsection{Motores de indução saturados}

As distorções harmônicas em motor de indução podem produzir perda de eficiência, sobreaquecimento, vibrações mecânicas na máquina e queda do fator de potência verdadeiro.

Os rotores tendem a ter variações maiores e suas perdas superam as perdas presentes no estator. Portanto, o sobreaquecimento do rotor é o principal problema associado às distorções de tensão nos terminais do motor de indução [3].

Harmônicas de seqüência positiva e negativa presentes na tensão de alimentação de um motor de indução geram oscilações em seu torque eletromagnético. A oscilação mecânica ocorre devido à interação entre as correntes harmônicas induzidas no rotor e o campo magnético no entreferro da freqüência fundamental. As distorções de harmônicas aplicadas ao motor de indução provocam oscilações resultantes suficientes para aumentar as vibrações no rotor. Tal processo eleva as perdas por atrito nos mancais dos rolamentos, reduzindo a vida útil e aumentando a probabilidade de uma falha mecânica da máquina.

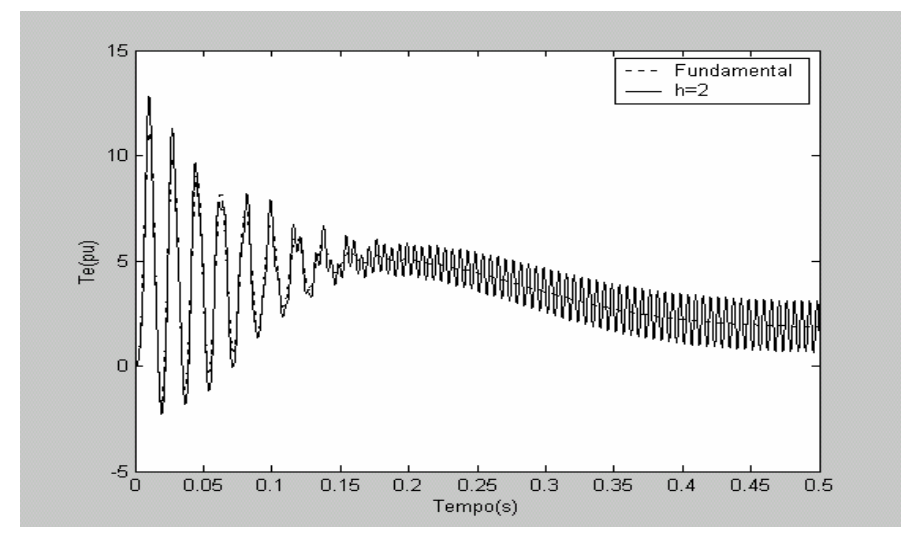

Figura 18 - Torque eletromagnético do motor na freqüência fundamental e na presença da $2^{\mathrm{a}}$ harmônica para TDHV $=20 \%$ - Fonte: V.E. Wagner, et al.(1993)

Conforme pode ser visto na Figura 19, o valor médio das oscilações do torque eletromagnético pode ser considerado igual a zero para quaisquer taxas de distorção harmônica aplicadas ao motor de indução. No entanto, as oscilações do torque eletromagnético assumem grandes proporções em regime permanente, para uma taxa de distorção de $20 \%$ e uma harmônica de $2^{\mathrm{a}}$ ordem. 


\subsubsection{Lâmpadas}

As distorções harmônicas provocadas por lâmpadas Figuras 20, 21, 23 e 24 têm sido um dos grandes problemas encontrados no que se refere aos consumidores residenciais. Observa-se que este tipo de carga provoca uma elevação da DTHi bem maior do que na tensão.

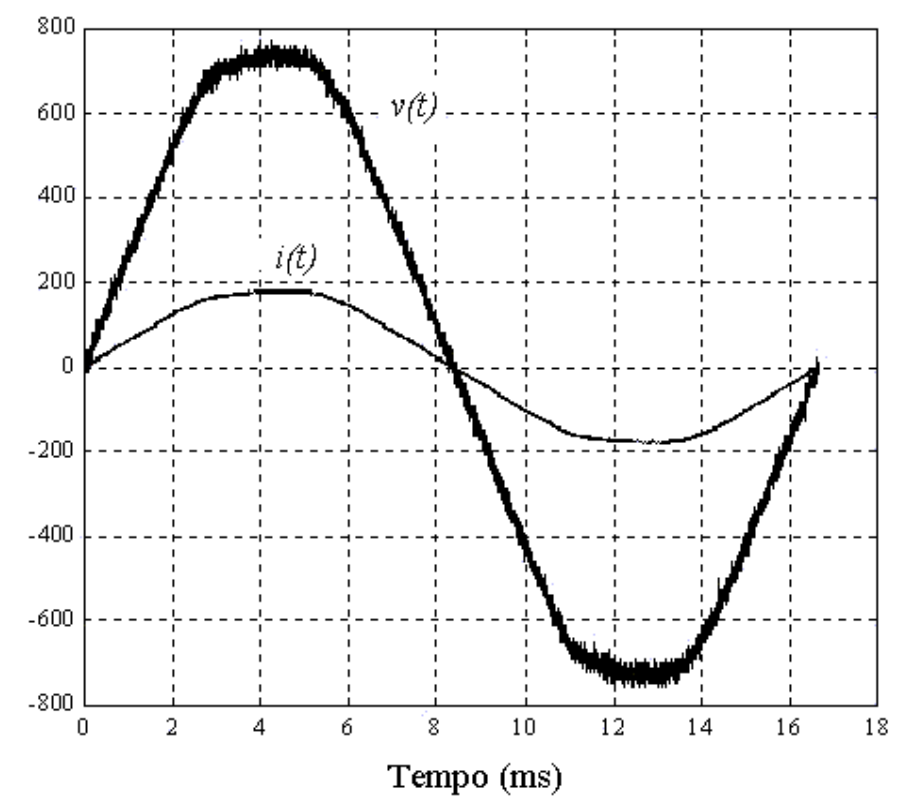

Figura 19 - Formas de ondas de tensão e corrente lâmpadas incandescentesFonte: Henriques, A. L.(2002) 


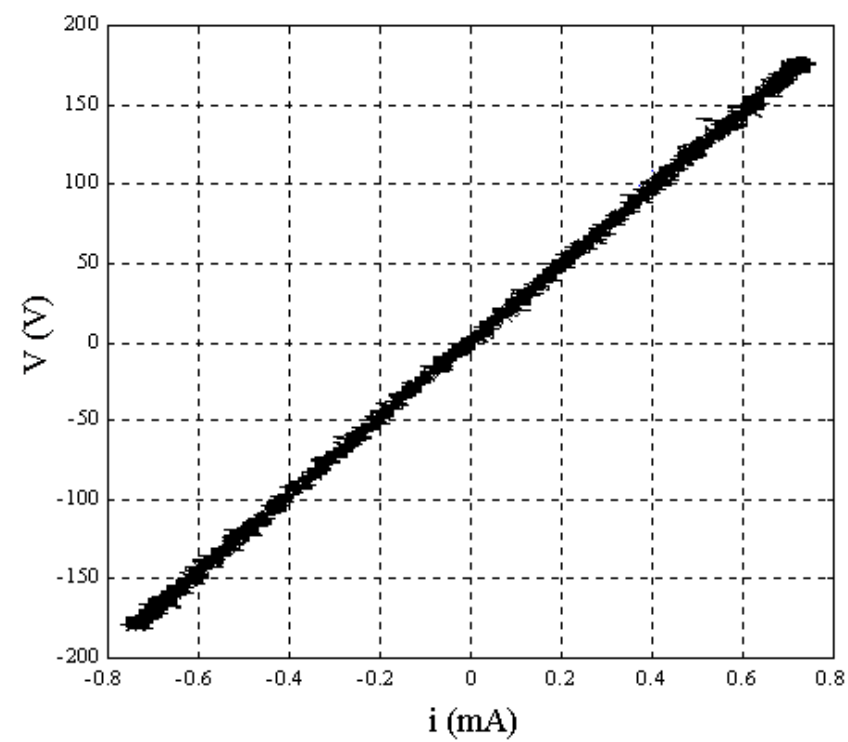

Figura 20 - Características lineares de lâmpadas incandescentes - Fonte: Henriques, A. L.(2002)

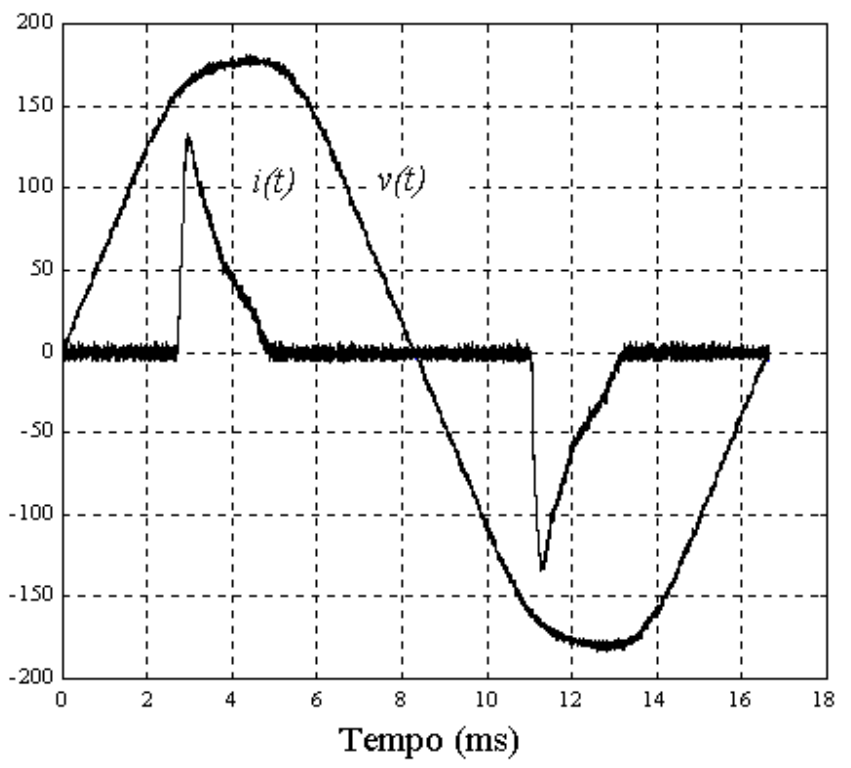

Figura 21 - Formas de ondas de tensão e corrente lâmpadas FLCs - Fonte: Henriques, A. L.(2002) 


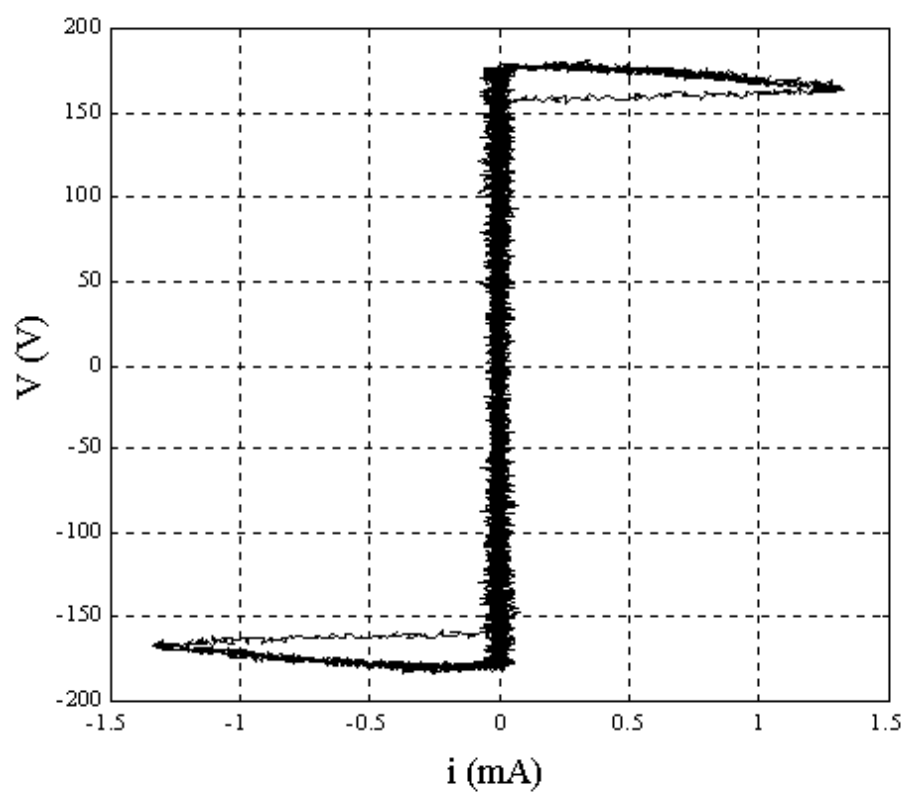

Figura 22 - Características não linear lâmpadas FLCs - Fonte: Henriques, A. L.(2002)

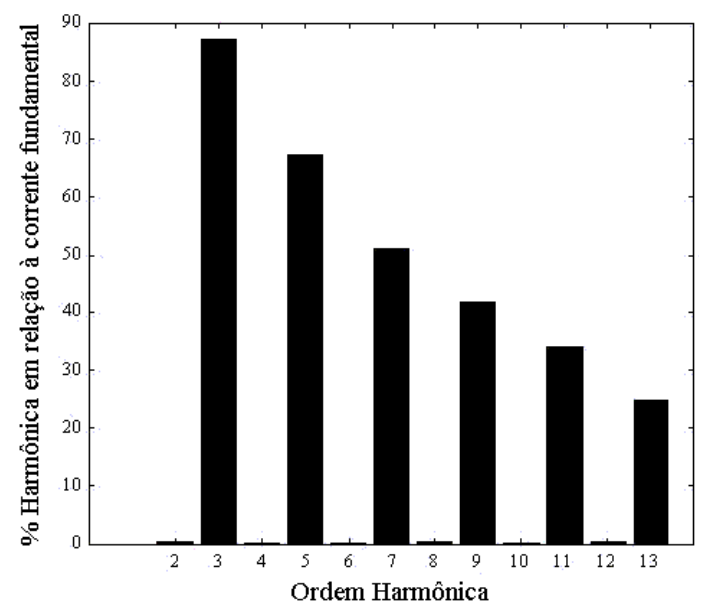

Figura 23 - Espectro harmônico do sinal de corrente em relação à fundamental das

FLCs testadas - Fonte: Henriques, A. L.(2002)

Alguns estudos [70] realizados com incandescente e carga linear apresentaram uma DHTi muito inferior às das LFC's. Segundo [71], esta distorção pode ser desprezada. Tais pesquisas observaram ainda que a potência de cada LFC é comparada com o seu respectivo nível de DHTi. Assim, concluíram que as lâmpadas de maior potência (no caso estudado, 23W) apresentaram níveis de DHTi mais elevados do que as LFC's de menor potência (no caso estudado, 15W). Constatou-se [70] também que, quando temos em um circuito cargas não lineares 
interadas (no caso, FLCs), o nível de DHTi é reduzido se comparado às mesmas cargas ligadas individualmente. Além disso, as altas ordens harmônicas foram eliminadas na condição de interação das cargas.

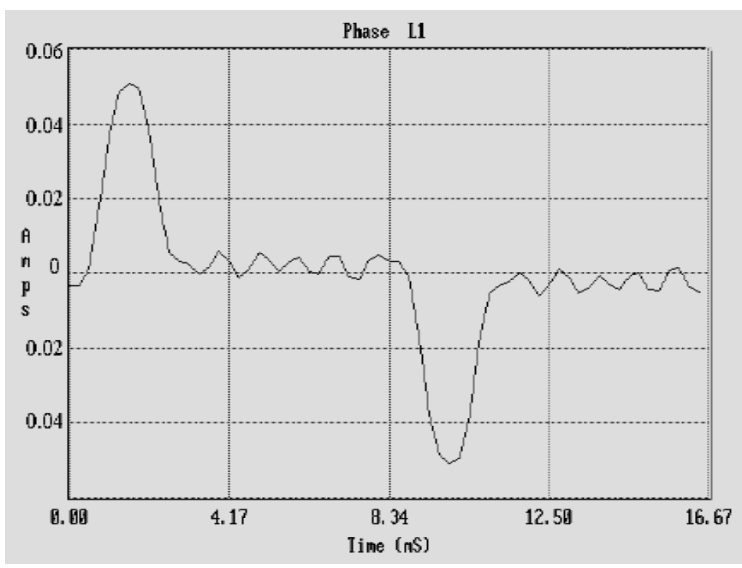

Figura 24 - Forma de onda da corrente harmônica por reator eletrônico - Fonte: Henriques, A. L.(2002) 


\section{GLOSSÁRIO DE TERMOS}

Phase-Locked Loop - Malha de Captura de Fase - É um sistema de realimentação (feedback) em que o sinal de realimentação é usado para sincronizar a frequência instantânea do sinal de saída com a frequência instantânea do sinal de entrada.

Notching - É um distúrbio de tensão causado pela operação normal de equipamentos de eletrônica de potência quando a corrente é comutada de uma fase para outra. Este fenômeno pode ser detectado através do conteúdo harmônico da tensão afetada. As componentes de freqüência associadas com os notchings são de alto valor. Desta forma, não podem ser medidas pelos equipamentos normalmente utilizados para análise harmônica.

Inter- harmônicos - São componentes de freqüência, em tensão ou corrente,que não são múltiplos inteiros da freqüência fundamental do sistema supridor (50 ou $60 \mathrm{~Hz}$ ). Eles podem aparecer como freqüências discretas ou como uma larga faixa espectral.

Os interharmônicos podem ser encontrados em redes de diferentes classes de tensão. As suas principais fontes são conversores estáticos de potência, cicloconversores, motores de indução e equipamentos a arco. Sinais carrier em linhas de potência também podem ser considerados inter-harmônicos.

Os efeitos deste fenômeno não são bem conhecidos, mas admite-se que podem afetar a transmissão de sinais carrier e induzir flicker visual no display de equipamentos como tubos de raios catódicos.

Nível CC - A presença de tensão ou corrente CC em um sistema elétrico CA é denominado $D C$ offset. Este fenômeno pode ocorrer como o resultado da operação ideal de retificadores de meia-onda. O nível CC em redes de corrente alternada pode levar à saturação de transformadores, resultando em perdas adicionais e redução da vida útil. Pode também causar corrosão eletrolítica dos eletrodos de aterramento e de outros conectores.

Ruídos - Ruído é definido como um sinal elétrico indesejado, contendo uma larga faixa espectral com freqüências menores que $200 \mathrm{KHz}$, as quais são superpostas às tensões ou correntes de fase, encontradas também em 
condutores de neutro em linhas de sinais. Os ruídos em sistemas de potência podem ser causados por equipamentos eletrônicos de potência, circuitos de controle, equipamentos a arco, retificadores a estado sólido e fontes chaveadas e, via de regra, ocupam aterramentos impróprios. Basicamente, os ruídos decorrem de uma distorção indesejada no sinal elétrico que não pode ser classificado como distorção harmônica ou transitória.

Flutuações ou oscilações de tensão - As flutuações de tensão correspondem a variações sistemáticas dos valores eficazes da tensão de suprimento dentro da faixa compreendida entre 0,95 e 1,05 pu. Tais flutuações são geralmente causadas por cargas industriais e manifestam-se de diferentes formas.

Flutuações Aleatórias - A principal fonte destas flutuações refere-se aos fornos a arco. Nestes, as amplitudes das oscilações dependem do estado de fusão do material, bem como do nível de curto-circuito da instalação.

Flutuações Repetitivas - Dentre as principais fontes geradoras de flutuações desta natureza, observam-se: Máquinas de solda; Elevadores de minas e Ferrovias.

Flutuações Esporádicas - a principal fonte causadora destas oscilações é a partida direta de grandes motores. Os principais efeitos nos sistemas elétricos, resultados das oscilações causadas pelos equipamentos mencionados anteriormente, são:

Oscilações de potência e torque das máquinas elétricas;

Queda de rendimento dos equipamentos elétricos;

Interferência nos sistemas de proteção;

Efeito flicker ou cintilação luminosa.

O fenômeno flicker consiste no efeito mais comum provocado pelas oscilações de tensão. Este tema merece especial atenção, uma vez que o desconforto visual - associado à percepção do olho humano sobre as variações da intensidade luminosa - é, em toda sua extensão, indesejável. A intensidade do efeito flicker está associada aos seguintes fatores:

Amplitude das oscilações;

Freqüência da moduladora;

Duração do distúrbio ou ciclo de operação da carga perturbadora. 


\section{REFERÊNCIAS BIBLIOGRÁFICAS}

[1] ARSENEAU,R.; Heydt, G.T.; Kempker, M.J. “Application of IEEE Standard 5191992 Harmonic Limits for Revenue Billing Meters". IEEE Transactions on Power Delivery, Vol. 12, No. 1, Jan. 1997.

[2] MORAES, C.C; "O Comportamento dos Motores Assíncronos em Regime de Tensão e Freqüência Variáveis” - Dissertação de Mestrado USP - Brasil - 1978.

[3] V.E. WAGNER, ET AL.; "Effects of Harmonics on Equipment", IEEE Transactions on Power Delivery, vol. 8, no. 2, pp. 672-680, Abr., 1993.

[4] IEEE Std 1459-2000; "IEEE Trial-use standard definitions for the measurement of electric power quantities under sinusoidal, non sinusoidal, balanced or unbalanced conditions" - IEEE Standard, Set. 2002.

[5] A. E. EMANUEL; "IEEE Standard 1459: A Long Overdue Document Industrial and Commercial Power Systems, 2003. 2003 IEEE Technical Conference", St. Louis, Missouri, USA, 4-8 Mai. 2003.

[6] M. Aiello, A. Cataliotti, V. cosentino, S. Nuccio; "A SelfSynchronizing Instrument for Harmonic Sources Detection in Power Systems", IEEE Transaction on Instrumentation and Measurement Vol. 54, N. 1, Fev. 2005.

[7] A. CATALIOTTI, V. COSENTINO, S. NUCCIO; "A time domain approach for IEEE Std 1459-2000 powers measurement in distorted and unbalanced power systems" IMTC 2004 - Instrumentation and Measurement Technology Conference, Como, Italy, 20-22 Mai. 2004.

[8] ASSOCIAÇÃO BRASILEIRA DE NORMAS TÉCNICAS; "Rio de Janeiro. NBR8377; Medidor de energia ativa, especificação." Rio de Janeiro, 1995. 17p. 
[9] ASSOCIAÇÃO BRASILEIRA DE NORMAS TÉCNICAS; “NBR 8378; Medidor de energia ativa, ensaios". Rio de Janeiro, 1995. 12p.

[10] ASSOCIAÇÃO BRASILEIRA DE NORMAS TÉCNICAS; “ NBR 5313; Aceitação de lotes de medidores de energia ativa, procedimento". Rio de Janeiro, 1997. $10 p$.

[11] ASSOCIAÇÃO BRASILEIRA DE NORMAS TÉCNICAS; "NBR 8380; Verificação em serviço de medidores de energia ativa, procedimento". Rio de Janeiro, 1984. 22p.

[12] ASSOCIAÇÃO BRASILEIRA DE NORMAS TÉCNICAS; "NBR 14519; Medidores eletrônicos de energia elétrica (estáticos), especificação." Rio de Janeiro,2000. 23p.

[13] ASSOCIAÇÃO BRASILEIRA DE NORMAS TÉCNICAS; "NBR 14520; Medidores eletrônicos de energia elétrica (estáticos), método de ensaio." Rio de Janeiro, 2000. 21p.

[14] ASSOCIAÇÃO BRASILEIRA DE NORMAS TÉCNICAS; "NBR 14521; Aceitação de lotes de medidores eletrônicos de energia elétrica, procedimento." Rio de Janeiro, 2000. 11p.

[15] INSTITUTO NACIONAL DE METROLOGIA, NORMALIZAÇÃO E QUALIDADE INDUSTRIAL; "Vocabulário internacional de termos fundamentais e gerais de metrologia." Brasília, SENAI/DN, 2000. 75p.

[16] RABINOVICH, Semyon G.; "Measurement Errors and Uncertainties". 2.ed. Los Angeles: Springer Verlag, 2000, 289p. ISBN 0-387-98835-1.

[17] R. ARSENEAU, P.S. FILIPSKI,; "A Calibration System for Evaluating the Performance of Harmonic Power Analyzers", Proceedings of the Sixth International Conference on Harmonics in Power Systems, Bologna, Italy, Sept. 1994, pp.3-8. 
[18] R. ARSENEAU, P.S. FILIPSKI,; "Application of a Three Phase Nonsinusoidal Calibration System for Testing Energy and Demand Meters Under Simulated Field Conditions", IEEE Trans. on Power Delivery, Vol. PWRD-3, NO. 2, Jul. 1988, pp. 874-879.

[19] R.H. STEVENS; "Harmonics and Related Factors Affecting Metering Accuracy", IEEE Tutorial Course on Nonsinsoidal Situation Course Text $90 \mathrm{EH}$ 0327-7-PWR 1990, pp. 61-66.

[20] R. ARSENEAU; G. T. HEYDT E M. J. KEMPKER; "Application of IEEE Standard 519-1992 Harmonic Limits for Revenue Billing Meters", IEEE Transactions on Power Delivery, Vol. 12, No. 1, Jan. 1997.

[21] IEEE STANDARD 519-1992; "Recommended Practices and Requirements for Harmonic Control in Electrical Power Systems", IEEE, New York, NY, 1993.

[22] ANSI/IEEE,; "Standard dictionary for power of electrical \& electronics terms," . USA: ANSI/IEEE, 1977.

[23] C. BUDEANU,; "Reactive and fictitious powers", Rumanian National Institute, No. 2, 1927.

[24] CZARNECKI, L. S.; "Considerations on the reactive power in nonsinusoidal situations," IEEE Trans. on Inst. and Meas, Vol. 34, No. 3, pp 399-404, Sept 1985.

[25] CZARNECKI, L. S.; "What is wrong with the Budeanu concept of reactive and distortion power and why it should be abandoned", IEEE Trans. on Inst. and Meas, Vol 36, No 3, pp 834-837, Set. 1987.

[26] P. S. FILIPSKI AND P. W. LABAJ,; "Evaluation of reactive power meters in the presence of high harmonic distortion", IEEE Trans on Pow. Del., Vol 7, No 4, pp 1793-1799, Out. 1992.

[27] D. M. MCNAMARA, A. K. ZIARANI AND T. H. ORTMEYER,; "A new technique of measurement of Nonstationary harmonics," IEEE Trans. On Power Delivery, vol. 22, no. 1, pp. 387-395, Jan. 2007. 
[28] E. L. OWEN,; "A history of harmonics in power systems", IEEE Ind. Appl. Mag., vol. 4, no. 1, pp. 6-12, Jan./Fev. 1998.

[29] W. M. GRADY AND S. SANTOSO,; "Understanding power system harmonics”, IEEE Power Eng. Rev., vol. 21, no. 11, pp. 8-11, Nov. 2001.

[30] J. DRIESEN, T. VAN CRAENENBROECK, AND D. VAN DOMMELEN,; "The registration of harmonic power by analog and digital power meters," IEEE Trans. Instrum. Meas., vol. 47, no. 1, pp. 195-198, Fev. 1998.

[31] S. L. CLARK, P. FAMOURI, AND W. L. COOLEY,; "Elimination of supply harmonics," IEEE Ind. Appl. Mag., vol. 3, no. 2, pp. 62-67, Mar./Abr. 1997.

[32] R. M. HIDALGO, J. G. FERNANDEZ, R. R. RIVERA, AND H. A. LARRONDO; "A simple adjustable window algorithm to improve FFT measurements," IEEE Trans. Instrum. Meas., vol. 51, no. 1, pp. 31-36, Fev. 2002.

[33] Z. FUSHENG, G. ZHONGXING, AND Y.WEI,; "The algorithm of interpolating windowed FFT for harmonic analysis of electric power system," IEEE Trans. Power Del., vol. 16, no. 2, pp. 160-164, Abr. 2001.

[34] A. TESTA, D. GALLO, AND R. LANGELLA,; "On the Processing of harmonics and interharmonics: Using Hanning window in standard framework," IEEE Trans. Power Del., vol. 19, no. 1, pp. 28-34, Jan. 2004.

[35] T. TA-PENG, W. ROFIG-CHING, AND N. CHIA-CHING,; "The optimization of spectral analysis for signal harmonics," IEEE Trans. Power Del., vol. 16, no. 2, pp. 149-153, Abr. 2001.

[36] A. A. GIRGIS AND F. M. HAM,; "A qualitative study of pitfalls in FFT," IEEE Trans. Aerosp. Electron. Syst., vol. 16, no. 4, pp. 434-439, Jul. 1980.

[37] V. A. KATIC', J. M. KNE'ZVIC', AND D. GRAOVAC,; "Application-oriented comparison of the methods for AC/DC converter harmonics analysis," IEEE Trans. Ind. Electron., vol. 50, no. 6, pp. 1100-1108, Dez. 2003. 
[38] M. KARIMI-GHARTEMANI AND M. R. IRAVANI,; "Measurement of harmonics/ inter-harmonics of time-varying frequencies," IEEE Trans. Power Del., vol. 20, no. 1, pp. 23-31, Jan. 2005.

[39] L. L. LAI, W. L. CHAN, C. T. TSE, AND A. T. P. SO,; "Real-time frequency and harmonic evaluation using artificial neural networks," IEEE Trans. Power Del., vol. 14, no. 1, pp. 52-59, Jan. 1999.

[40] A. A. GIRGIS, W. B. CHANG, AND E. B. MAKRAM,; "A digital recursive measurement scheme for on-line tracking of power system harmonics," IEEE Trans. Power Del., vol. 6, no. 3, pp. 1153-1160, Jul. 1991.

[41] E. Y. HAMID AND Z. I. KAWASAKI,; "Instrument for the quality analysis of power systems based on the wavelet packet transform," IEEE Eng. Rev., vol. 22, no. 3, pp. 52-54, Mar. 2002.

[42] SVENSSON, S.; "Power measurement techniques for non-sinusoidal conditions -The significance of harmonics for the measurement of power and other AC quantities," Tese de doutorado - Department of Electric Power Engineering CHALMERS UNIVERSITY OF TECHNOLOGY, Göteborg Sweden 1999.

[43] SCHNEIDER; PROCOBRE; "Workshop Instalações Elétricas de Baixa Tensão," Qualidade de energia - Harmônicas / p.11 - mar. 2003.

[44] SAIDEL, M.A.; "Tópicos em eficiência energética e uso racional de energia," Apostila da disciplina PEA - 2007.

[45] GAUDINO, G. A.; "Introdução à qualidade de potência módulo-2," curso a distância CIER- Comisão de Integração de Energia Regional, 2005.

[46] EMANUEL, A. E. ,; "Harmonics in The Early of electrical engineering: A BriefReview of Events, People and Documents", IX International Conference on Harmonic and Quality of Power, Proceedings, Orlando, Florida, 2000. 
[47] ARSENEAU,R.; HEYDT, G.T.; KEMPKER, M.J. "Application of IEEE Standard 519-1992 Harmonic Limits for Revenue Billing Meters." IEEE Transactions on Power Delivery, Vol. 12, No. 1, Jan. 1997.

[48] EN 50160; "Voltage characteristics of the electricity supplied by public distribution systems", CENELEC Stand. EN 50160, Nov. 1999.

[49] IEC Standard 61000-4-7; "Electromagnetic Compatibility (EMC) - Part 4: Testing and Measurement Techniques - Section 7: General Guide on Harmonics and Interharmonics Measurement and Instrumentation for Power Supply Systems and Equipment Connected Thereto" - IEC, 2002.

[50] IEC 61000-4-30; "Electromagnetic Compatibility (EMC) - Part 4: Testing and Measurement Techniques - Section 30: Power Quality Measurement Methods" - IEC, 2003.

[51] IEC 61000-2-4; "Electromagnetic Compatibility (EMC) - Part 2: Environment - Section 4: Compatibility levels in industrial plants for low-frequency conducted disturbances" - IEC, 2002.

[52] IEC 61000-3-2; " Electromagnetic compatibility (EMC) - Part 3-2: Limits Limits for harmonic current emissions (equipment input current $<=16 \mathrm{~A}$ per phase)" - IEC, 2004.

[54] JÚNIOR, H.F,; "Gerenciamento e Controle de Qualidade de Energia em Grandes Consumidores com Fábricas Alocadas Distantes," Dissertação de Mestrado USP - Brasil - 2004.

[55] YAMAMOTO, I.; MATSUI, K.; TSUBOI, K.; UEDA, F.; "A Harmonic Meter Using a Phase Loked Loop," Ootaka, Midoriku, Nagoya, Japan, IEEE - 2001.

[56] YAMAGUCHI, T.; MATSUI, K.; TSUBOI, K.; UEDA, F.; "A Simple Harmonic Meter using Phase Locked Loop," C.U.. Ootaka, Midoriku, Nagoya, Japan, IEEE 1998. 
[57] LIN, T., DOMIJAN, A.,; "Measurement of Harmonics/Inter-harmonics of Time-Varying Frequencies," IEEE Transactions on Power Delivery, v. 20, n. 4, p.2552-2562, out. 2005.

[58] YAMAGUCHI, T.; MATSUI, K.; TSUBOI, K.; UEDA, F.,; "A Simple and Low Cost Measuring Method for Harmonics in the Power System," C.U.. Ootaka, Midoriku, Nagoya, Japan, IEEE - 1998.

[59] KADANÍK, P.; "Power\&Energy Messurement- A Brief Survey,"- Prague 1999.

[60] POMILIO, J. A., "Influência dos Harmônicos nas Instalações Elétricas Industriais," revista o setor elétrico abril-2006.

[61] ANEEL - AGÊNCIA NACIONAL DE ENERGIA ELÉTRICA; "Procedimentos de distribuição de energia elétrica no sistema elétrico nacional," Prodist - módulos 5 e $8-2008$.

[62] V.E WAGNER, CHAIRMAN,; "Effects of Harmonics on Equipament," IEEE Transactions on Power Delivery, Vol.8, № 2, Abril-1993.

[63] DOMIJIAN, A.; SANTANDER, E. E.; "Watthour meter accuracy under controlled unbalanced harmonic voltage and currente conditions" - IEEE Trans. On Power Delivery, Vol. 11, No. 1, Janeiro, 1996.

[64] FILIPSKY, P. S.; LABAJ, P. W.; "Evaluation of reactive power meter in the presence of high harmonic distortion" - IEEE Trans. Power Delivery, Vol, 7, Outubro, 1992.

[65] DRIESEN, J., CRAENENBROECK, T.; "The registration of harmonic power by analog and digital power meters" - IEEE Trans. On Instrumentation and Measurement, Vol. 47, no 1, fevereiro, 1998.

[66] CLARKE, F. J. J., STOCKTON, J. R.; "Principles and theory of wattmeters operating on the basis of regularly spaced sample pairs" - J. Phys. E. Sci. Instrum., V. 15, 1982. 
[67] ORSINI, L.Q, DENISE, C.; "Curso de Circuitos Elétricos,” Vol.2 - Editora: Edgard Blulcher- 2004.

[68] W. D. STEVENSON JR.; "Elementos de anaálise de sistemas de potência"McGraw-Hill, edição de 1978.

[69] IEEE-1459-2000,; "Trial-use Standard definitions for the measurement of electric power quantities under sinusoidal, nonsinusoida, balanced ou unbalanced conditions". 2000.

[70] HENRIQUES, A. L.; “ Medição de Energia Elétrica para Faturamento: Estudo Comparativo de Medidores Eletrônicos e Eletromecânicos, com foco no desempenho sob condições não senoidais"- Dissertação de Mestrado, CPDEE - Brasil - 2002.

[71] TOPALIS, F. V.; "Eficiency of Energy Saving Lamps and Harmonic Distortion in Distribution Systems", IEEE Transactions on Power Delivery, vol. 8, no 4, pág.2038-2042, Out. 1993.

[72] IEEE-18-1980,; "An American National Standard Shunt Power Capacitors", IEEE-1980.

[73] CED 322 / QUEN 004 (III) / RL 001/OR; “Projeto integrado de qualidade de energia. Normalização, medição e tarifação. Tarifação e medição de sistemas distorcidos", CPFL - EPUSP - IEE/USP, Agosto, 2000.

[74] "GEORGE WESTINGHOUSE", disponível em:

"http://inventors.about.com/library/inventors/blwestinghouse.htm."- dez -2009.

[75] “THE INVENTIONS OF THOMAS EDISON”, disponível em :

“http://inventors.about.com/library/inventors/bledison.htm".- janeiro de 2009.

[76] ELETROPAULO, E. S.P.S/A, "Departamento de treinamento técnico e comercial- Medição de energia elétrica", São Paulo, 1993. 
[77] BORTONI, E.DA C.; ARAUJO, W. P.; DONADIO, R. G. "Desempenho de Medidores de Watt-hora Indutivos em Ambientes não Senoidais" - IEEE - 2005.

[78] KRUNG, S. R., "Aplicação do Método de Designin Macroergonômico no Projeto de Postos de Trabalho : Estudo de Caso de Posto de Pré-Calibração de Medidores de Energia Monofásicos", Dissertação de Mestrado, UFRGS - Porto Alegre -2000 .

[79] LANDISGYR, "Vista Explodida de Medidor de Energia e Eletromecânico" disponível em: (http://www.landisgyr.com.br/upload/opcoes/M12_por_6p.pdf) outubro de 2009.

[80] INMETRO, 'Portaria Inmetro no. 431, RTM - Regulamento Técnico Metrológico", Instituto Nacional de Metrologia, Normalização e Qualidade Insustrial - Rio de Janeiro - Dezembro de 2007.

[81] CZARNECKI, L. S., "Comments on Active Power Flow and Energy Accounts in Electrical Systems with Nonsinosoidal Waveforms and Asymmetry", IEEE Transactions on Power Delivery, Vol. 11, No. 3, Jul. 1996. 